\title{
Marine Rare Actinomycetes: A Promising Source of Structurally Diverse and Unique Novel Natural Products
}

\author{
Ramesh Subramani ${ }^{1}$ (D) and Detmer Sipkema ${ }^{2, *(D)}$ \\ 1 School of Biological and Chemical Sciences, Faculty of Science, Technology \& Environment, \\ The University of the South Pacific, Laucala Campus, Private Mail Bag, Suva, Republic of Fiji; \\ subramani_r@usp.ac.fj \\ 2 Laboratory of Microbiology, Wageningen University \& Research, Stippeneng 4, \\ 6708 WE Wageningen, The Netherlands \\ * Correspondence: detmer.sipkema@wur.nl; Tel.: +31-317-483113
}

Received: 7 March 2019; Accepted: 23 April 2019; Published: 26 April 2019

\begin{abstract}
Rare actinomycetes are prolific in the marine environment; however, knowledge about their diversity, distribution and biochemistry is limited. Marine rare actinomycetes represent a rather untapped source of chemically diverse secondary metabolites and novel bioactive compounds. In this review, we aim to summarize the present knowledge on the isolation, diversity, distribution and natural product discovery of marine rare actinomycetes reported from mid-2013 to 2017. A total of 97 new species, representing 9 novel genera and belonging to 27 families of marine rare actinomycetes have been reported, with the highest numbers of novel isolates from the families Pseudonocardiaceae, Demequinaceae, Micromonosporaceae and Nocardioidaceae. Additionally, this study reviewed 167 new bioactive compounds produced by 58 different rare actinomycete species representing 24 genera. Most of the compounds produced by the marine rare actinomycetes present antibacterial, antifungal, antiparasitic, anticancer or antimalarial activities. The highest numbers of natural products were derived from the genera Nocardiopsis, Micromonospora, Salinispora and Pseudonocardia. Members of the genus Micromonospora were revealed to be the richest source of chemically diverse and unique bioactive natural products.
\end{abstract}

Keywords: rare actinomycetes; marine actinobacteria; cultivation; natural products; bioactive compounds

\section{Introduction}

Emerging infectious diseases and multidrug-resistant human pathogens are becoming a major threat to global health [1]. Therefore, there is an urgent need for new antibiotics to fight evolving bacterial infections. Despite the use of large synthetic combinatorial libraries of molecules to develop novel drugs, natural products and microbial metabolites, in particular, are a predominant source of bioactive scaffolds that represent the foundation for the development of life-saving antibiotics [2]. Nature encompasses millions of prokaryotes and eukaryotes with particularly high diversity in oceans and rainforests. However, so far only a small fraction (approximately 250,000-300,000 living species) of at least 1.5 million fungi, 0.5 million plant species and $10^{11}-10^{12}$ microbial species on Earth have been documented [3,4]. Moreover, even the known species have only been explored for bioactivity or for natural product discovery up to a limited extent. Therefore, natural resources are virtually unlimited for natural product discovery. The phylum Actinobacteria represents one of the largest phyla among the 30 major phyla currently recognized within the domain Bacteria. There are 6 classes, 18 orders, 14 suborders, 63 families and 374 genera recorded in this phylum until October 2016 (http://www.bacterio.net/-classifphyla.html\#actinobacteria). In this review paper the term 
"actinomycetes" (http://www.bacterio.net/-classifphyla.html\#actinobacteria) will be used to refer the members of the order Actinomycetales of the phylum Actinobacteria. The members of actinomycetes have been characterized as the most important group of microorganisms in the field of biotechnology, as producers of bioactive secondary metabolites with medical, industrial and agricultural applications [5]. However, until now, only less than $1 \%$ of the actinomycetes have been identified, investigated and documented [3]. Out of 500,000 natural compounds reported worldwide from biological sources, approximately 70,000 are microbially-derived compounds (both from bacteria and fungi), of which $29 \%$ is derived from actinomycetes. Approximately $60 \%$ of antibiotics applied, were isolated from actinomycetes between 1950 and 1970, exclusively from the genus Streptomyces [3]. However, in more recent history, high replication of discovery of compounds has been reported from Streptomyces species, which diverted the attention to non-Streptomyces actinomycetes and a noteworthy renaissance in antibiotics development from microorganisms has come with the exploration of previously poorly assessed microorganisms from underexplored environments. The unexplored and underexplored environments including marine ecosystems are promising sources of rare actinomycetes that are believed to be rich sources of interestingly new compounds [6,7]. 'Rare actinomycetes' are defined as the actinomycete strains less frequently isolated than that of the 'commonly' isolated Streptomyces spp., even though they may not actually be rare in the environment.

Oceans occupy $71 \%$ of the Earth's surface holding $97 \%$ of the planet's water and nearly $87 \%$ of life with essentially untouched fauna and flora [3] and are a great source for undiscovered organisms including microorganisms and novel natural products. Marine-derived rare actinomycetes are reported to be a potentially rich source of diverse chemicals, structurally unique secondary metabolites and novel therapeutic compounds [2,6]. Only 11 rare actinomycetes genera had been reported by 1970, followed by 100 genera by 2005 and 220 genera by 2010 [7]. High-throughput metagenome sequencing methods have expanded our knowledge and revealed the presence of many novel actinomycetes that were not previously detected in cultivation studies $[5,8,9]$. The retrieval of rare actinomycetes in conventional cultivation experiments is generally lower than that of the streptomycete strains [5]. However, recent understanding of marine actinomycetes' physiological, chemical, and structural features has enabled the design of selective isolation media [5]. A total of 13,700 bioactive metabolites were reported from actinomycetes up to 2010, of which 10,400 were derived from streptomycetes and 3300 from rare actinomycete strains [3]. In 1974, only 125 active metabolites had been isolated from rare actinomycetes, increasing to 361,745, 1276, 2250, 2500 bioactive metabolites by 1980, 1984, 1988, 2005 and 2010, respectively [7]. In our previous review, we summarized the novel families, novel genera, and new species of rare actinomycetes from marine habitats including bioactive compounds reported from 2007 to mid-2013 [7]. The goal of this present review is to summarize new species of marine rare actinomycetes, and the bioactive compounds discovered between mid-2013 and 2017 and discuss their chemical diversity and biotechnological potential.

\section{Isolation Methods for Marine Rare Actinomycetes}

Members of the phylum Actinobacteria adapt well to and successfully colonize different extreme environments including the deep sea [10] and genera of this phylum exhibit huge diversity in terms of their morphology, physiology, and metabolic capabilities [5]. Marine rare actinomycetes generally require special growth conditions compared to terrestrial actinomycete species [11-14]. Notably, it has been observed that a large number of bacterial cells in under/unexplored environments are viable but not culturable (VBNC), as approximately $1 \%$ of bacterial cells can form colonies on isolation media by conventional methods [15]. Therefore, high throughput molecular techniques, including metagenomics, are increasingly favored to investigate microbial communities in the environment [16] for which culture-based approaches have been rather unsuccessful up to now. Concurrently, knowledge of functional characteristics of actinomycetes based on cultivation-independent studies, has led to improved strategies with respect to growth conditions and cultivation media to recover previously unculturable actinomycetes $[5,17-21]$. 


\subsection{Basic Approaches for Isolation Media for Marine Rare Actinomycetes}

Targeting unknown rare actinomycetes for isolation requires knowledge and experience of actinomycetes taxonomy, physiology and environmental factors, such as $\mathrm{pH}$, cultivation temperature, oxygen, nutrient requirements etc. [22]. Sodium, is one of the most important medium components for growth of marine microorganisms including marine actinomycetes such as Salinispora spp. and therfore growth media should generally have osmotic values similar to seawater [13]. Besides, different carbon (soluble starch, glucose, dextrose, maltose, trehalose, mannitol, raffinose, fucose, chitin, glycerol and oatmeal) and combined carbon-nitrogen sources (peptone, yeast extract, casein, malt extract, meat extract, beef extract and tryptone) have been supplemented in isolation media for successful isolation of marine rare actinomycete taxa [23-27]. In addition, researchers have added sediment extracts, sponge extracts and natural seawater alone or as a supplement to mimic natural environmental conditions [12,28-34]. In general, low-nutrient media are more efficient than nutrient-rich media for isolation of marine rare actinomycetes $[13,28,35]$. Generally, some basic approaches may be followed for isolation of marine rare actinomycetes: 1 , Three to five different isolation media with various components should be employed for any target genus of actinomycetes [9,11,28]; 2, The isolation media must meet the requirements of the target actinomycetes and at the same time should limit the growth of unwanted microbes [22,28]; 3, Growth inhibitors, in the form of antibiotics or chemicals, should be added into isolation media to inhibit or restrict the growth of Gram-negative bacteria and fungi [11,28]; 4, The medium should be so designed that it mimicks the microbe's natural environmental conditions $[12,28,29] ; 5$, The medium should also suppress the growth of fast-growing and common streptomycete strains [22].

\subsection{Pretreatment of Marine Samples}

Marine samples, particularly sediments used for the isolation of rare actinomycetes, may be treated prior to isolation to remove common terrestrial actinomycetes and unwanted microorganisms to reduce replication of isolation. Commonly used pre-treatment methods for the isolation of rare actinomycetes from marine samples generally include dilution and mixing with sterile natural seawater [25,36,37], artificial seawater [38-40], deionized/distilled water supplemented with $\mathrm{NaCl}$ [41,42], multi-salts [24,26,40], vitamin B mixtures [43], one-quarter Ringer's solution [44] and saline solution [45] before transferring the inoculum to Petri dishes [44]. A variety of pre-treatment methods for selectively isolating actinomycetes has been applied (Table 1). However, the drying of the environmental sample using laminar air flow, dilution with seawater or saline prior to sample heating are most frequently employed pre-treatments (Table 1). Actinomycetes spores are generally resistant to desiccation and heating and can thus be used to select against other Gram positive bacteria [46]. Further, actinomycetes spores are resistant to a wide range of chemicals, such as benzethonium chloride, chlorhexidine gluconate, phenol, sodium dodecyl sulfate, and different antibiotics. These chemicals have been used to selectively isolate actinomycete taxa. Treatment with these chemicals for $30 \mathrm{~min}$. can kill or inhibit aerobic Gram negative bacteria, endospore-forming bacilli and pseudomonads, thus increasing the chance of selectively isolating actinomycetes, and reduce other types of bacteria [22]. Additionally, ultrasonic waves can release actinomycetes propagules from sediment particles into suspension, thus also increasing the number of Actinobacterial strains and reducing unwanted bacteria [47].

\section{Marine Habitats: The Largest Reservoir for Rare Actinomycetes}

The world's oceans constitute more than $90 \%$ of the inhabitable space on the planet and it is the largest reservoir of life on Earth. Approximately $80 \%$ of all life on Earth lives in the ocean and the oceans harbour 32 out of 33 known animal phyla, of which 15 are exclusively marine [48]. 
Table 1. Pre-treatment methods for the selective isolation of marine rare actinomycetes.

\begin{tabular}{|c|c|c|c|c|c|}
\hline Pre-treatment & Marine Source & Isolation Medium & $\begin{array}{c}\text { Incubation } \\
\text { Temperature/Time }\end{array}$ & Target Rare Genera & Ref. \\
\hline \multicolumn{6}{|c|}{ Heat } \\
\hline \multirow[t]{2}{*}{$\begin{array}{l}\text { Incubation in water bath at } \\
500^{\circ} \mathrm{C} \text { for } 60 \mathrm{~min}\end{array}$} & WS & $\begin{array}{l}\text { Starch-casein agar }+10 \mu \mathrm{g} \\
\text { nalidixic acid, } 25 \mu \mathrm{g} \text { nystatin } \\
\text { and } 10 \mu \mathrm{g} \text { cycloheximide }\end{array}$ & $24^{\circ} \mathrm{C}$ for 28 days & Micromonospora & [45] \\
\hline & WS & M1 agar $+75 \mu$ g cycloheximide & $\begin{array}{l}20-24^{\circ} \mathrm{C} \text { for } \\
14-28 \text { days }\end{array}$ & Micromonospora & [49] \\
\hline $55^{\circ} \mathrm{C}$ for $20 \mathrm{~min}$ & WS & $\begin{array}{l}\text { Glucose peptone tryptone agar } \\
+50 \mathrm{mg} \text { nystatin, } 50 \mathrm{mg} \\
\text { cycloheximide, } 25 \mathrm{mg} \\
\text { novobiocin and } 20 \mathrm{mg} \\
\text { nalidixic acid }\end{array}$ & $28^{\circ} \mathrm{C}$ for 21 days & Micromonospora & [52] \\
\hline $\begin{array}{l}\text { Incubation in water bath at } \\
60^{\circ} \mathrm{C} \text { for } 10 \mathrm{~min}\end{array}$ & DS & $\begin{array}{l}\text { M1-M12 agar }+100 \mu \mathrm{g} \\
\text { cycloheximide and } 50 \mu \mathrm{g} \\
\text { nystatin }\end{array}$ & $28^{\circ} \mathrm{C}$ for 3 months & $\begin{array}{l}\text { Micromonospora and } \\
\text { Salinispora }\end{array}$ & [28] \\
\hline $\begin{array}{c}\text { Speedvac } 30^{\circ} \mathrm{C}, 16 \mathrm{~h} ; 120^{\circ} \mathrm{C}, \\
60 \mathrm{~min}\end{array}$ & DS & $\begin{array}{l}\text { Different selective media }+ \\
\text { cycloheximide }(50 \mu \mathrm{g} / \mathrm{mL}), \\
\text { nystatin }(75 \mu \mathrm{g} / \mathrm{mL}) \text { and } \\
\text { nalidixic acid }(30 \mu \mathrm{g} / \mathrm{mL})\end{array}$ & $20^{\circ} \mathrm{C}$ for $2-6$ weeks & Rare actinomycetes & [54] \\
\hline $41{ }^{\circ} \mathrm{C}$ for 10,30 and 60 days & DS & Different selective media & $28^{\circ} \mathrm{C}$ for $2-3$ weeks & $\begin{array}{l}\text { Streptoverticillium, } \\
\text { Catellatospora, } \\
\text { Nocardia and } \\
\text { Actinopolyspora }\end{array}$ & [55] \\
\hline $70^{\circ} \mathrm{C}$ for $15 \mathrm{~min}$ & WS & Different selective media & $25^{\circ} \mathrm{C}$ for 4 weeks & $\begin{array}{l}\text { Micromonospora, } \\
\text { Microbispora, } \\
\text { Actinoplanes and } \\
\text { Actinomadura }\end{array}$ & {$[56]$} \\
\hline $60^{\circ} \mathrm{C}$ for $6 \mathrm{~min}$ & WS & $\begin{array}{c}\text { M1 medium and Glucose-yeast } \\
\text { extract medium }+ \text { nystatin } \\
(50 \mu \mathrm{g} / \mathrm{mL}) \text {, and nalidixic acid } \\
(10 \mu \mathrm{g} / \mathrm{mL})\end{array}$ & $25^{\circ} \mathrm{C}$ for 6 weeks & $\begin{array}{c}\text { Nocardia, } \\
\text { Nonomuraea, } \\
\text { Rhodococcus, } \\
\text { Saccharopolyspora } \\
\text { and Gordonia }\end{array}$ & [59] \\
\hline \multicolumn{6}{|c|}{ Physical } \\
\hline $\begin{array}{l}\text { Dry in laminar air flow hood; } \\
\text { Stamping }\end{array}$ & WS/DS & $\begin{array}{c}\text { M1-M12 agar }+100 \mu \mathrm{g} \\
\text { cycloheximide and } 50 \mu \mathrm{g} \\
\text { nystatin }\end{array}$ & $28^{\circ} \mathrm{C}$ for 3 months & $\begin{array}{l}\text { Micromonospora and } \\
\text { Salinispora }\end{array}$ & {$[28,53]$} \\
\hline \multicolumn{6}{|c|}{ Mechanic } \\
\hline $\begin{array}{l}\text { Shake with glass beads for } \\
30 \mathrm{~s} \text { and settled for } 5 \mathrm{~min}\end{array}$ & WS & $\begin{array}{l}\text { Different selective media + } \\
\text { cycloheximide }(50 \mu \mathrm{g} / \mathrm{mL}) \text {, } \\
\text { nystatin }(75 \mu \mathrm{g} / \mathrm{mL}) \text { and } \\
\text { nalidixic acid }(30 \mu \mathrm{g} / \mathrm{mL})\end{array}$ & $20^{\circ} \mathrm{C}$ for 6 weeks & Rare actinomycetes & [54] \\
\hline \multicolumn{6}{|c|}{ Chemical/+ Heat } \\
\hline $\begin{array}{c}1.5 \% \text { phenol }+30 \mathrm{~min} \text { at } \\
30^{\circ} \mathrm{C}\end{array}$ & DS & $\begin{array}{l}\text { Different selective media + } \\
\text { cycloheximide }(50 \mu \mathrm{g} / \mathrm{mL}), \\
\text { nystatin }(75 \mu \mathrm{g} / \mathrm{mL}) \text { and } \\
\text { nalidixic acid }(30 \mu \mathrm{g} / \mathrm{mL})\end{array}$ & $20^{\circ} \mathrm{C}$ for $2-6$ weeks & Micromonospora & [4] \\
\hline $\begin{array}{c}0.02 \% \text { benzethonium } \\
\text { chloride }+30 \text { min at } 30{ }^{\circ} \mathrm{C}\end{array}$ & DS & $\begin{array}{l}\text { Different selective media + } \\
\text { cycloheximide }(50 \mu \mathrm{g} / \mathrm{mL}), \\
\text { nystatin }(75 \mu \mathrm{g} / \mathrm{mL}) \text { and } \\
\text { nalidixic acid }(30 \mu \mathrm{g} / \mathrm{mL})\end{array}$ & $20^{\circ} \mathrm{C}$ for $2-6$ weeks & Rare actinomycetes & [54] \\
\hline
\end{tabular}


Table 1. Cont.

\begin{tabular}{|c|c|c|c|c|c|}
\hline Pre-treatment & Marine Source & Isolation Medium & $\begin{array}{c}\text { Incubation } \\
\text { Temperature/Time }\end{array}$ & Target Rare Genera & Ref \\
\hline $1.5 \%$ phenol & DS & $\begin{array}{l}\text { Different selective media + } \\
\text { cycloheximide }(50 \mu \mathrm{g} / \mathrm{mL}), \\
\text { nystatin }(75 \mu \mathrm{g} / \mathrm{mL}) \text { and } \\
\text { nalidixic acid }(30 \mu \mathrm{g} / \mathrm{mL})\end{array}$ & $20^{\circ} \mathrm{C}$ for $2-6$ weeks & Rare actinomycetes & [54] \\
\hline Chloramine- $\mathrm{T}$ & DS & $\begin{array}{l}\text { Different selective media + } \\
\text { cycloheximide }(25-100 \mu \mathrm{g} / \mathrm{mL}) \\
\text { and nystatin }(25-50 \mu \mathrm{g} / \mathrm{mL})\end{array}$ & $\begin{array}{c}28^{\circ} \mathrm{C} \text { for } \\
1-12 \text { weeks }\end{array}$ & $\begin{array}{l}\text { Actinomadura, } \\
\text { Micromonospora, } \\
\text { Nocardia, } \\
\text { Nonomuraea, } \\
\text { Rhodococcus, } \\
\text { Streptomyces and } \\
\text { Verrucosispora }\end{array}$ & [60] \\
\hline \multicolumn{6}{|c|}{ Centrifugation } \\
\hline Differential centrifugation & WS & Selective media & $28^{\circ} \mathrm{C}$ for 12 weeks & $\begin{array}{l}\text { Micromonospora, } \\
\text { Rhodococcus and } \\
\text { Streptomyces }\end{array}$ & [30] \\
\hline \multicolumn{6}{|c|}{ Freezing } \\
\hline $\begin{array}{l}\text { Freeze }\left(-20^{\circ} \mathrm{C}, 24 \mathrm{~h}\right), \\
\text { thawed, dilution }\end{array}$ & WS & $\begin{array}{l}\text { M1-M12 agar }+100 \mu \mathrm{g} \\
\text { cycloheximide and } 50 \mu \mathrm{g} \\
\text { nystatin }\end{array}$ & $28^{\circ} \mathrm{C}$ for 3 months & $\begin{array}{l}\text { Micromonospora and } \\
\text { Salinispora }\end{array}$ & [28] \\
\hline Freeze at $-18^{\circ} \mathrm{C}$ & WS & $\begin{array}{l}\text { Different selective media + } \\
\text { nystatin }(50 \mu \mathrm{g} / \mathrm{mL}) \text { and } \\
\text { nalidixic acid }(10 \mu \mathrm{g} / \mathrm{mL})\end{array}$ & $28^{\circ} \mathrm{C}$ for $2-3$ weeks & $\begin{array}{c}\text { Nocardiopsis, } \\
\text { Nocardia and } \\
\text { Streptosporangium }\end{array}$ & [61] \\
\hline \multicolumn{6}{|c|}{ Radiation } \\
\hline $\begin{array}{l}\text { UV irradiation for } 30 \mathrm{~s} \\
\text { (distance } 20 \mathrm{~cm}, 254 \mathrm{~nm} \text {, } \\
15 \mathrm{~W} \text { ) }\end{array}$ & WS & $\begin{array}{l}\text { Different selective media }+ \\
\text { nystatin }(50 \mu \mathrm{g} / \mathrm{mL}) \text { and } \\
\text { nalidixic acid }(10 \mu \mathrm{g} / \mathrm{mL})\end{array}$ & $28^{\circ} \mathrm{C}$ for $2-3$ weeks & $\begin{array}{l}\text { Nocardiopsis, } \\
\text { Nocardia and } \\
\text { Pseudonocardia }\end{array}$ & [61] \\
\hline $\begin{array}{l}\text { Superhigh frequency } \\
\text { radiation inmicrowave oven } \\
\text { for } 45 \mathrm{~s}(2460 \mathrm{MHz}, 80 \mathrm{~W})\end{array}$ & WS & $\begin{array}{l}\text { Different selective media + } \\
\text { nystatin }(50 \mu \mathrm{g} / \mathrm{mL}) \text { and } \\
\text { nalidixic acid }(10 \mu \mathrm{g} / \mathrm{mL})\end{array}$ & $28^{\circ} \mathrm{C}$ for $2-3$ weeks & $\begin{array}{l}\text { Streptosporangium } \\
\text { and Rhodococcus }\end{array}$ & [61] \\
\hline $\begin{array}{l}\text { Extremely high frequency } \\
\text { radiation }(1 \mathrm{kHz} \text { within } \\
\text { wavelength band of } \\
8-11.5 \mathrm{~mm})\end{array}$ & WS & $\begin{array}{l}\text { Different selective media }+ \\
\text { nystatin }(50 \mu \mathrm{g} / \mathrm{mL}) \text { and } \\
\text { nalidixic acid }(10 \mu \mathrm{g} / \mathrm{mL})\end{array}$ & $28^{\circ} \mathrm{C}$ for $2-3$ weeks & $\begin{array}{c}\text { Nocardiopsis, } \\
\text { Nocardia and } \\
\text { Streptosporangium }\end{array}$ & [61] \\
\hline
\end{tabular}

WS: Wet Sediment; DS: Dried Sediment.

Marine habitats are also a rich source of diverse and largely uncharacterized microbial communities including actinomycetes [62]. This habitat shows extreme variations in ecological pressure, including competition for space, predation, available nutrients, light, oxygen concentration and pressure. Marine organisms including actinomycetes have developed a diverse range of secondary metabolites with unique structural elements to ensure their survival in these habitats [63]. Diverse new rare species including novel genera and novel families of actinomycetes have been isolated from marine habitats, such as coastal, tidal and deep-sea sediments, marine organisms (sponges, corals and ascidians), seawater and also mangrove forests [7]. Approximately 220 genera of rare actinomycetes were reported from marine sources until 2010 [64] and in the following sections we summarize new rare actinomycete isolates from these habitats since then [7]. For this review we've applied a conservative threshold on labelling a species as "novel" when sharing less than $97 \%$ similarity of the $16 \mathrm{~S}$ rRNA gene to known species [65-70]. For the labelling of genera and families as "novel" we followed Silva taxonomy [71].

\subsection{Rare Actinomycetes from Marine Sediments, Seawater, Eukaryotic Hosts and Mangroves}

Approximately $83 \%$ of marine sediments are more than $1000 \mathrm{~m}$ below sea level, so most marine sediments are located in a cold, lightless, high pressure habitat where food is supplied from distant surface waters [72]. Deep-sea environments are divided into three zones: the bathyal (depth range between 200 and $2000 \mathrm{~m}$ ), the abyssal (depth from 2000 to $6000 \mathrm{~m}$ ) and the hadal (depth below $6000 \mathrm{~m}$ ) [73]. Especially the abyssal and hadal zones are largely unexplored. Highest biodiversity has been recorded at a depth of $3000 \mathrm{~m}$ and the heterogeneity of biomass is expanding to $5000 \mathrm{~m}[74,75]$. Cold deep-sea muds have an astounding species richness and diversity compared to tropical rain forests [76]. The majority of these species has not been isolated in the laboratory and an estimated $95 \%$ of these species are unidentified and mostly considered as new species [74]. 
Actinomycetes, including rare actinomycetes, are abundant in diverse marine sediments. A total of 48 new rare actinomycete species belonging to 16 different actinomycete families were isolated from marine sediments in the period from mid 2013 to 2017 (Table 2). Among them, 5 novel genera: Flaviflexus, Halopolyspora, Mariniluteicoccus, Sediminivirga and Haloactinomyces were described. The actinomycete families reported from marine sediments to which the novel species belong are Pseudonocardiaceae ( 8 new species), Nocardioidaceae (5 new species), Nocardiopsaceae (4 new species), Microbacteriaceae (4 new species), Micrococcaceae (4 new species), Propionibacteriaceae (4 new species), Micromonosporaceae (3 new species), Nocardiaceae (2 new species), Demequinaceae (2 new species), Intrasporangiaceae (2 new species), Bogoriellaceae ( 2 new species), Acidimicrobiaceae ( 2 new species), Brevibacteriaceae (2 new species), Actinopolysporaceae (2 new species), Actinomycetaceae (1 new species) and Cellulomonadaceae (1 new species).

Although earlier culture-dependent studies have described microbial population size to be only a few hundred cells per $\mathrm{mL}$ of seawater, the staining of cells using fluorescence microscopy studies demonstrated nominal cell densities of $>10^{5}$ cells per mL of seawater $[77,78]$, which anticipates that the ocean harbors $3.6 \times 10^{29}$ microbial cells [79]. The microorganisms in the seawater play an important role in marine biogeochemical processes involved in cycling and decomposition of organic matter [80]. A total of 8 new rare actinomycete species were reported from seawater for the period mid-2013 to 2017 (Table 3), among which 2 novel genera, Pontimonas and Tamlicoccus. They belong to six actinomycete families: Nocardioidaceae (3 new species), Cellulomonadaceae (1 new species), Micrococcaceae (1 new species), Microbacteriaceae (1 new species), Dermacoccaceae (1 new species) and Dermabacteraceae (1 new species). From these studies, it is apparent that lower numbers of rare actinomycetes are isolated from seawater than from sediments. However, novel genera have been reported from seawater, which contribute to the extension of phylogenetic diversity of rare actinomycetes (Table 3) [7].

A substantial number of rare actinomycetes were reported to be associated to various members of marine benthic communities, such as sponges, corals, ascidians, sea anemones, sea cucumbers, sea urchins and seaweeds $[7,62,81]$. Five novel genera, 17 new rare actinomycete species belonging to 11 different actinomycete families were reported from marine plants and animals between 2007 and mid-2013 [7]. A total of 14 new species of rare actinomycetes belonging to 12 different families have been reported from various sponges, corals, algae, sea urchin, jelly fish and fish between mid-2013 and 2017 (Table 4). The families of novel (potentially symbiotic) actinomycete species reported from mid-2013 to 2017 are Micromonosporaceae (2 new species), Pseudonocardiaceae (2 new species), Microbacteriaceae (1 new species), Mycobacteriaceae (1 new species), Nocardioidaceae (1 new species), Micrococcaeae (1 new species), Intrasporangiaceae (1 new species), Nocardiaceae (1 new species), Rubrobacteraceae (1 new species), Actinosynnemataceae (1 new species), Gordoniaceae (1 new species) and Promicromonosporaceae (1 new species). Thus, marine organisms remain a rich source of novel rare actinomycetes (Table 4) and a substantial number of host-associated rare actinomycete genera have not been reported from other marine habitats (Labedella, Phycicola, Iamia, Euzebya and Koreibacter) [7]. Interestingly, Microbacterium aureliae was reported for the first time from Aurelia aurita, the moon jellyfish. 
Table 2. New species of rare actinomycetes from marine sediments reported during the period of mid 2013-2017.

\begin{tabular}{|c|c|c|c|}
\hline Strain/Family & Nature of Sample & Isolation Medium & Ref. \\
\hline $\begin{array}{c}\text { Saccharomonospora } \\
\text { amisosensis/Pseudonocardiaceae }\end{array}$ & Deep marine sediment at a depth of $60 \mathrm{~m}$ & $\begin{array}{l}\text { SM3 medium (yeast nitrogen base } 67.0 \mathrm{~g} \text {, casamino acids } 100 \mathrm{mg} \text { were } \\
\text { added to a litre of distilled water and the solution sterilised using cellulose } \\
\text { filters }(0.20 \mathrm{~mm}) \text { prior to the addition of sterilised di-potassium hydrogen } \\
\text { phosphate }(200 \mathrm{~mL} ; 10 \%, \mathrm{w} / \mathrm{v}) ; 100 \mathrm{~mL} \text { of this basal medium was added to } \\
900 \mathrm{~mL} \text { of sterilised molten agar }(1.5 \% \text {, w/v) followed by filter sterilised } \\
\text { solutions of } \mathrm{D}(+) \text { melezitose }(1 \%, \mathrm{w} / \mathrm{v}) \text {, cycloheximide }\left(50 \mu \mathrm{gL}^{-1}\right) \text {, } \\
\text { neomycin sulphate }(4 \mu \mathrm{g} \mathrm{mL}-1) \text { and nystatin }(50 \mu \mathrm{g} \mathrm{mL}-1)\end{array}$ & [82] \\
\hline $\begin{array}{c}\text { Saccharomonospora } \\
\text { oceani/Pseudonocardiaceae }\end{array}$ & Marine sediment & Trypticase soy broth agar (DSMZ Medium 535) & [83] \\
\hline $\begin{array}{c}\text { Actinophytocola } \\
\text { sediminis/Pseudonocardiaceae }\end{array}$ & Marine sediment at a depth of $2439 \mathrm{~m}$ & $\begin{array}{l}\text { Starch casein nitrate agar medium }(10.0 \mathrm{~g} \text { soluble starch, } 0.3 \mathrm{~g} \text { casein, } 2 \mathrm{~g} \\
\mathrm{KNO}_{3}, 0.05 \mathrm{~g} \mathrm{MgSO}_{4} .7 \mathrm{H}_{2} \mathrm{O}, 35 \mathrm{~g} \mathrm{NaCl}, 2 \mathrm{~g} \mathrm{~K}_{2} \mathrm{HPO}_{4}, 0.02 \mathrm{~g} \mathrm{CaCO}_{3}, 10 \mathrm{mg} \\
\left.\mathrm{FeSO}_{4}, 20 \mathrm{~g} \text { agar, distilled water } 1 \mathrm{~L}\right)\end{array}$ & [84] \\
\hline $\begin{array}{c}\text { Pseudonocardia } \\
\text { sediminis/Pseudonocardiaceae }\end{array}$ & Sea sediment at a depth of $652 \mathrm{~m}$ & $\begin{array}{l}\text { DSMZ } 621 \text { medium ( } 250 \mathrm{mg} \text { each of Bacto peptone (Difco), Bacto yeast } \\
\text { extract and glucose, as well as } 20 \mathrm{~mL} \text { Hutner's basal salts medium, } 10 \mathrm{~mL} \\
\text { vitamin solution no. } 6,35 \mathrm{~g} \mathrm{NaCl} \text { and } 1000 \mathrm{~mL} \text { distilled water) }\end{array}$ & [85] \\
\hline Amycolatopsis flava/Pseudonocardiaceae & Marine sediment & $\begin{array}{l}\text { CMKA medium }\left[\left(\mathrm{L}^{-1}\right) 0.5 \mathrm{~g} \text { casein hydrolysate, } 1.5 \mathrm{~g} \text { mannitol, } 1 \mathrm{~g} \mathrm{KNO} \text {, }\right. \\
2 \mathrm{~g}\left(\mathrm{NH}_{4}\right)_{2} \mathrm{SO}_{4}, 0.5 \mathrm{~g} \mathrm{~K}_{2} \mathrm{HPO}_{4}, 0.5 \mathrm{~g} \mathrm{CaCO}_{3}, 20 \mathrm{~g} \text { agar]. The multi-salts } \\
\text { comprised of } 49 \%(\mathrm{w} / \mathrm{w}) \mathrm{MgCl}_{2} \cdot 6 \mathrm{H}_{2} \mathrm{O}, 32 \%(\mathrm{w} / \mathrm{w}) \mathrm{NaCl}, 14 \%(\mathrm{w} / \mathrm{w}) \mathrm{CaCl}_{2} \\
\text { and } 5 \%(\mathrm{w} / \mathrm{w}) \mathrm{KCl}\end{array}$ & [86] \\
\hline $\begin{array}{c}\text { Saccharopolyspora } \\
\text { griseoalba/Pseudonocardiaceae }\end{array}$ & Marine sediment & $\begin{array}{l}\text { CMKA medium }\left[\left(\mathrm{L}^{-1}\right) 0.5 \mathrm{~g} \text { casein hydrolysate, } 1.5 \mathrm{~g} \text { mannitol, } 1 \mathrm{~g} \mathrm{KNO} \text {, }\right. \\
2 \mathrm{~g}\left(\mathrm{NH}_{4}\right)_{2} \mathrm{SO}_{4}, 0.5 \mathrm{~g} \mathrm{~K}_{2} \mathrm{HPO}_{4}, 0.5 \mathrm{~g} \mathrm{CaCO}_{3}, 20 \mathrm{~g} \text { agar]. The multi-salts } \\
\text { comprised of } 49 \%(\mathrm{w} / \mathrm{w}) \mathrm{MgCl}_{2} \cdot 6 \mathrm{H}_{2} \mathrm{O}, 32 \%(\mathrm{w} / \mathrm{w}) \mathrm{NaCl}, 14 \%(\mathrm{w} / \mathrm{w}) \mathrm{CaCl}_{2} \\
\text { and } 5 \%(\mathrm{w} / \mathrm{w}) \mathrm{KCl}\end{array}$ & [87] \\
\hline $\begin{array}{c}\text { Amycolatopsis } \\
\text { albispora/Pseudonocardiaceae }\end{array}$ & Deep-sea sediment at a depth of $-2945 \mathrm{~m}$ & $\begin{array}{l}\text { Modified Zobell } 2216 \mathrm{E} \text { agar ( } 1.0 \mathrm{~g} \text { yeast extract, } 5.0 \mathrm{~g} \text { tryptone, } 34 \mathrm{~g} \mathrm{NaCl} \text {, } \\
15 \mathrm{~g} \text { agar and } 1 \mathrm{~L} \text { distilled water) }\end{array}$ & [88] \\
\hline $\begin{array}{c}\text { Pseudonocardia } \\
\text { profundimaris/Pseudonocardiaceae }\end{array}$ & Marine sediment at a depth of $-7118 \mathrm{~m}$ & $\begin{array}{l}\text { Modified ZoBell } 2216 \mathrm{E} \text { agar plates }(0.5 \% \text { tryptone, } 0.1 \% \text { yeast extract, } 3.4 \% \\
\text { sodium chloride and } 1.8 \% \text { agar) }\end{array}$ & [89] \\
\hline Nocardioides pacificus/Nocardioidaceae & $\begin{array}{l}\text { Deep sub-seafloor sediment at a depth of } \\
\qquad 107.3-107.4 \mathrm{~m}\end{array}$ & Marine agar 2216 (Difco) & [90] \\
\hline
\end{tabular}


Table 2. Cont

\begin{tabular}{|c|c|c|c|}
\hline Strain/Family & Nature of Sample & Isolation Medium & Ref. \\
\hline Nocardioides nanhaiensis/Nocardioidaceae & Sea sediment at a depth of $880 \mathrm{~m}$ & $\begin{array}{l}\text { DSMZ } 621 \text { medium ( } 250 \mathrm{mg} \text { each of Bacto peptone (Difco), Bacto yeast } \\
\text { extract and glucose, as well as } 20 \mathrm{~mL} \text { Hutner's basal salts medium, } 10 \mathrm{~mL} \\
\text { vitamin solution no. } 6,35 \mathrm{~g} \mathrm{NaCl} \text { and } 1000 \mathrm{~mL} \text { distilled water) }\end{array}$ & [91] \\
\hline Nocardioides antarcticus/Nocardioidaceae & Marine sediment & Marine agar 2216 (Becton Dickinson) & [92] \\
\hline Nocardioides litoris/Nocardioidaceae & Marine beach sediment & $\begin{array}{l}\text { Starch casein agar }\left(1 \% \text { soluble starch, } 0.03 \% \text { casein, } 0.2 \% \mathrm{KNO}_{3}, 0.2 \%\right. \\
\mathrm{NaCl}, 0.005 \% \mathrm{MgSO}_{4} .7 \mathrm{H}_{2} \mathrm{O}, 0.2 \% \mathrm{~K}_{2} \mathrm{HPO}_{4}, 0.02 \% \mathrm{CaCO}_{3}, 0.001 \% \\
\mathrm{FeSO}_{4} .7 \mathrm{H}_{2} \mathrm{O}, 1.8 \% \text { agar) }\end{array}$ & [93] \\
\hline Nocardioides flavus/Nocardioidaceae & Marine sediment at a depth of $-7068 \mathrm{~m}$ & Seawater agar (15.0 g agar and $1 \mathrm{~L}$ natural seawater) & [35] \\
\hline $\begin{array}{c}\text { Streptomonospora } \\
\text { sediminis/Nocardiopsaceae }\end{array}$ & Marine sediment & $\begin{array}{l}\text { Agar medium (glycerine } 10.0 \mathrm{~g} \text {, L-arginine } 5.0 \mathrm{~g},\left(\mathrm{NH}_{4}\right)_{2} \mathrm{SO}_{4} 2.64 \mathrm{~g} \text {; } \\
\mathrm{KH}_{2} \mathrm{PO}_{4} 2.38 \mathrm{~g}, \mathrm{~K}_{2} \mathrm{HPO}_{4} 5.65 \mathrm{~g}, \mathrm{MgSO}_{4} .7 \mathrm{H}_{2} \mathrm{O} 1.0 \mathrm{~g}, \mathrm{CuSO}_{4} .5 \mathrm{H}_{2} \mathrm{O} 0.0064 \mathrm{~g} \text {, } \\
\mathrm{FeSO}_{4} .7 \mathrm{H}_{2} \mathrm{O} 0.0011 \mathrm{~g} ; \mathrm{MnCl}_{2} .4 \mathrm{H}_{2} \mathrm{O} 0.0079 \mathrm{~g} ; \mathrm{ZnSO}_{4} .7 \mathrm{H}_{2} \mathrm{O} 0.0015 \mathrm{~g} \text {, agar } \\
15.0 \text { g; distilled water } 1.0 \mathrm{~L} \text { ) }\end{array}$ & [94] \\
\hline $\begin{array}{c}\text { Streptomonospora } \\
\text { nanhaiensis/Nocardiopsaceae }\end{array}$ & Marine sediment at a depth of $2918 \mathrm{~m}$ & $\begin{array}{l}\text { Agar medium (glycerine } 10.0 \mathrm{~g} \text {, L-arginine } 5.0 \mathrm{~g},\left(\mathrm{NH}_{4}\right)_{2} \mathrm{SO}_{4} 2.64 \mathrm{~g} \text {; } \\
\mathrm{KH}_{2} \mathrm{PO}_{4} 2.38 \mathrm{~g}, \mathrm{~K}_{2} \mathrm{HPO}_{4} 5.65 \mathrm{~g}, \mathrm{MgSO}_{4} .7 \mathrm{H}_{2} \mathrm{O} 1.0 \mathrm{~g}, \mathrm{CuSO}_{4} .5 \mathrm{H}_{2} \mathrm{O} 0.0064 \mathrm{~g} \text {, } \\
\mathrm{FeSO}_{4} .7 \mathrm{H}_{2} \mathrm{O} 0.0011 \mathrm{~g} ; \mathrm{MnCl}_{2} .4 \mathrm{H}_{2} \mathrm{O} 0.0079 \mathrm{~g} ; \mathrm{ZnSO}_{4} .7 \mathrm{H}_{2} \mathrm{O} 0.0015 \mathrm{~g} \text {, agar } \\
15.0 \text { g; distilled water } 1.0 \mathrm{~L} \text { ) }\end{array}$ & [94] \\
\hline Nocardiopsis oceani/Nocardiopsaceae & \multirow{2}{*}{ Marine sediment at a depth of $2460 \mathrm{~m}$} & \multirow{2}{*}{$\begin{array}{l}\text { Gauze's synthetic medium no. } 1 \text { (soluble starch } 20.0 \mathrm{~g}, \mathrm{KNO}_{3} 1.0 \mathrm{~g}, \mathrm{NaCl} \\
0.5 \mathrm{~g} \text {, } \mathrm{MgSO}_{4} .7 \mathrm{H}_{2} \mathrm{O}, 0.5 \mathrm{~g}, \mathrm{~K}_{2} \mathrm{HPO}_{4} 0.5 \mathrm{~g}, \mathrm{FeSO}_{4} .7 \mathrm{H}_{2} \mathrm{O} 10.0 \mathrm{mg} \text {, agar } 15.0 \mathrm{~g} \\
\text { and distilled water } 1.0 \mathrm{~L} \text { ) }\end{array}$} & \multirow{2}{*}{ [95] } \\
\hline Nocardiopsis nanhaiensis/Nocardiopsaceae & & & \\
\hline $\begin{array}{c}\text { Microbacterium } \\
\text { hydrothermale/Microbacteriaceae }\end{array}$ & $\begin{array}{l}\text { Hydrothermal sediment at a depth of } \\
\qquad 2943 \mathrm{~m}\end{array}$ & $\begin{array}{l}\text { Modified ZoBell } 2216 \mathrm{E} \text { agar plates ( } 0.5 \% \text { tryptone, } 0.1 \% \text { yeast extract, } 3.4 \% \\
\text { sodium chloride and } 1.8 \% \text { agar) }\end{array}$ & [96] \\
\hline Agromyces marinus/Microbacteriaceae & Sea sediment & $\begin{array}{l}\text { NBRC medium } 802 \text { [Polypepton (Wako) } 2 \text { g, yeast extract } 0.4 \mathrm{~g} \text {, } \\
\mathrm{MgSO}_{4} .7 \mathrm{H}_{2} \mathrm{O} 0.2 \mathrm{~g} \text { and agar } 15 \mathrm{~g} \text { in } 1.0 \mathrm{~L} \text { distilled water supplemented } \\
\left.\text { with } \mathrm{NaCl}\left(30 \mathrm{~g}^{-1}\right) \text {, cycloheximide }\left(50 \mathrm{mg}^{-1}\right) \text { and nalidixic acid }\left(20 \mathrm{mg}^{-1}\right)\right] \text {. }\end{array}$ & [97] \\
\hline $\begin{array}{c}\text { Microbacterium } \\
\text { enclense/Microbacteriaceae }\end{array}$ & Marine sediment & Marine agar (HiMedia) & [98] \\
\hline $\begin{array}{c}\text { Microbacterium } \\
\text { nanhaiense/Microbacteriaceae }\end{array}$ & Sea sediment at a depth of $2093 \mathrm{~m}$ & $\begin{array}{l}\text { Yeast extract/malt extract agar ( } 1 \mathrm{~L} \text { seawater, } 0.5 \mathrm{~g} \text { malt extract, } 0.2 \mathrm{~g} \text { yeast } \\
\text { extract, } 0.1 \mathrm{~g} \text { glucose and } 20 \mathrm{~g} \text { agar) }\end{array}$ & [99] \\
\hline
\end{tabular}


Table 2. Cont.

\begin{tabular}{|c|c|c|c|}
\hline Strain/Family & Nature of Sample & Isolation Medium & Ref. \\
\hline Zhihengliuella flava/Micrococcaceae & Sea sediment & $\begin{array}{l}\text { NBRC medium } 802(0.2 \% \text { polypeptone, } 0.04 \% \text { yeast extract, } 0.02 \% \\
\left.\mathrm{MgSO}_{4} .7 \mathrm{H}_{2} \mathrm{O} \text { and } 1.5 \% \text { agar }\right)\end{array}$ & [100] \\
\hline Kocuria indica/Micrococcaceae & Marine sediment & Marine agar 2216 (Difco) & [101] \\
\hline Nesterenkonia alkaliphila/Micrococcaceae & Deep-sea sediment at a depth of $7118 \mathrm{~m}$ & $\begin{array}{l}\text { Modified ISP } 1 \text { ( } 1 \mathrm{~L} \text { natural seawater, } 10 \mathrm{~g} \text { glucose, } 5 \text { g peptone, } 5 \mathrm{~g} \text { yeast } \\
\text { extract, } 0.2 \mathrm{~g} \mathrm{MgSO}_{4} \cdot 7 \mathrm{H}_{2} \mathrm{O}, 10 \mathrm{~g} \mathrm{NaHCO}_{3}, 27 \mathrm{~g} \mathrm{Na}_{2} \mathrm{CO}_{3} \cdot 10 \mathrm{H}_{2} \mathrm{O} \text { and } \\
15 \mathrm{~g} \text { agar) }\end{array}$ & [102] \\
\hline Kocuria subflava/Micrococcaceae & Marine sediment & $\begin{array}{l}\text { No. } 38 \text { medium }\left[\left(\mathrm{L}^{-1}\right) \text { yeast extract } 0.4 \mathrm{~g} \text {; glucose } 0.4 \mathrm{~g} \text {; malt extract } 0.4 \mathrm{~g} \text {; }\right. \\
\text { B-vitamin trace } 1 \mathrm{~mL}(0.5 \mathrm{mg} \text { each of thiamine- } \mathrm{HCl}(\mathrm{B} 1) \text {, riboflavin, niacin, } \\
\text { pyridoxin, ca-pantothenate, inositol, } p \text {-aminobenzoic acid, and } 0.25 \mathrm{mg} \text { of } \\
\text { biotin, agar } 15 \mathrm{~g} \text {, distilled water } 1000 \mathrm{~mL}]\end{array}$ & [103] \\
\hline $\begin{array}{c}\text { Luteococcus } \\
\text { sediminum/Propionibacteriaceae }\end{array}$ & Deep subseafloor sediment & Marine agar 2216 (Difco) & [104] \\
\hline $\begin{array}{l}\text { Mariniluteicoccus flavus (novel } \\
\text { genus)/Propionibacteriaceae }\end{array}$ & Deep-sea sediment at a depth of $2439 \mathrm{~m}$ & $\begin{array}{l}\mathrm{HP} \text { agar medium ( } 5 \mathrm{~g} \text { fucose, } 1 \mathrm{~g} \text { proline, } 1 \mathrm{~g}\left(\mathrm{NH}_{4}\right)_{2} \mathrm{SO}_{4}, 2 \mathrm{~g} \mathrm{CaCl}_{2}, 1 \mathrm{~g} \\
\mathrm{~K}_{2} \mathrm{HPO}_{4}, \mathrm{~B} \text { vitamin mixture }(0.5 \mathrm{mg} \text { each thiamine hydrochloride, } \\
\text { riboflavin, niacin, pyridoxine, calcium pantothenate, inositol and } \\
\text {-aminobenzoic acid and } 0.25 \mathrm{mg} \text { biotin), } 35 \mathrm{~g} \mathrm{NaCl}, 12 \mathrm{~g} \text { agar, } 1000 \mathrm{~mL} \\
\text { distilled water) }\end{array}$ & [43] \\
\hline $\begin{array}{c}\text { Tessaracoccus } \\
\text { lapidicaptus/Propionibacteriaceae }\end{array}$ & $\begin{array}{l}\text { Deep subsurface sediment at a depth of } \\
\qquad 297 \mathrm{~m}\end{array}$ & 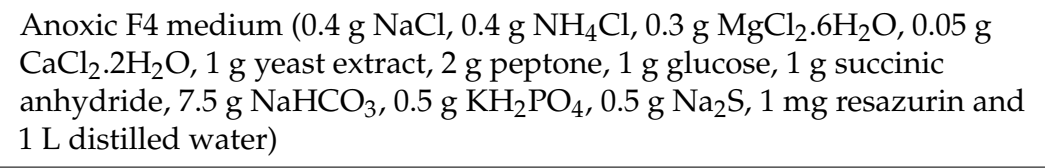 & [105] \\
\hline Tessaracoccus arenae/Propionibacteriaceae & Sea sediment & Marine agar 2216 (Difco) & [106] \\
\hline Rhodococcus enclensis/Nocardiaceae & Marine sediment & Marine agar 2216 (Difco) & [107] \\
\hline Nocardia jiangsuensis/Nocardiaceae & Coastal sediment & $\begin{array}{l}\text { Starch arginine agar }\left(2.5 \mathrm{~g} \text { soluble starch, } 1.0 \mathrm{~g} \text { arginine, } 1.0 \mathrm{~g}\left(\mathrm{NH}_{4}\right)_{2} \mathrm{SO}_{4}\right. \\
2.0 \mathrm{~g} \mathrm{CaCl}_{2}, 1.0 \mathrm{~g} \mathrm{~K}_{2} \mathrm{HPO}_{4}, 0.2 \mathrm{~g} \mathrm{MgSO}_{4} .7 \mathrm{H}_{2} \mathrm{O}, 10 \mathrm{mg} \mathrm{FeSO} \mathrm{FH}_{4} .7 \mathrm{H}_{2} \mathrm{O}, 15.0 \mathrm{~g} \\
\text { agar supplemented with } 3 \%(\mathrm{w} / \mathrm{v}) \mathrm{NaCl} \text {, nystatin and nalidixic acid })\end{array}$ & [108] \\
\hline $\begin{array}{l}\text { Micromonospora } \\
\text { fluostatini/Micromonosporaceae }\end{array}$ & Marine sediment & $\begin{array}{l}\text { M1 medium ( } 10 \mathrm{~g} \text { soluble starch, } 4 \mathrm{~g} \text { yeast extract, } 2 \mathrm{~g} \text { peptone, } 18 \mathrm{~g} \text { agar, } \\
\text { and } 1 \mathrm{~L} \text { of natural seawater) }\end{array}$ & [109] \\
\hline
\end{tabular}


Table 2. Cont.

\begin{tabular}{|c|c|c|c|}
\hline Strain/Family & Nature of Sample & Isolation Medium & Ref. \\
\hline $\begin{array}{c}\text { Micromonospora } \\
\text { yasonensis/Micromonosporaceae }\end{array}$ & Marine sediment at a depth of $45 \mathrm{~m}$ & $\begin{array}{l}\text { SM3 medium (Gauze's medium } 2) \text { [ } 20 \mathrm{~g} \text { casaminoacids, } 20 \mathrm{~g} \text { soluble starch, } \\
4 \mathrm{~g} \text { yeast extract, } 15 \mathrm{~g} \text { agar, } 1 \mathrm{~L} \text { distilled water] supplemented with filter } \\
\text { sterilised cycloheximide }(50 \mu \mathrm{g} \mathrm{mL}-1) \text {, nalidixic acid }\left(10 \mu \mathrm{g} \mathrm{mL}^{-1}\right) \text {, } \\
\text { novobiocin }\left(10 \mu \mathrm{g} \mathrm{mL}^{-1}\right) \text { and nystatin }\left(50 \mu \mathrm{gL}^{-1}\right)\end{array}$ & [110] \\
\hline $\begin{array}{c}\text { Micromonospora } \\
\text { profundi/Micromonosporaceae }\end{array}$ & Marine sediment at a depth of $45 \mathrm{~m}$ & $\begin{array}{l}\text { ISP } 2 \text { medium (yeast extract } 4.0 \mathrm{~g} \text {, malt extract } 10.0 \mathrm{~g} \text {, dextrose } 4.0 \mathrm{~g} \text {, } \\
\text { distilled water } 1 \mathrm{~L} \text { and Bacto agar } 20.0 \mathrm{~g} \text { ) }\end{array}$ & [111] \\
\hline Demequina activiva/Demequinaceae & Tidal flat sediment & Marine agar 2216 (Becton Dickinson) & [112] \\
\hline Demequina litorisediminis/Demequinaceae & Tidal flat sediment & Marine agar 2216 (Difco) & [113] \\
\hline Janibacter cremeus/Intrasporangiaceae & Sea sediment & $\begin{array}{l}\text { NBRC medium } 802(1.0 \% \text { polypeptone, } 0.2 \% \text { yeast extract, } 0.1 \% \\
\mathrm{MgSO} 4.7 \mathrm{H}_{2} \mathrm{O} \text { and } 1.5 \% \text { agar) }\end{array}$ & [114] \\
\hline Janibacter indicus/Intrasporangiaceae & Hydrothermal sediment & $\begin{array}{l}\text { ZoBell } 2216 \mathrm{E} \text { agar }(0.5 \% \text { tryptone, } 0.1 \% \text { yeast extract, } 3.4 \% \text { sodium chloride } \\
\text { and } 1.8 \% \text { agar) }\end{array}$ & [115] \\
\hline Georgenia sediminis/Bogoriellaceae & Marine Sediment at a depth of $141 \mathrm{~m}$ & Marine agar 2216 (Becton Dickinson) & [116] \\
\hline Georgenia subflava/Bogoriellaceae & $\begin{array}{c}\text { Deep sea sediment at a depth of } 6310 \mathrm{~m} \\
\text { water depth }\end{array}$ & $\begin{array}{l}\text { Modified ZoBell 2216E agar ( } 1.0 \mathrm{~g} \text { yeast extract, } 5.0 \mathrm{~g} \text { tryptone, } 1 \mathrm{~L} \text { of } \\
\text { clarified seawater, } 15.0 \mathrm{~g} \text { agar) }\end{array}$ & [117] \\
\hline $\begin{array}{c}\text { Ilumatobacter } \\
\text { nonamiense/Acidimicrobiaceae }\end{array}$ & Seashore sediment & 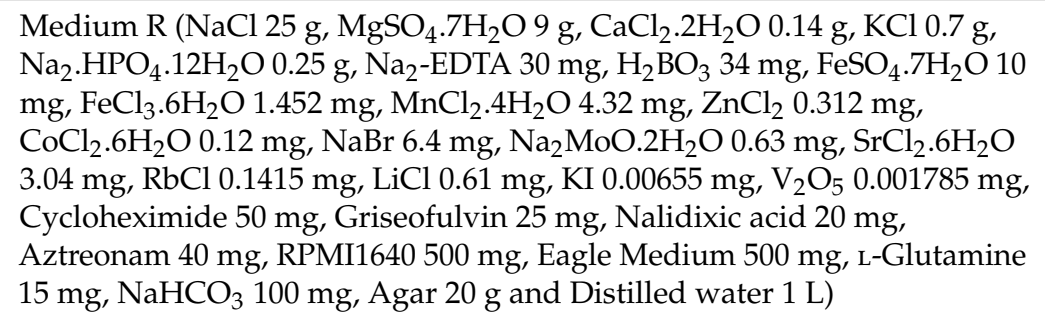 & [118] \\
\hline $\begin{array}{c}\text { Ilumatobacter } \\
\text { coccineum/Acidimicrobiaceae }\end{array}$ & Seashore sand & & \\
\hline $\begin{array}{l}\text { Sediminivirga luteola (novel } \\
\text { genus)/Brevibacteriaceae }\end{array}$ & Marine sediment at a depth of $-5233 \mathrm{~m}$ & $\begin{array}{l}\text { Isolation medium (10 g glucose, } 5 \text { g peptone, } 5 \text { g yeast extract, } 0.2 \mathrm{~g} \\
\mathrm{MgSO}_{4} \cdot 7 \mathrm{H}_{2} \mathrm{O}, 10 \mathrm{~g} \mathrm{NaHCO} 3,27 \mathrm{~g} \mathrm{Na}_{2} \mathrm{CO}_{3} \cdot 10 \mathrm{H}_{2} \mathrm{O}, 20 \mathrm{~g} \text { agar and } 1 \mathrm{~L} \\
\text { natural seawater) }\end{array}$ & [25] \\
\hline
\end{tabular}


Table 2. Cont.

\begin{tabular}{|c|c|c|c|}
\hline Strain/Family & Nature of Sample & Isolation Medium & Ref. \\
\hline $\begin{array}{c}\text { Brevibacterium } \\
\text { sediminis/Brevibacteriaceae }\end{array}$ & Deep-sea sediment at a depth of $-2461 \mathrm{~m}$ & $\begin{array}{l}\text { ISP } 2 \text { medium (yeast extract } 4.0 \mathrm{~g} \text {, malt extract } 10.0 \mathrm{~g} \text {, dextrose } 4.0 \mathrm{~g} \text {, } \\
\text { distilled water } 1 \mathrm{~L} \text { and Bacto agar } 20.0 \mathrm{~g} \text { ) }\end{array}$ & [119] \\
\hline $\begin{array}{c}\text { Halopolyspora alba (novel } \\
\text { genus)/Actinopolysporaceae }\end{array}$ & Sea sediment & $\begin{array}{l}\text { CMKA medium }\left[\left(0.5 \mathrm{~g} \text { casein acids hydrolysate, } 1.5 \mathrm{~g} \text { mannitol, } 1 \mathrm{~g} \mathrm{KNO} \mathrm{KN}_{3} \text {, }\right.\right. \\
2 \mathrm{~g}\left(\mathrm{NH}_{4}\right)_{2} \mathrm{SO}_{4}, 0.5 \mathrm{~g} \mathrm{~K}_{2} \mathrm{HPO}_{4}, 0.5 \mathrm{~g} \mathrm{CaCO}, 20 \mathrm{~g} \text { agar and } 20 \%(\mathrm{w} / \mathrm{v}) \\
\text { multi-salts]. The multi-salts comprised } 49 \%(\mathrm{w} / \mathrm{w}) \mathrm{MgCl}_{2}, 32 \%(\mathrm{w} / \mathrm{w}) \\
\mathrm{NaCl}, 14 \%(\mathrm{w} / \mathrm{w}) \mathrm{CaCl}_{2} \text { and } 5 \%(\mathrm{w} / \mathrm{w}) \mathrm{KCl}\end{array}$ & {$[24]$} \\
\hline $\begin{array}{l}\text { Haloactinomyces albus (novel } \\
\text { genus)/Actinopolysporaceae }\end{array}$ & Marine sediment & $\begin{array}{l}\text { CMKA medium }\left[\left(0.5 \mathrm{~g} \text { casein acids hydrolysate, } 1.5 \mathrm{~g} \text { mannitol, } 1 \mathrm{~g} \mathrm{KNO} \mathrm{KN}_{3},\right.\right. \\
2 \mathrm{~g}\left(\mathrm{NH}_{4}\right)_{2} \mathrm{SO}_{4}, 0.5 \mathrm{~g} \mathrm{~K}_{2} \mathrm{HPO}_{4}, 0.5 \mathrm{~g} \mathrm{CaCO}, 20 \mathrm{~g} \text { agar and } 20 \%(\mathrm{w} / \mathrm{v}) \\
\text { multi-salts]. The multi-salts comprised } 49 \%(\mathrm{w} / \mathrm{w}) \mathrm{MgCl}_{2}, 32 \%(\mathrm{w} / \mathrm{w}) \\
\mathrm{NaCl}, 14 \%(\mathrm{w} / \mathrm{w}) \mathrm{CaCl}_{2} \text { and } 5 \%(\mathrm{w} / \mathrm{w}) \mathrm{KCl}\end{array}$ & [26] \\
\hline $\begin{array}{l}\text { Flaviflexus huanghaiensis (novel } \\
\text { genus)/Actinomycetaceae }\end{array}$ & Coastal sediment & Marine agar 2216 (Difco) & [120] \\
\hline $\begin{array}{c}\text { Paraoerskovia } \\
\text { sediminicola/Cellulomonadaceae }\end{array}$ & Sea sediment & $\begin{array}{l}\mathrm{NBRC} \text { medium } 802(1.0 \% \text { polypeptone, } 0.2 \% \text { yeast extract, } 0.1 \% \\
\left.\mathrm{MgSO}_{4} .7 \mathrm{H}_{2} \mathrm{O} \text { and } 1.5 \% \text { agar }\right)\end{array}$ & [121] \\
\hline
\end{tabular}


Table 3. New species of rare actinomycetes from seawater reported during the period of mid 2013-2017.

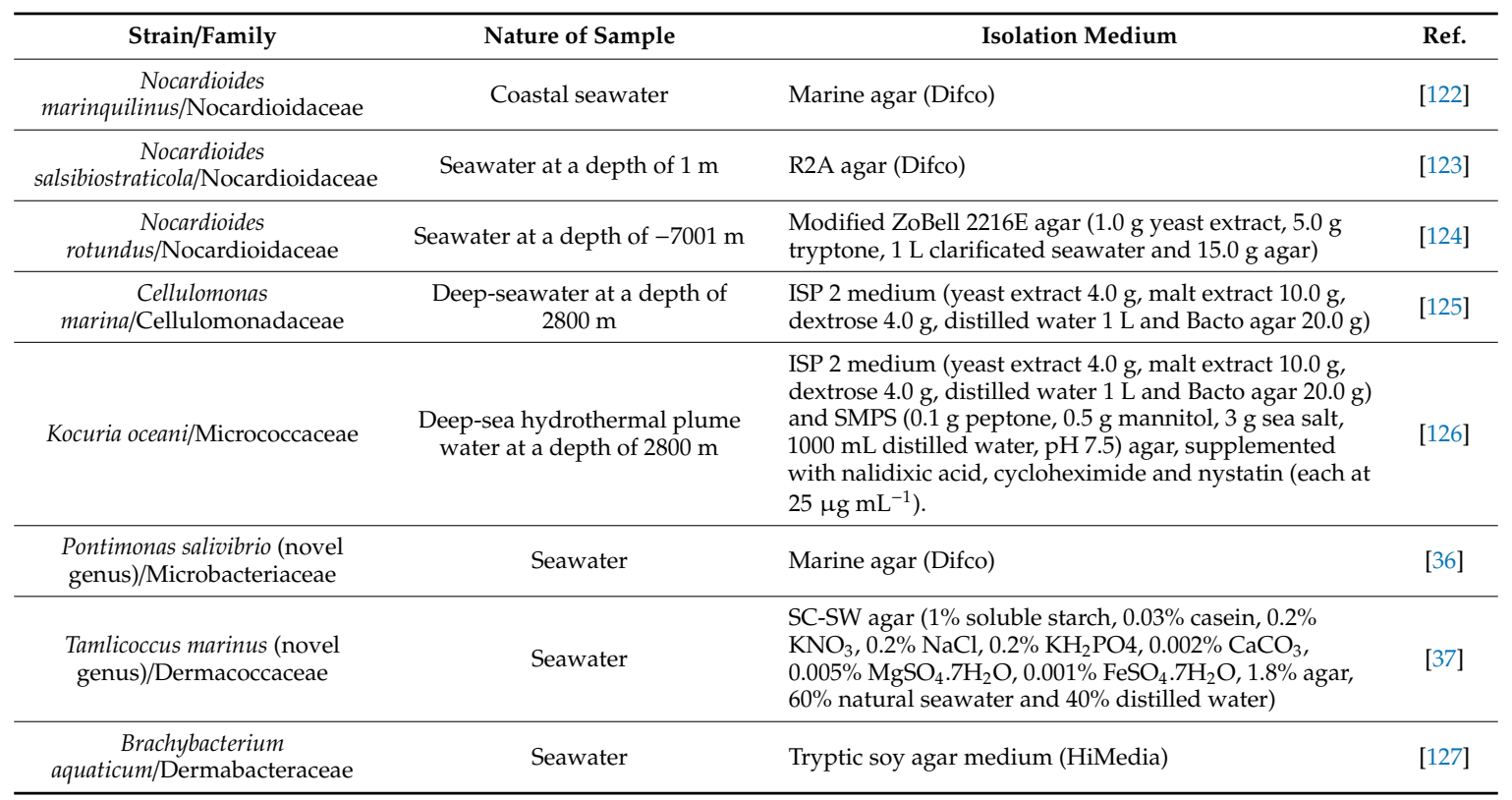

Mangrove forests are highly dynamic ecosystems that cover and protect approximately $75 \%$ of the world's tropical and subtropical coastal areas [128] and harbor a rich diversity of marine, freshwater and terrestrial flora and fauna. The diversity of the microbial community in mangrove environments is still rather unexplored [60]. The large fluctuation of salinity and tidal gradients make the mangrove forests unique environments that favors the production of unusual metabolites among the residing microorganisms [60]. Novel actinomycetes reported from different mangrove habitats including sediments, mangrove plant rhizosphere soil and mangrove endophytes are classified into 25 genera, 11 families and 8 suborders [7,129]. A total of 27 new species of rare actinomycetes belonging to 13 different families have been reported from mangrove habitats for the period mid-2013-2017 (Table 5). Among them, two novel genera, Mamia and Monashia, were reported to be isolated from the $20 \mathrm{~cm}$ top-layer of mangrove soil. The families reported in mangrove sediments between mid-2013 and 2017 are Demequinaceae (9 new species), Micromonosporaceae ( 5 new species), Nocardiopsaceae (2 new species), Micrococcaceae (2 new species), Nocardioidaceae (1 new species), Intrasporangiaceae (1 new species), Pseudonocardiaceae (1 new species), Microbacteriaceae (1 new species), Thermomonosporaceae (1 new species), Jiangellaceae (1 new species), Beutenbergiaceae (1 new species), Streptosporangiaceae (1 new species) and Kineosporiaceae (1 new species). 
Table 4. New species of symbiotic rare actinomycetes from eukaryotic hosts reported during the period of mid 2013-2017.

\begin{tabular}{|c|c|c|c|}
\hline Strain/Family & Nature of Sample & Isolation Medium & Reference \\
\hline Verrucosispora andamanensis/Micromonosporaceae & Marine sponge Xestospongia sp. & $\begin{array}{l}\text { Starch-casein nitrate seawater agar }(10 \mathrm{~g} \text { soluble } \\
\text { starch, } 1 \mathrm{~g} \text { sodium caseinate, } 0.5 \mathrm{~g} \mathrm{KH}_{2} \mathrm{PO}_{4}, 0.5 \mathrm{~g} \\
\left.\mathrm{MgSO}_{4} \text { and } 18 \mathrm{~g} \text { agar in } 1 \mathrm{~L} \text { of seawater }\right)\end{array}$ & [130] \\
\hline Micromonospora spongicola/Micromonosporaceae & Marine sponge at a depth of $5 \mathrm{~m}$ & $\begin{array}{l}\text { Starch-casein nitrate agar }(10 \mathrm{~g} \text { soluble starch, } 1 \mathrm{~g} \\
\text { sodium caseinate, } 2 \mathrm{~g} \mathrm{KNO}, 0.5 \mathrm{~g} \mathrm{KH}_{2} \mathrm{PO}_{4}, 0.5 \mathrm{~g} \\
\left.\mathrm{MgSO}_{4} \text { and } 18 \mathrm{~g} \text { agar in } 1 \mathrm{~L} \text { seawater }\right)\end{array}$ & [131] \\
\hline Prauserella coralliicola/Pseudonocardiaceae & $\begin{array}{l}\text { Marine coral Galaxea fascicularis at a } \\
\text { depth of } 5 \mathrm{~m}\end{array}$ & $\begin{array}{l}\text { Isolation medium (yeast extract } 0.25 \mathrm{~g}, \mathrm{~K}_{2} \mathrm{HPO}_{4} \\
0.5 \mathrm{~g} \text {, agar } 12 \mathrm{~g}, 500 \mathrm{~mL} \text { seawater and } 500 \mathrm{~mL} \\
\text { distilled water) }\end{array}$ & [132] \\
\hline Saccharopolyspora spongiae/Pseudonocardiaceae & $\begin{array}{l}\text { Marine sponge Scopalina ruetzleri at } \\
\text { depths between } 20 \text { and } 30 \mathrm{~m}\end{array}$ & $\begin{array}{l}\text { M1 medium [ } 1 \% \text { starch, } 0.4 \% \text { yeast extract, } 0.2 \% \\
\text { peptone, } 2 \% \text { agar containing artificial seawater } \\
\left(33 \mathrm{~g} \text { red sea salt } \mathrm{L}^{-1} \text { ) amended with }\right. \\
\text { cycloheximide and nystatin (each at } 25 \mu \mathrm{g} \mathrm{mL}^{-1} \text { )] }\end{array}$ & [40] \\
\hline Microbacterium aureliae/Microbacteriaceae & Moon jellyfish Aurelia aurita & $\begin{array}{l}\text { Zobell marine agar (HiMedia) and Tryptic soy } \\
\text { agar (HiMedia) }\end{array}$ & [133] \\
\hline Mycobacterium stephanolepidis/Mycobacteriaceae & Marine teleost fish Stephanolepis cirrhifer & $\begin{array}{l}\text { Middlebrook } 7 \mathrm{H} 11 \text { agar with oleic albumin } \\
\text { dextrose catalase (OADC) enrichment (Becton } \\
\text { Dickinson) }\end{array}$ & [134] \\
\hline Marmoricola aquaticus/Nocardioidaceae & marine sponge Glodia corticostylifera & $\begin{array}{l}\text { M1 agar (soluble starch } 10 \mathrm{~g} \mathrm{~L}^{-1} \text {, yeast extract } \\
4 \mathrm{~g} \mathrm{~L}^{-1} \text {, peptone } 2 \mathrm{~g} \mathrm{~L}^{-1} \text {, agar } 15 \mathrm{~g} \mathrm{~L}^{-1}, 80 \% \\
\text { artificial seawater) }\end{array}$ & [38] \\
\hline Arthrobacter echini/Micrococcaceae & Purple sea urchin Heliocidaris crassispina & Marine agar 2216 (Difco) & [135] \\
\hline Ornithinimicrobium algicola/Intrasporangiaceae & Marine green alga Ulva sp. & $\begin{array}{l}\text { Modified R2A medium (yeast extract } 0.5 \mathrm{~g} \text {, } \\
\text { peptone } 0.5 \mathrm{~g} \text {, casein enzyme hydrolysate } 0.5 \mathrm{~g} \text {, } \\
\text { yeast extract } 0.5 \mathrm{~g} \text {, glucose } 0.5 \mathrm{~g} \text {, water soluble } \\
\text { starch } 0.5 \mathrm{~g} \text {, dipotassium phosphate } 0.3 \mathrm{~g} \text {, } \\
\text { magnesium sulphate } 0.05 \mathrm{~g} \text {, sodium pyruvate } \\
0.3 \mathrm{~g} \text {, sodium chloride } 20.0 \mathrm{~g} \text { and distilled water } \\
1000 \mathrm{~mL} \text { ) }\end{array}$ & [41] \\
\hline
\end{tabular}


Table 4. Cont

\begin{tabular}{|c|c|c|c|}
\hline Strain/Family & Nature of Sample & Isolation Medium & Reference \\
\hline Nocardia xestospongiae/Nocardiaceae & Marine sponge Xestospongia sp. & $\begin{array}{l}\text { Modified starch-casein nitrate seawater agar } \\
\text { containing } 10 \mathrm{~g} \text { soluble starch, } 1 \mathrm{~g} \text { sodium } \\
\text { caseinate, } 0.5 \mathrm{~g} \mathrm{KH}_{2} \mathrm{PO}_{4}, 0.5 \mathrm{~g} \mathrm{MgSO}_{4} \text { and } 18 \mathrm{~g} \\
\text { agar in } 1 \mathrm{~L} \text { seawater, } \mathrm{pH} 8.3 \text {, supplemented with } \\
50 \mathrm{mg} \text { nalidixic acid L }{ }^{-1} \text { and } 200 \mathrm{mg} \text { nystatin } \mathrm{L}^{-1}\end{array}$ & [136] \\
\hline Rubrobacter aplysinae/Rubrobacteraceae & Marine sponge Aplysina aerophoba & Tryptone soy agar (Oxoid) & [137] \\
\hline $\begin{array}{c}\text { Actinokineospora } \\
\text { spheciospongiae/Actinosynnemataceae }\end{array}$ & Marine sponge Spheciospongia vagabunda & $\begin{array}{l}\text { ISP } 2 \text { medium (yeast extract } 4.0 \mathrm{~g} \text {, malt extract } \\
10.0 \mathrm{~g} \text {, dextrose } 4.0 \mathrm{~g} \text {, distilled water } 1 \mathrm{~L} \text { and } \\
\text { Bacto agar } 20.0 \mathrm{~g} \text { ) }\end{array}$ & [138] \\
\hline Williamsia spongiae/Gordoniaceae & $\begin{array}{l}\text { Marine sponge Amphimedon viridis at } \\
\text { depths of between } 5 \text { and } 10 \mathrm{~m}\end{array}$ & $\begin{array}{l}\text { Tryptic Soy Agar [Oxoid; prepared with } 80 \%(\mathrm{v} / \mathrm{v}) \\
\text { artificial seawater] }\end{array}$ & [39] \\
\hline $\begin{array}{c}\text { Myceligenerans } \\
\text { cantabricum/Promicromonosporaceae }\end{array}$ & Marine coral at a depth of $1500 \mathrm{~m}$ & $\begin{array}{l}\text { 1/3 Tryptic soy agar (Merck) and and } 1 / 6 \mathrm{M} \text {-BLEB } \\
\text { agar }(9 \mathrm{~g} \text { MOPS BLEB base (Oxoid) in } 1 \mathrm{~L} \\
\text { Cantabrian seawater, containing the antifungal } \\
\text { cycloheximide }\left(80 \mu \mathrm{g} \mathrm{mL} \mathrm{m}^{-1}\right) \text { and } \\
\text { anti-Gram-negative bacteria nalidixic acid } \\
\left(20 \mathrm{mg} \mathrm{mL}^{-1}\right)\end{array}$ & [139] \\
\hline
\end{tabular}


Table 5. New species of rare actinomycetes from mangrove environment reported during the period of mid 2013-2017.

\begin{tabular}{|c|c|c|c|}
\hline Strain/Family & Nature of Sample & Isolation Medium & Ref. \\
\hline Lysinimicrobiumaestuarii/Demequinaceae & Sediment of mangrove tidal flat & \multirow{9}{*}{$\begin{array}{l}1 / 5 \mathrm{NBRC} \text { medium } 802[0.2 \%(\mathrm{w} / \mathrm{v}) \text { polypeptone, } \\
0.04 \%(\mathrm{w} / \mathrm{v}) \text { yeast extract, } 0.02 \%(\mathrm{w} / \mathrm{v}) \mathrm{MgSO}_{4} .7 \mathrm{H}_{2} \mathrm{O} \\
\text { and } 1.5 \%(\mathrm{w} / \mathrm{v}) \text { agar; } \mathrm{pH} 7.0] \text { supplemented with } 5.0 \% \\
(\mathrm{w} / \mathrm{v}) \mathrm{NaCl}, 0.005 \%(\mathrm{w} / \mathrm{v}) \text { cycloheximide and } 0.002 \% \\
(\mathrm{w} / \mathrm{v}) \text { nalidixic acid }\end{array}$} & \multirow{9}{*}[140]{} \\
\hline Lysinimicrobium flavum/Demequinaceae & \multirow{3}{*}{ Rhizosphere soil of mangrove } & & \\
\hline Lysinimicrobium gelatinilyticum/Demequinaceae & & & \\
\hline Lysinimicrobium iriomotense/Demequinaceae & & & \\
\hline Lysinimicrobium luteum/Demequinaceae & Soil of mangrove forest & & \\
\hline Lysinimicrobium pelophilum/Demequinaceae & Mud of mangrove tidal flat & & \\
\hline Lysinimicrobium rhizosphaerae/Demequinaceae & Rhizosphere soil of mangrove & & \\
\hline Lysinimicrobium soli/Demequinaceae & Soil of mangrove forest & & \\
\hline Lysinimicrobium subtropicum/Demequinaceae & Rhizosphere soil of mangrove & & \\
\hline Micromonospora wenchangensis/Micromonosporaceae & Mangrove soil & $\begin{array}{l}\text { Glucose-peptone-tryptone agar supplemented with } \\
50 \mathrm{mg} \text { nystatin } \mathrm{L}^{-1}, 50 \mathrm{mg} \text { cycloheximide } \mathrm{L}^{-1}, 25 \mathrm{mg} \\
\text { novobiocin } \mathrm{L}^{-1} \text { and } 20 \mathrm{mg} \text { nalidixic acid } \mathrm{L}^{-1}\end{array}$ & [52] \\
\hline Micromonospora zhanjiangensis/Micromonosporaceae & Mangrove soil & $\begin{array}{l}\text { 1/10 ATCC } 172 \text { agar supplemented with nalidixic acid } \\
\left(10 \mu \mathrm{gL} \mathrm{mL}^{-1}\right) \text {, novobiocin }\left(10 \mu \mathrm{g} \mathrm{mL}^{-1}\right) \text {, nystatin } \\
\left(50 \mu \mathrm{g} \mathrm{mL}^{-1}\right) \text { and } \mathrm{K}_{2} \mathrm{Cr}_{2} \mathrm{O}_{7}\left(20 \mu \mathrm{g} \mathrm{mL}^{-1}\right)\end{array}$ & [141] \\
\hline Micromonospora ovatispora/Micromonosporaceae & Mangrove soil & ATCC 172 agar & [142] \\
\hline Micromonospora sediminis/Micromonosporaceae & Mangrove sediment & $\begin{array}{l}\text { AV medium }(1.0 \text { g glucose, } 1.0 \text { g glycerol, } 0.3 \mathrm{~g} \\
\mathrm{L}-\text {-arginine, } 0.3 \mathrm{~g} \mathrm{~K}_{2} \mathrm{HPO}_{4}, 0.2 \mathrm{~g} \mathrm{MgSO}_{4} .7 \mathrm{H}_{2} \mathrm{O}, 0.3 \mathrm{~g} \\
\mathrm{NaCl}, 18 \mathrm{~g} \text { agar, artificial seawater added up to } 1 \mathrm{~L})\end{array}$ & [42] \\
\hline Micromonospora mangrovi/Micromonosporaceae & Mangrove soil & $\begin{array}{l}\text { Glucose-peptone-tryptone agar (glucose } 10 \mathrm{~g} \text {, peptone } \\
5 \mathrm{~g} \text {, tryptone } 3 \mathrm{~g}, \mathrm{NaCl} 5 \mathrm{~g} \text {, agar } 15 \mathrm{~g} \text {, } \mathrm{dd}_{2} \mathrm{O} 1 \mathrm{~L} \\
\text { supplemented with } 50 \mathrm{mg} / \mathrm{L} \text { of nystatin, } 50 \mathrm{mg} / \mathrm{L} \mathrm{of} \\
\text { cycloheximide, } 25 \mathrm{mg} / \mathrm{L} \text { of novobiocin and } 20 \mathrm{mg} / \mathrm{L} \text { of } \\
\text { nalidixic acid) }\end{array}$ & [143] \\
\hline
\end{tabular}


Table 5. Cont

\begin{tabular}{|c|c|c|c|}
\hline Strain/Family & Nature of Sample & Isolation Medium & Ref. \\
\hline Nocardiopsis mangrovei/Nocardiopsaceae & Mangrove sediment & $\begin{array}{l}\text { Humic acid vitamin agar (humic acid } 1.0 \mathrm{~g}, \mathrm{KCl} 1.7 \mathrm{~g} \text {, } \\
\mathrm{Na}_{2} \mathrm{HPO}_{4} 0.5 \mathrm{~g}, \mathrm{MgSO}_{4} \cdot 7 \mathrm{H}_{2} \mathrm{O} 0.5 \mathrm{~g}, \mathrm{CaCO}_{3} 0.02 \mathrm{~g} \text {, } \\
\mathrm{FeSO}_{4} \cdot 7 \mathrm{H}_{2} \mathrm{O}, 0.01 \mathrm{~g}, \mathrm{~B} \text { vitamins }(0.5 \mathrm{mg} \text { each of } \\
\text { thiamin, riboflavin, niacin, pyridoxin, calcium } \\
\text { D-pantothenate, inositol, } p \text {-aminobenzoic acid and } \\
0.25 \mathrm{mg} \text { biotin), cycloheximide } 25 \mathrm{mg} \text {; potassium } \\
\text { dichromate } 50 \mathrm{mg} \text {, nystatin } 50 \mathrm{mg} \text {, agar } 15.0 \mathrm{~g} \text { per litre } \\
\text { of distilled water) }\end{array}$ & [27] \\
\hline Nocardiopsis sediminis/Nocardiopsaceae & Mangrove sediment & $\begin{array}{l}\text { Starch casein agar }(1 \% \text { soluble starch, } 0.03 \% \text { casein, } \\
0.2 \% \mathrm{KNO}_{3}, 0.2 \% \mathrm{NaCl}, 0.005 \% \mathrm{MgSO}_{4} .7 \mathrm{H}_{2} \mathrm{O}, 0.2 \% \\
\mathrm{~K}_{2} \mathrm{HPO}_{4}, 0.02 \% \mathrm{CaCO}_{3}, 0.001 \% \mathrm{FeSO}_{4} .7 \mathrm{H}_{2} \mathrm{O} \\
1.8 \% \text { agar) }\end{array}$ & [144] \\
\hline Sinomonas humi/Micrococcaceae & Mangrove soil & $\begin{array}{l}\text { Starch casein agar [ } 1 \% \text { soluble starch, } 0.03 \% \text { casein, } \\
0.2 \% \mathrm{KNO}_{3}, 0.2 \% \mathrm{NaCl}, 0.005 \% \mathrm{MgSO}_{4} .7 \mathrm{H}_{2} \mathrm{O}, 0.2 \% \\
\mathrm{~K}_{2} \mathrm{HPO}_{4}, 0.02 \% \mathrm{CaCO}_{3}, 0.001 \% \mathrm{FeSO}_{4} .7 \mathrm{H}_{2} \mathrm{O}, 1.8 \% \\
\text { agar supplemented with cycloheximide }\left(25 \mu \mathrm{g} \mathrm{mL}{ }^{-1}\right) \\
\left.\text { and nystatin }\left(10 \mu \mathrm{g} \mathrm{mL} \mathrm{mL}^{-1}\right)\right]\end{array}$ & [51] \\
\hline Kocuria pelophila/Micrococcaceae & Rhizosphere soil of mangrove & $\begin{array}{l}\text { NBRC medium } 802[1.0 \%(\mathrm{w} / \mathrm{v}) \text { polypeptone, } 0.2 \% \\
(\mathrm{w} / \mathrm{v}) \text { yeast extract, } 0.1 \%(\mathrm{w} / \mathrm{v}) \mathrm{MgSO}_{4} .7 \mathrm{H}_{2} \mathrm{O} \text { and } 1.5 \% \\
(\mathrm{w} / \mathrm{v}) \text { agar] }\end{array}$ & [145] \\
\hline Mumia flava (novel genus)/Nocardioidaceae & Mangrove soil & $\begin{array}{l}\text { ISP } 2 \text { medium [yeast extract } 4.0 \mathrm{~g} \text {, malt extract } 10.0 \mathrm{~g} \text {, } \\
\text { dextrose } 4.0 \mathrm{~g} \text {, Distilled water } 1 \mathrm{~L} \text { and Bacto agar } \\
20.0 \mathrm{~g} \text { supplemented with cycloheximide }(25 \mu \mathrm{g} \\
\left.\left.\mathrm{mL}^{-1}\right) \text { and nystatin }\left(10 \mu \mathrm{g} \mathrm{mL}^{-1}\right)\right]\end{array}$ & [146] \\
\hline Monashia flava (novel genus)/Intrasporangiaceae & Mangrove soil & $\begin{array}{l}\text { Starch casein agar [ } 1 \% \text { soluble starch, } 0.03 \% \text { casein, } \\
0.2 \% \mathrm{KNO}_{3}, 0.2 \% \mathrm{NaCl}, 0.005 \% \mathrm{MgSO}_{4} .7 \mathrm{H}_{2} \mathrm{O}, 0.2 \% \\
\mathrm{~K}_{2} \mathrm{HPO}_{4}, 0.02 \% \mathrm{CaCO}_{3}, 0.001 \% \mathrm{FeSO}_{4} .7 \mathrm{H}_{2} \mathrm{O}, 1.8 \% \\
\text { agar supplemented with cycloheximide }\left(25 \mu \mathrm{g} \mathrm{mL} \mathrm{m}^{-1}\right) \\
\left.\text { and nystatin }\left(10 \mu \mathrm{g} \mathrm{mL} \mathrm{mL}^{-1}\right)\right]\end{array}$ & [23] \\
\hline
\end{tabular}


Table 5. Cont

\begin{tabular}{|c|c|c|c|}
\hline Strain/Family & Nature of Sample & Isolation Medium & Ref. \\
\hline Pseudonocardia nematodicida/Pseudonocardiaceae & Mangrove sediment & $\begin{array}{l}\text { Modified gause inorganic agar ( } 20 \mathrm{~g} \text { soluble starch, } 1 \mathrm{~g} \\
\mathrm{KNO}_{3}, 0.5 \mathrm{~g} \mathrm{~K}_{2} \mathrm{HPO}_{4}, 0.5 \mathrm{~g} \mathrm{MgSO}_{4} .7 \mathrm{H}_{2} \mathrm{O}, 0.01 \mathrm{~g} \\
\left.\mathrm{FeSO}_{4} .7 \mathrm{H}_{2} \mathrm{O}, 15 \mathrm{~g} \text { agar, } 1 \mathrm{~L} \text { aged seawater }\right)\end{array}$ & [147] \\
\hline Microbacterium mangrovi/Microbacteriaceae & Mangrove soil & $\begin{array}{l}\text { Starch casein agar [ } 1 \% \text { soluble starch, } 0.03 \% \text { casein, } \\
0.2 \% \mathrm{KNO}_{3}, 0.2 \% \mathrm{NaCl}, 0.005 \% \mathrm{MgSO}_{4} .7 \mathrm{H}_{2} \mathrm{O}, 0.2 \% \\
\mathrm{~K}_{2} \mathrm{HPO}_{4}, 0.02 \% \mathrm{CaCO}_{3}, 0.001 \% \mathrm{FeSO}_{4} .7 \mathrm{H}_{2} \mathrm{O}, 1.8 \% \\
\text { agar supplemented with cycloheximide }\left(25 \mu \mathrm{g} \mathrm{mL}{ }^{-1}\right) \\
\left.\text { and nystatin }\left(10 \mu \mathrm{g} \mathrm{mL}^{-1}\right)\right]\end{array}$ & {$[50]$} \\
\hline Actinoallomurus acanthiterrae/Thermomonosporaceae & Rhizosphere soil of Acanthus ilicifolius & $\begin{array}{l}\text { Oatmeal agar [Oatmeal } 20.0 \mathrm{~g} \text {, agar } 18.0 \mathrm{~g} \text {, } \\
\text { supplemented with novobiocin }\left(25 \mu \mathrm{g} \mathrm{mL} \mathrm{m}^{-1}\right) \text {, nystatin } \\
(30 \mu \mathrm{g} \mathrm{mL}-1) \text {, nalidixic acid }\left(10 \mu \mathrm{gL}^{-1}\right) \text { and } \\
\mathrm{K}_{2} \mathrm{Cr}_{2} \mathrm{O}_{7}\left(20 \mathrm{mg} \mathrm{mL}^{-1} \text { ] }\right.\end{array}$ & [148] \\
\hline Jiangella mangrovi/Jiangellaceae & Mangrove soil & Marine agar 2216 (Difco) & [149] \\
\hline Serinibacter tropicus/Beutenbergiaceae & Rhizosphere soil of mangrove & $\begin{array}{l}\text { NBRC medium } 802[0.2 \%(\mathrm{w} / \mathrm{v}) \text { polypeptone, } 0.04 \% \\
(\mathrm{w} / \mathrm{v}) \text { yeast extract, } 0.02 \%(\mathrm{w} / \mathrm{v}) \mathrm{MgSO}_{4} .7 \mathrm{H}_{2} \mathrm{O} \text { and } \\
1.5 \%(\mathrm{w} / \mathrm{v}) \text { agar] supplemented with } 5.0 \%(\mathrm{w} / \mathrm{v}) \mathrm{NaCl} \text {, } \\
0.005 \%(\mathrm{w} / \mathrm{v}) \text { cycloheximide and } 0.002 \%(\mathrm{w} / \mathrm{v}) \\
\text { nalidixic acid }\end{array}$ & [150] \\
\hline Nonomuraea purpurea/Streptosporangiaceae & Mangrove sediment & Marine agar 2216 (Difco) & [151] \\
\hline Kineococcus mangrovi/Kineosporiaceae & Mangrove sediment & $\begin{array}{l}\text { Starch casein agar [ } 1 \% \text { soluble starch, } 0.03 \% \text { casein, } \\
0.2 \% \mathrm{KNO}_{3}, 0.2 \% \mathrm{NaCl}_{1} 0.005 \% \mathrm{MgSO}_{4} .7 \mathrm{H}_{2} \mathrm{O}, 0.2 \% \\
\mathrm{~K}_{2} \mathrm{HPO}_{4}, 0.02 \% \mathrm{CaCO}_{3}, 0.001 \% \mathrm{FeSO}_{4} .7 \mathrm{H}_{2} \mathrm{O}, 1.8 \% \\
\text { agar supplemented with nalidixic acid }\left(25 \mu \mathrm{g} \mathrm{mL}{ }^{-1}\right) \\
\left.\text { and ketokonazole }\left(100 \mu \mathrm{g} \mathrm{mL} \mathrm{mL}^{-1}\right)\right]\end{array}$ & [152] \\
\hline
\end{tabular}




\subsection{Marine Rare Actinomycetes Diversity: A Decade of Experience (2007-2017)}

In summary, a total of 97 new species belonging to 27 different rare actinomycete genera, of which 9 represent novel genera, were reported, from the marine environment between mid-2013 and 2017 (Tables 2-6; Figure 1). Furthermore, the families Pseudonocardiaceae, Demequinaceae, Micromonosporaceae and Nocardioidaceae were most frequently isolated from the marine environment. For the period 2007-mid 2013, 80 new species belonging to 23 families of marine rare actinomycetes were reported (Table 6). These data show that the discovery rate of new rare actinomycetes from marine habitats is steady. Interestingly, isolates from 10 actinomycete families, such as Actinomycetaceae, Actinopolysporaceae, Brevibacteriaceae, Rubrobacteraceae, Actinosynnemataceae, Gordoniaceae, Jiangellaceae, Kineosporiaceae, Dermacoccaceae and Dermabacteraceae were reported for the period between mid-2013 and 2017 that were not reported for the period 2007 to mid-2013. Cumulatively this means that a total of of 177 new species of rare actinomycetes representing 33 families including 3 novel families and 29 novel genera were reported from marine habitats in the last 10 years (Table 6). Actinomycete families such as Micromonosporaceae, Nocardioidaceae, Pseudonocardiaceae, Microbacteriaceae, Micrococcaceae, Demequinaceae, Nocardiopsaceae, Propionibacteriaceae and Intrasporangiaceae are the families most frequently reported from marine habitats during this period. However, no novel actinomycete family has been reported from marine habitats since mid-2013.

Table 6. Number of new species of rare actinomycetes reported from marine environment between 2007 and 2017.

\begin{tabular}{|c|c|c|c|}
\hline Particular & 2007 to $\mathrm{mid}-2013$ * & Mid-2013 to 2017 & Total (2007-2017) \\
\hline New species reported & 80 & 97 & 177 \\
\hline Novel families reported & 3 & - & 3 \\
\hline Novel genera reported & 20 & 9 & 29 \\
\hline Total families reported & 23 & 27 & 33 \\
\hline \multicolumn{4}{|c|}{ No. of new species reported in each family } \\
\hline Micromonosporaceae & 13 & 10 & 23 \\
\hline Nocardioidaceae & 10 & 9 & 19 \\
\hline Pseudonocardiaceae & 6 & 11 & 17 \\
\hline Microbacteriaceae & 5 & 8 & 13 \\
\hline Micrococcaceae & 5 & 8 & 13 \\
\hline Demequinaceae & 1 & 11 & 12 \\
\hline Nocardiopsaceae & 4 & 6 & 10 \\
\hline Micrococcineae & 10 & - & 10 \\
\hline Propionibacteriaceae & 4 & 4 & 8 \\
\hline Intrasporangiaceae & 4 & 4 & 8 \\
\hline Nocardiaceae & 2 & 4 & 6 \\
\hline Streptosporangiaceae & 3 & 1 & 4 \\
\hline Promicromonosporaceae & 3 & 1 & 4 \\
\hline Cellulomonadaceae & 1 & 2 & 3 \\
\hline Acidimicrobiaceae & 1 & 2 & 3 \\
\hline Bogoriellaceae & 1 & 2 & 3 \\
\hline Beutenbergiaceae & 1 & 1 & 2 \\
\hline Thermomonosporaceae & 1 & 1 & 2 \\
\hline Actinopolysporaceae & - & 2 & 2 \\
\hline Brevibacteriaceae & - & 2 & 2 \\
\hline Alteromonadaceae & 1 & - & 1 \\
\hline Tsukamurellaceae & 1 & - & 1 \\
\hline Iamiaceae & 1 & - & 1 \\
\hline Euzebyaceae & 1 & - & 1 \\
\hline Geodermatophilaceae & 1 & - & 1 \\
\hline Actinomycetaceae & - & 1 & 1 \\
\hline Rubrobacteraceae & - & 1 & 1 \\
\hline Actinosynnemataceae & - & 1 & 1 \\
\hline Gordoniaceae & - & 1 & 1 \\
\hline Jiangellaceae & - & 1 & 1 \\
\hline Kineosporiaceae & - & 1 & 1 \\
\hline Dermacoccaceae & - & 1 & 1 \\
\hline Dermabacteraceae & - & 1 & 1 \\
\hline
\end{tabular}

* Adapted from Subramani and Aalbersberg [7]. 


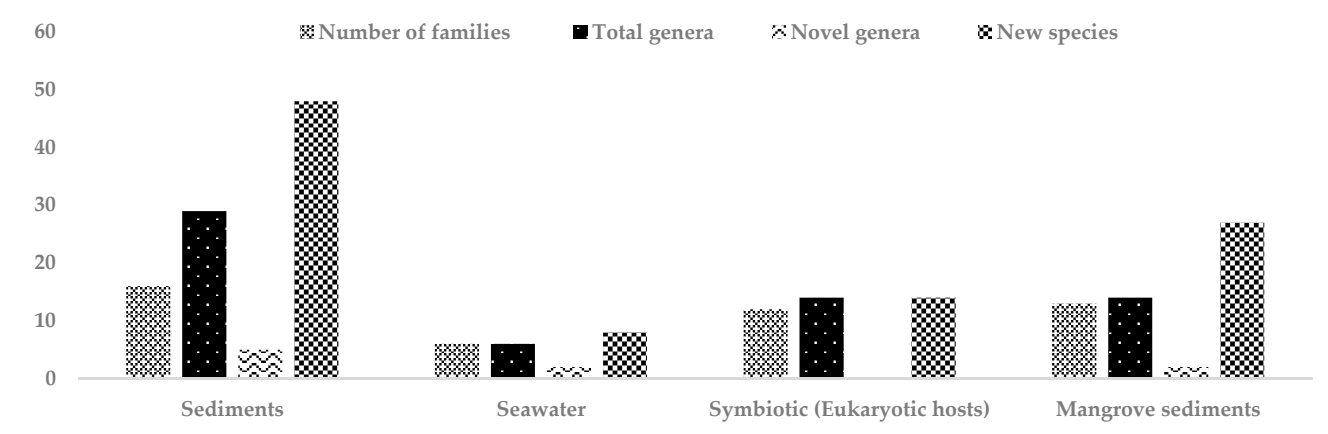

Figure 1. Total number of families, novel genera and new species of rare actinomycetes reported from different marine habitats between mid-2013 and 2017.

\section{Actinomycetes as Sources of Antibiotics}

Actinomycetes has been one of the most fertile sources for the discovery of new antibiotics since they were first discovered and a number of the antibiotics currently in use are natural products or analogs of natural products from actinomycetes [153]. Actinomycin was the first antibiotic discovered from actinomycetes in 1940 from a culture of Streptomyces antibioticus [154], followed by streptothricin from Streptomyces lavendulae in 1942 [155], and streptomycin from Streptomyces griseus in 1944 [156]. Streptomyces species have been the key source of clinical antibiotics, and more than $80 \%$ of all antibiotics of actinomycetes origin have been derived from this single genus [3,157]. Out of all microbially-derived antibiotic classes, 10 classes are exclusively produced by actinomycetes. Those are polyene macrolides, oligomycin-type large-membered macrolides, daunomycin-type anthracyclines, nigericin-type polyether antibiotics, nonactin-type cyclopolylactones, aminoglycosides, anthracyclines, streptothricins, actinomycins and quinoxaline-peptides [3]. The antibiotics production of different actinomycete strains can vary enormously as some actinomycete species produce a single antibiotic, whereas some produce a wide-range of different compounds and compound classes [5]. A total of 30 new antibiotics have been launched worldwide since 2000. Of the 30 new antibiotics, 2 were natural products (NP), 12 were NP-derived and 16 were synthetic antibiotics [158]. Out of these 30 new antibiotics, 12 were reported from members of actinomycetes, either as natural product or natural product-derivatives representing 7 different antibiotic classes (Table 7). Due to the decline in the number of new chemical scaffolds and rediscovery of known molecules, the innovation in antibiotic development has slowed down. The exploration of alternative taxa, which have not been previously cultivated, could alleviate urgent needs related to resistance against currently used antibiotics.

\subsection{Rare Actinomycetes: A Target for Future Drugs}

As a result, rare actinomycetes are becoming an increasingly important focus of investigation in the search for novel natural products because (1) they occupy a poorly explored taxonomic and environmental space, which reduces the likelihood of replication of discovery, and (2) the phylum Actinobacteria is a rich source of bioactive secondary metabolites [46] that can be expected to yield novel chemical scaffolds for the development of new antibiotics.

\subsection{Marine Rare Actinomycetes Is a Source of Antibiotics}

Approximately 100 new bioactive compounds were reported from 38 rare actinomycete strains belonging to 15 genera described between 2007 and mid-2013. Out of these 15 different genera, Salinispora (20 new compounds), Verrucosispora (18 new compounds), Nocardiopsis (12 new compounds), Actinoalloteichus (11 new compounds), Marinispora (10 new compounds) and Micromonospora (9 new compounds) were predominant for discovery of novel secondary metabolites from 2007 to mid-2013 [7]. A total of 4 compounds derived from marine actinomycetes are currently in clinical trials (Table 7) of which 3 were obtained from marine Salinispora spp. indicating that Streptomyces spp. are no longer the most important biological resource for new antibiotics. 
Table 7. Antibiotics of therapeutic natural products derived from actinomycetes.

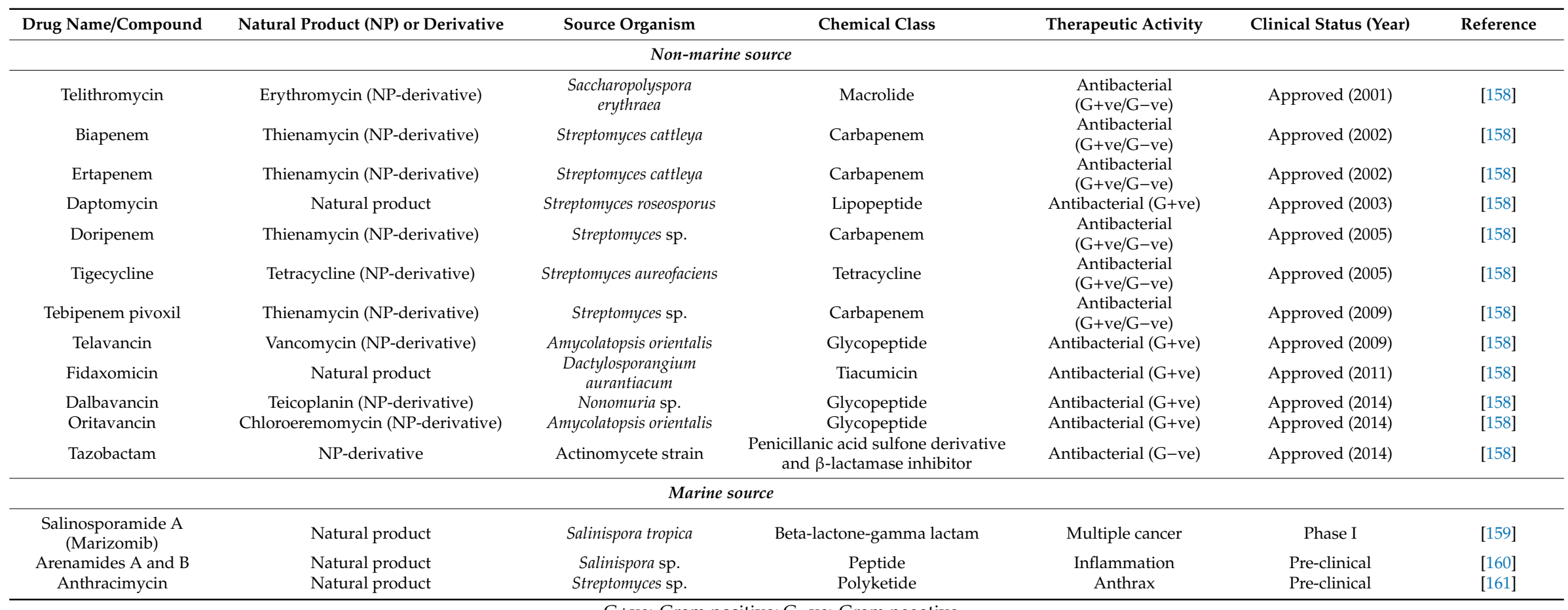

G+ve: Gram positive; G-ve: Gram negative. 
4.3. Novel/New Compounds from Marine Rare Actinomycetes between mid-2013 and 2017

A total of 167 different new bioactive compounds were reported from 58 rare actinomycete strains belonging to 24 genera from mid-2013 to 2017 (Table 8). Among them, genera such as Nocardiopsis (40 new compounds), Micromonospora (37 new compounds), Salinispora (21 new compounds) and Pseudonocardia (14 new compounds) are leading with respect to the number of novel secondary metabolites (Table 8). Among them, there are new/novel pyrones, structurally diverse natural products and unique chemical moieties (Figures 2-5).

Table 8. Numbers of new natural products/bioactive compounds produced by rare actinomycete genera from the marine environment between 2007 and 2017.

\begin{tabular}{|c|c|c|c|}
\hline Particular & 2007 to $\mathrm{mid}-2013$ * & Mid-2013 to 2017 & Total (2007-2017) \\
\hline Novel/new compounds reported & 100 & 167 & 267 \\
\hline $\begin{array}{l}\text { Total number of rare } \\
\text { actinomycetes }\end{array}$ & 38 & 58 & 96 \\
\hline Total genera reported & 15 & 24 & 28 \\
\hline \multicolumn{4}{|c|}{ No. of new compounds reported in each genus } \\
\hline Nocardiopsis & 12 & 40 & 52 \\
\hline Micromonospora & 9 & 37 & 46 \\
\hline Salinispora & 20 & 21 & 41 \\
\hline Pseudonocardia & 3 & 14 & 17 \\
\hline Verrucosispora & 18 & 2 & 20 \\
\hline Amycolatopsis & 1 & 3 & 4 \\
\hline Serinicoccus & 1 & 1 & 2 \\
\hline Kocuria & 1 & - & 1 \\
\hline Actinoalloteichus & 11 & 5 & 16 \\
\hline Actinomadura & 3 & 5 & 8 \\
\hline Dermacoccus & 7 & 3 & 10 \\
\hline Kitasatospora & 1 & - & 1 \\
\hline Nocardia & 2 & - & 2 \\
\hline Saccharomonospora & 1 & 5 & 6 \\
\hline Marinispora & 10 & - & 10 \\
\hline Actinokineospora & - & 2 & 2 \\
\hline Solwaraspora & - & 2 & 2 \\
\hline Micrococcus & - & 1 & 1 \\
\hline Microbacterium & - & 3 & 3 \\
\hline Rubrobacter & - & 2 & 2 \\
\hline Saccharothrix & - & 4 & 4 \\
\hline Actinomycetospora & - & 3 & 3 \\
\hline Williamsia & - & 1 & 1 \\
\hline Streptomonospora & - & 4 & 4 \\
\hline Nesterenkonia & - & 1 & 1 \\
\hline Kribbella & - & 4 & 4 \\
\hline Streptosporangium & - & 3 & 3 \\
\hline Saccharopolyspora & - & 1 & 1 \\
\hline
\end{tabular}

* Adapted from Subramani and Aalbersberg [7]. 


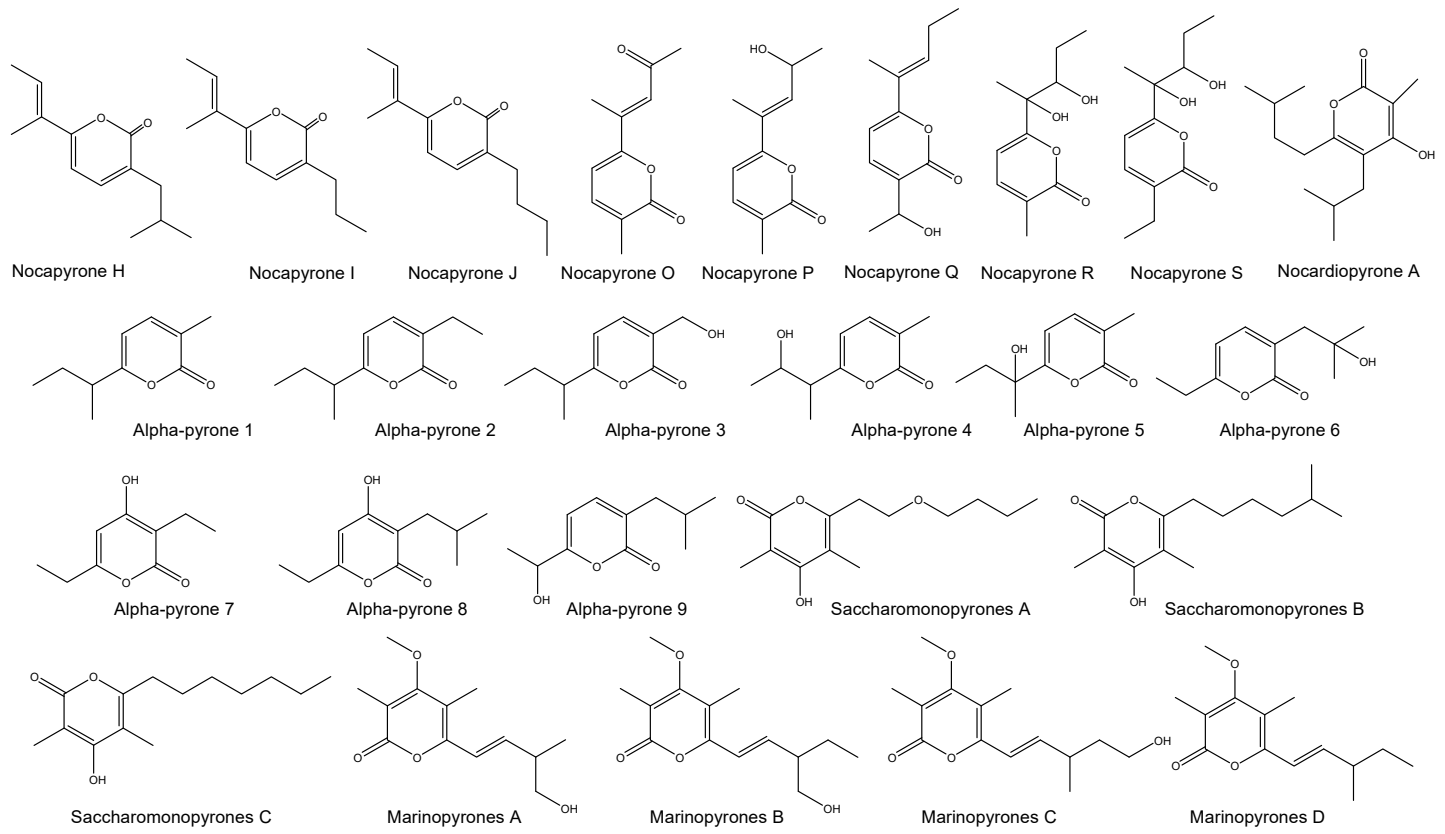

Figure 2. New pyrones produced by marine rare Nocardiopsis spp., Streptomonospora sp. and Saccharomonospora sp. between mid-2013 and 2017.
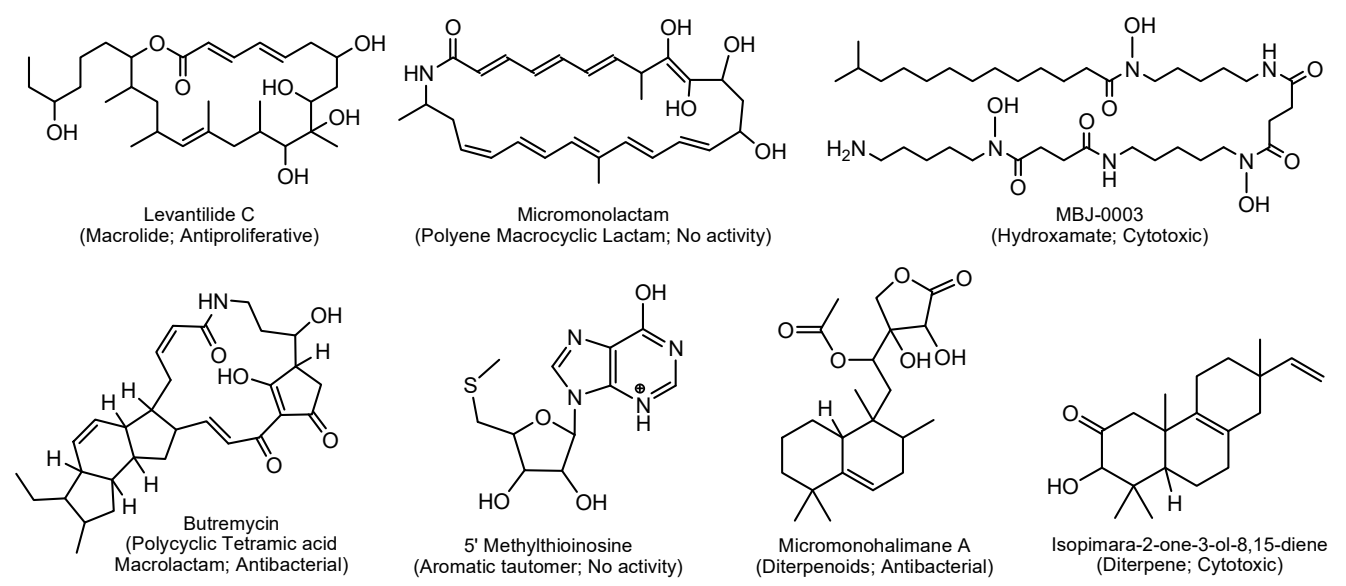<smiles>Cc1cc(O)c2c(c1)COC1C(=O)c3c(O)cccc3C(=O)C21</smiles>

Lagumycin B
(Angucycline; Cytotoxic)<smiles>Cc1cc2nc(C(=O)O)c(O)c(O)c2cc1C</smiles>

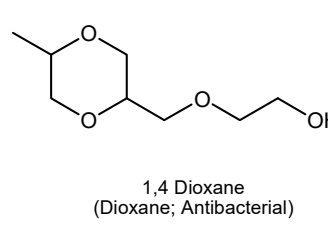

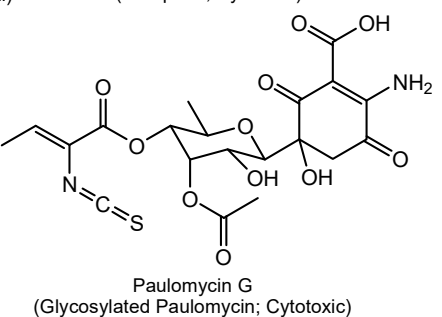

Figure 3. Some novel natural products from marine Micromonospora spp. reported from mid-2013 to 2017.

A total of 7 different chemical classes of natural products were reported from marine Nocardiopsis spp. between mid-2013 and 2017 of which, $\alpha$-pyrones (18 out of 40 compounds) were predominant (Table 9; Figure 2). These molecules have a wide range of biological activities, such as pro-inflammatory activity (enhancing and stimulating the inflammatory response), anti-inflammatory activity, antibacterial and cytotoxic activities (Table 9). In addition, the genera Streptomonospora and Saccharomonospora also produce a substantial number of $\alpha$-pyrones. Besides, nocarimidazoles from Nocardiopsis sp. possess a 4-aminoimidazole ring rarely found in microbial secondary metabolites [162] and rare 
prolinyl-macrolactam polyketides were isolated from Nocardiopsis sp. [163]. Sterol O-acyltransferase [SOAT, also known as acyl-CoA: cholesterol acyltransferase (ACAT)], an endoplasmic reticulum membrane protein, catalyzes the synthesis of cholesteryl ester from free cholesterol and long-chain fatty acyl-CoA. SOAT has been postulated as a target for modulation by a new type of antiatherosclerotic agent. Interestingly, a diketopiperazine derived from marine Nocardiopsis $\mathrm{sp}$. was found to be an effective SOAT inhibitor [164].

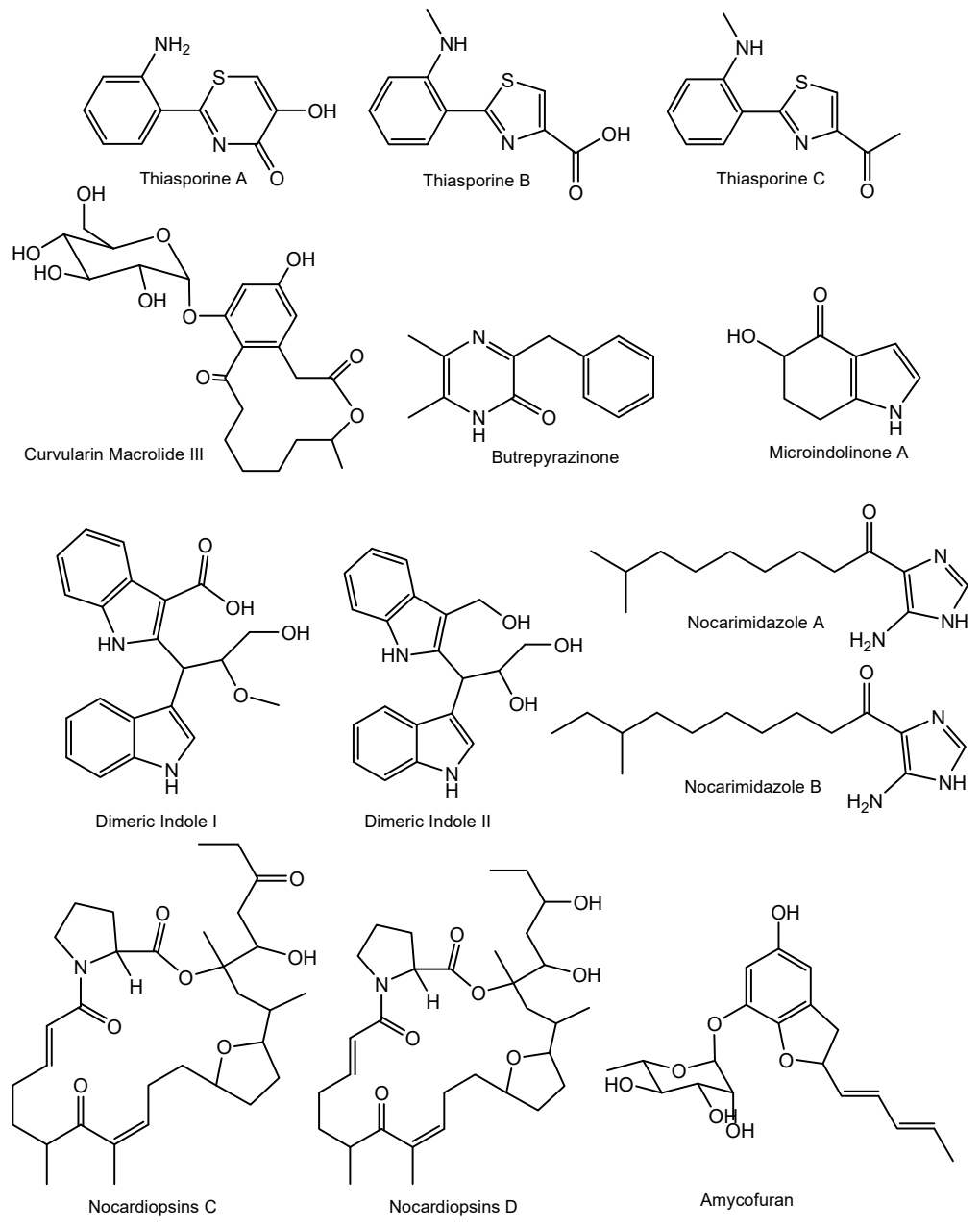

Figure 4. Some of the unique chemical moieties in natural products produced by marine rare actinomycetes between mid-2013 and 2017.

Marine Micromonospora spp. produced 37 out of the 167 compounds reported from mid-2013-2017 and were chemically diverse (Table 9; Figure 3). In total, 13 chemical classes, including macrolides, polyene macrocyclic lactams, polycyclic tetramic acid macrolactams, aromatic tautomers, hydroxamates, diterpenoids, diterpenes, angucyclines, quinolone alkaloids, dioxanes, glycosylated paulomycins, glycosides and aglycone spirotetrorates were identified in Micromonospora spp. during this period. Polyene macrolactams are an underexplored group of natural products that have only been found in actinomycetes. Micromonolactam is a new polyene macrocyclic lactam isolated from a marine Micromonospora sp. (Figure 3). However, micromonolactam did not show antibacterial activities against test pathogens [165]. Another interesting group of natural products, paulomycins, are glycosylated molecules containing a pauloate residue that are of pharmacological interest due to their strong antibiotic properties [166]. Paulomycin G is structurally unique because it is the smallest bioactive paulomycin in the paulomycin family of antibiotics, lacking the paulomycose moiety (Figure 3). Furthermore, a number of novel chemical skeletal structures are reported from marine Micromonospora spp. For 
example, polycyclic tetramic acid macrolactams of butremycin [167], halimane-type diterpenoids of micromonohalimanes [168] and a novel pimarane diterpene in isopimara-2-one-3-ol-8,15-diene [169] (Figure 3).

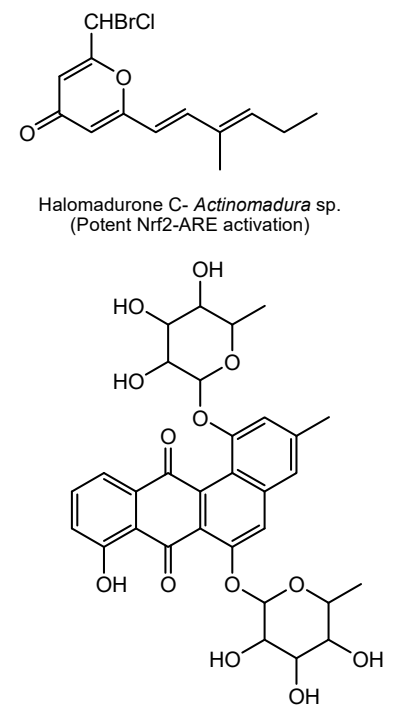

Actinosporin A- Actinokineospora sp. (Antiparasitic activity)
(

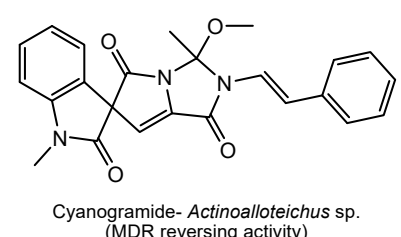

ogramide- Actinoalloteichus
(MDR reversing activity)

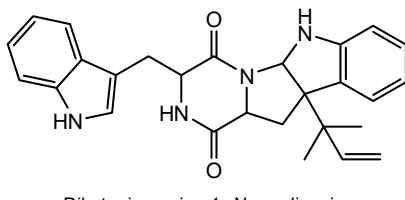

Diketopiperazine 1- Nocardiopsis sp. (Sterol O-acyltransferase inhibitor)

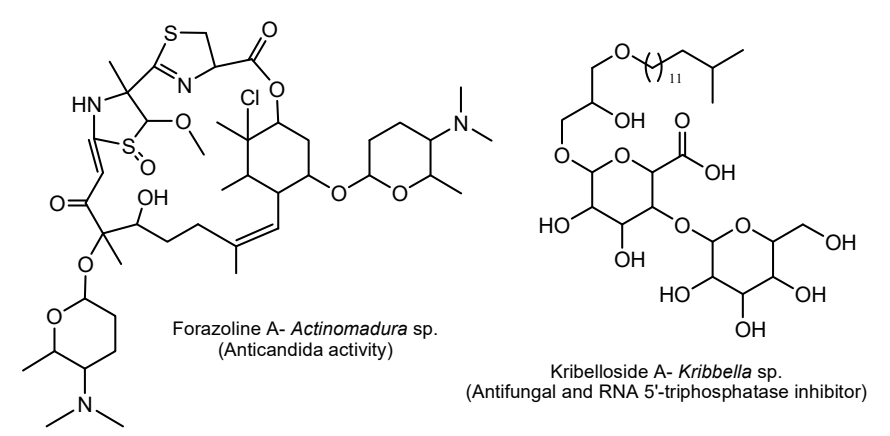

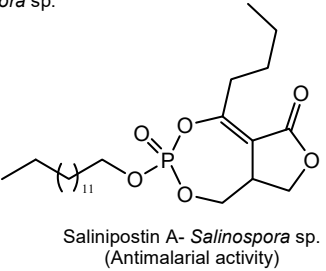

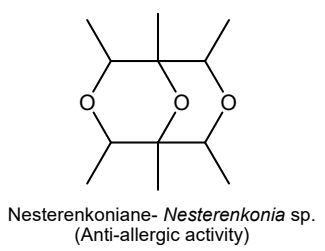

Figure 5. Some unusual biologically active compounds produced by marine rare actinomycetes between mid-2013 and 2017.

Additionally, other rare actinomycete genera have yielded a number of unique chemical moieties, which were not previously reported from microbially-derived natural products (Figure 4). For example, thiasporine $\mathrm{A}$ is the first natural product with a 5-hydroxy-4H-1,3-thiazin-4-one moiety, along with two new thiazole derivatives and were reported from Actinomycetospora chlora [170] (Figure 4). Other unusual structures include a curvularin macrolide with a rare $\alpha$-D-glucopyranose substituent from Pseudonocardia sp. [171]; a butrepyrazinone, from Verrucosispora sp. that possesses an unusual methylation pattern on the pyrazinone ring [172], a novel indole microindolinone A from Microbacterium sp. [173], new dimeric indole derivatives with acetylcholinesterase (AchE) inhibitory activity from Rubrobacter radiotolerans [174] and a structurally new amycofuran bearing a rhamnose sugar from Amycolatopsis sp. [175].

Actinomadura sp. derived halomadurones (Figure 5) demonstrated potent nuclear factor E2-related factor antioxidant response element (Nrf2-ARE) activation, which is an important therapeutic approach for treatment of neurodegenerative diseases [176]. Cyanogramide obtained from Actinoalloteichus cyanogriseus showed efficient anticancer activity by reversing the adriamycin-induced resistance of K562/A02 and MCF-7/Adr cells, and the vincristine-induced resistance of KB/VCR cells [177]. 
Table 9. Novel/new bioactive compounds produced by marine rare actinomycetes between mid 2013 and 2017.

\begin{tabular}{|c|c|c|c|c|}
\hline Compounds & Chemical Family/Class & Marine Source & Biological Activity & Reference \\
\hline Halomadurones A-D & Halogenated electrophilic pyrones & Actinomadura sp. & Potent Nrf2-ARE activation & [176] \\
\hline Levantilide C & 20-membered macrolide & Micromonospora sp. & Antiproliferative activity & [178] \\
\hline Nocapyrones H-J & $\alpha$-pyrones & Nocardiopsis sp. & $\begin{array}{l}\text { Pro-inflammatory factor, stronger inhibitory } \\
\text { effect on nitric oxide }\end{array}$ & [179] \\
\hline Nocardiopsins C and D & Prolinyl-macrolactam polyketides & Nocardiopsis sp. & Not specified & [163] \\
\hline Nocardiopyrone A & $\alpha$-pyrone polyketide & Nocardiopsis sp. & Not specified & [163] \\
\hline Nocardiamide A and B & Cyclic hexapeptides & Nocardiopsis sp. & Antimicrobial activity & [180] \\
\hline Cyanosporasides C-F & Polyketides & Salinispora pacifica & Not specified & [181] \\
\hline Micromonolactam & Polyene macrocyclic lactam & Micromonospora sp. & No antimicrobial activity & [165] \\
\hline Cyanogramide & Spirocyclic alkaloid & Actinoalloteichus cyanogriseus & Multidrug-resistance (MDR) reversing activity & [177] \\
\hline Actinosporins A and B & O-glycosylated angucyclines & Actinokineospora sp. & Moderate activity against Trypanosoma brucei & [182] \\
\hline Solwaric acids $\mathrm{A}$ and $\mathrm{B}$ & Trialkyl-substituted aromatic acids & Solwaraspora sp. & Antibacterial activity against MDR pathogens & [183] \\
\hline Seriniquinone & Quinones & Serinicoccus sp. & A selective anticancer agent & [184] \\
\hline Cyanogrisides $\mathrm{E}-\mathrm{H}$ & Acyclic bipyridine glycosides & Actinoalloteichus cyanogriseus & Cytotoxicity & [185] \\
\hline Forazoline A & Polyketides & Actinomadura sp. & Anti-candida activity & [186] \\
\hline Amycofuran & Benzofuran glycoside & Amycolatopsis sp. & Modest cytotoxicity & [175] \\
\hline Amycolactam & Indole alkaloids & Amycolatopsis sp. & Cytotoxicity & [175] \\
\hline Amycocyclopiazonic acid & Cyclopiazonic acid & Amycolatopsis sp. & Modest cytotoxicity & [175] \\
\hline Dermacozines H-J & Heteroaromatic phenazines & Dermacoccus abyssi & Radical scavenging activity & [187] \\
\hline Microluside A & O-glycosylated xanthone & Micrococcus sp. & Antibacterial activity & [188] \\
\hline Nocapyrone R & $\alpha$-pyrones & Nocardiopsis sp. & No cytotoxicity & [189] \\
\hline Butremycin & Polycyclic tetramic acid macrolactams & Micromonospora sp. & Weak antibacterial activity & [167] \\
\hline 5'-Methylthioinosine & Protonated aromatic tautomer & Micromonospora sp. & No antibacterial activity & [167] \\
\hline Butrepyrazinone & Pyrazinone & Verrucosispora sp. & No antibacterial activity & [172] \\
\hline
\end{tabular}


Table 9. Cont

\begin{tabular}{|c|c|c|c|c|}
\hline Compounds & Chemical Family/Class & Marine Source & Biological Activity & Reference \\
\hline MBJ-0003 & Hydroxamate & Micromonospora sp. & Moderate cytotoxicity & [190] \\
\hline Microbacterins A and B & Peptaibols & Microbacterium sediminis & Potent cytotoxic activity & [191] \\
\hline Salinipostins A-K & Bicyclic Phosphotriesters & Salinospora sp. & Antimalarial activity & [192] \\
\hline Nocarimidazoles A and B & 4-aminoimidazole alkaloids & Nocardiopsis sp. & Weak antibacterial activity & [162] \\
\hline Dimeric indole derivatives 1 and 2 & Dimeric indoles & Rubrobacter radiotolerans & Acetylcholinesterase (AchE) inhibitory activity & [174] \\
\hline Saccharothrixones A-D & Aromatic polyketides & Saccharothrix sp. & Cytotoxic activity & [193] \\
\hline Thiasporines A-C & Thiazine and Thiazole Derivatives & Actinomycetospora chlora & Cytotoxicity & [170] \\
\hline Diketopiperazine 1 & Diketopiperazine & Nocardiopsis sp. & Sterol $O$-acyltransferase inhibitor & [164] \\
\hline Isopimara-2-one-3-ol-8,15-diene & Pimarane Diterpene & Micromonospora sp. & Weak cytotoxicity & [169] \\
\hline $\begin{array}{l}\text { Lagumycin B, Dehydrorabelomycin, } \\
\text { Phenanthroviridone, WS-5995 A }\end{array}$ & Angucyclines & Micromonospora sp. & Cytotoxicity & [169] \\
\hline Micromonohalimane A and B & Halimane-type diterpenoids & Micromonospora sp. & $\begin{array}{c}\text { Modest antibacterial activity against MRSA, } \\
\text { bacteriostatic }\end{array}$ & [168] \\
\hline Quinoline alkaloid & Alkaloid & Micromonospora sp. & Antibacterial activity & [194] \\
\hline 1,4-dioxane derivative & Dioxane & Micromonospora sp. & Antibacterial activity & [194] \\
\hline Pseudonocardides A-G & $\gamma$-butyrolactones & Pseudonocardia sp. & Antibacterial and cytotoxic activities & [195] \\
\hline Curvularin macrolides $1-5$ & Macrolides & Pseudonocardia sp. & Antibacterial and cytotoxic activities & [171] \\
\hline$\alpha$-pyrones $1-8$ & $\alpha$-pyrones & Nocardiopsis spp. & Moderate antibacterial activity & [196] \\
\hline Compounds $1-12$ & Benzamides, Indoles & Nocardiopsis sp. & $\begin{array}{c}\text { Antibacterial, antifungal and cytotoxic } \\
\text { activities }\end{array}$ & [197] \\
\hline 3-benzyl-3 $\alpha, 4 \beta$-dihydroxypentan-2-one & Phenolics & Williamsia sp. & Not specified & [198] \\
\hline Marinopyrones A-D & $\alpha$-pyrones & Streptomonospora sp. & Inhibition of NO production & [199] \\
\hline $\begin{array}{l}\text { Glycerol 1-hydroxy-2,5-dimethyl } \\
\text { benzoate }\end{array}$ & Salicylic derivative & Verrucosispora sp. & Anti-MRSA activity & [200] \\
\hline Isomethoxyneihumicin & Lactam-lactim tautomers & Nocardiopsis alba & Strong cytotoxicity & [201] \\
\hline
\end{tabular}


Table 9. Cont.

\begin{tabular}{|c|c|c|c|c|}
\hline Compounds & Chemical Family/Class & Marine Source & Biological Activity & Reference \\
\hline Microindolinone A & Novel indole & Microbacterium sp. & No anti-allergic and anti-proliferative activities & [173] \\
\hline Nesterenkoniane & Novel cyclic ether & Nesterenkonia flava & Moderate anti-allergic activity & [202] \\
\hline Nocapyrones O-S & $\alpha$-pyrones & Nocardiopsis sp. & Cytotoxicity & [203] \\
\hline Paulomycin G & Glycosylated paulomycins & Micromonospora matsumotoense & Strong cytotoxic activity & [166] \\
\hline Saccharomonopyrones A-C & $\alpha$-pyrones & Saccharomonospora sp. & Weak antioxidant activity & [204] \\
\hline Tetrocarcin Q & Spirotetronate glycoside & Micromonospora carbonacea & Moderate antibacterial activity & [205] \\
\hline 22-dehydroxymethyl-kijanolide & Spirotetronate aglycone & Micromonospora harpali & No antibacterial activity & [206] \\
\hline 8-hydroxy-22-dehydroxymethyl-kijanolide & Spirotetronate aglycone & Micromonospora harpali & No antibacterial activity & [206] \\
\hline Microsporanates A-F & Spirotetronate glycosides & Micromonospora harpali & Antibacterial activity & [206] \\
\hline Tetrocarcin P & Spirotetronate glycoside & Micromonospora harpali & Antibacterial activity & [206] \\
\hline Nocazines $F$ and $G$ & Diketopiperazine & Nocardiopsis sp. & Excellent cytotoxicity & [207] \\
\hline Kribellosides A-D & Alkyl glyceryl ethers & Kribbella sp. & $\begin{array}{l}\text { Antifungal and RNA } 5^{\prime} \text {-triphosphatase } \\
\text { inhibitor }\end{array}$ & [208] \\
\hline Branimycins $B$ and $C$ & Macrolide & Pseudonocardia carboxydivorans & Antibacterial activities & [209] \\
\hline 1,2-naphthoquinone & Naphthalene derivative & Saccharopolyspora sp. & No cytotoxicity & [210] \\
\hline
\end{tabular}


A marine sponge-derived Actinokineospora sp. produces actinosporins with selective activity against the parasite Trypanosoma brucei brucei, the causative agent of sleeping sickness [182]. Fungal infections, particularly candidiasis, is one of the serious diseases worldwide. A novel antifungal polyketide, forazoline A isolated from Actinomadura sp. showing significant activity against Candida albicans works through a new mechanism of action by disrupting membrane integrity [186]. Another way of controlling candidiasis is by capping enzyme repressors. Inhibitors of the enzyme RNA $5^{\prime}$-triphosphatase in yeast may be used against pathogenic yeasts such as Candida. Interestingly, novel kribellosides from a marine Kribbella sp. inhibit activity of Cet1p (RNA 5'-triphosphatase) from Saccharomyces cerevisiae in vitro [208]. Another interesting biological activity is anti-allergic activity shown by nesterenkoniane, a novel cyclic ether isolated from the deep-sea-derived Nesterenkonia flava. Nesterenkoniane is the first report on secondary metabolites from the genus of Nesterenkonia [202]. Furthermore, discovery of anti-malarial drugs is one of the targets of research in pharma industries. Salinipostin A, isolated from the marine genus Salinispora shows potent antimalarial activity against Plasmodium falciparum growth $\left(\mathrm{EC}_{50}=50 \mathrm{nM}\right)$ and a high selectivity index $\left(\mathrm{SI}>10^{3}\right)$ [192] (Figure 5).

\subsection{Genome Mining of Marine Rare Actinomycetes}

The rapid development of genome and metagenome sequencing methods including identification of secondary metabolite gene clusters has lead to the discovery of the genetic machinery encoding for novel natural products from microorganisms that have not yet been chemically identified [211]. The majority of these gene clusters encode for polyketides (PK), non-ribosomally synthesized peptides (NRP), ribosomally and post-translationally modified peptides (RiPPs) and aminoglycosides [211]. The bioinformatic analysis of genomes can also reveal silent secondary metabolite gene clusters, which are not expressed under standard laboratory conditions [212]. More than 23,000 PK and NRP have been reported so far, many of them found in actinomycetes, and they are being widely tested for pharmaceutical applications $[213,214]$. This approach has also been used for the identification of new antibiotic scaffolds from rare genera of actinomycetes from marine sediments [16]. Recently, Schorn and colleagues [215] have shown that rare marine actinomycetes-derived genomes demonstrated a high degree of novelty and diversity, with Corynebacterium, Gordonia, Nocardiopsis, Saccharomonospora and Pseudonocardia as genera representing the highest biosynthetic gene cluster diversity. A total of 13 new bioactive compounds have been derived from marine rare actinomycetes, such as Saccharomonospora sp., Salinispora spp., Micromonospora spp. and Streptosporangium sp. using genome-based approaches between mid 2013 and 2017 (Table 10).

These numbers of new biosynthetic gene clusters and corresponding compounds will undoubtly increase in the near future due to revolutionary developments in the genome- and metagenome-based approaches for drug discovery [215] and it likely that omics-based screening for novel bioactive compounds will prevail over microbial isolation as the most efficient method for first identification of bioactivity potential of strains and environmental samples [216].

Table 10. New bioactive compounds discovered from marine rare actinomycetes using genome-based approaches between mid-2013 and 2017.

\begin{tabular}{ccccc}
\hline Compounds & Chemical Class/Family & Marine Source & Biological Activity & Reference \\
\hline Taromycin A & Dichlorinated lipopeptide & Saccharomonospora sp. & $\begin{array}{c}\text { Moderate bioactivity against MDR } \\
\text { pathogens }\end{array}$ & [217] \\
\hline Retimycin A & Quinomycin-like depsipeptide & Salinispora sp. & Cytotoxicity against HCT-116 & [218] \\
\hline Sioxanthin & Carotenoid & Salinispora sp. & Siderophore & [219] \\
\hline Lobosamides A-C & Polyene macrolactams & Micromonospora sp. & Anti-protozoan parasite, Trypanosoma brucei & {$[220]$} \\
\hline Hexaricins A-C & Pentangular polyphenols & Streptosporangium sp. & Not specified & Modest antibacterial activity \\
\hline Tetrocarcin N and O & Glycosidic spirotetronates & Micromonospora sp. & Not specified & [222] \\
\hline Rifsaliniketal & Saliniketal & Salinispora sp. & Antibacterial activity \\
\hline Nenestatin A & Benzofluorene & Micromonospora & echinospora & [223] \\
\hline
\end{tabular}




\section{Conclusions}

In the last decade (2007-2017), a great range of diverse, new and rare actinomycetes have been isolated from the marine environment. Employment of heat-treatment of marine sediment samples, the use of low-nutrient agar medium (seawater agar) or a growth medium with natural seawater along with the use of antifungal agents, favor the isolation of marine rare actinomycetes. At least 177 new species, which represent 29 novel genera and 3 novel families, were obtained as pure cultures. Micromonosporaceae, Nocardioidaceae, Pseudonocardiaceae, Microbacteriaceae, Micrococcaceae, Demequinaceae, Nocardiopsaceae, Propionibacteriaceae and Intrasporangiaceae were the families most frequently isolated from the marine environment.

In total, 267 new natural products derived from 96 different marine rare actinomycete strains belonging to 28 genera have been reported from 2007 to 2017. Out of these 28 marine genera, Nocardiopsis, Micromonospora, Salinispora, Verrucosispora, Pseudonocardia and Actinoalloteichus are topmost producers of novel new secondary metabolites.

The rare actinomycetes isolated and biomolecules discovered represent most likely only the low-hanging fruits and the immense diversity of microorganisms in marine habitats as shown from large cultivation-independent studies $[225,226]$ are the proof for the presence of an even larger diversity of currently uncultivable rare actinomycetes and putative secondary metabolites. This uncultured majority should be the target of future selective isolation strategies and procedures. In addition, genetic engineering of whole biosynthetic gene clusters is finally gaining ground [216] and may be the key to access hidden gene clusters from rare actinomycetes. A breakthrough in heterologous expression would herald 'another golden age' of novel bioactive natural product discovery, for which marine rare actinomycetes may be one of the important sources.

Author Contributions: R.S. conceived, designed the work and wrote the manuscript; D.S. conceived, critically analyzed the data, revised and corrected the manuscript.

Funding: D.S. acknowledges funding from the European Union's Horizon 2020 research and innovation program under Grant Agreement No. 679849 (SponGES).

Acknowledgments: We are thankful to Steven Sutcliffe, the University of the South Pacific for English proofreading of the manuscript.

Conflicts of Interest: The authors declare no conflict of interest.

\section{References}

1. Khan, S.N.; Khan, A.U. Breaking the spell: Combating multidrug resistant 'Superbugs'. Front. Microbiol. 2016, 7, 174. [CrossRef] [PubMed]

2. Challinor, V.L.; Bode, H.B. Bioactive natural products from novel microbial sources. Ann. N. Y. Acad. Sci. 2015, 1354, 82-97. [CrossRef] [PubMed]

3. Berdy, J. Thoughts and facts about antibiotics: Where we are now and where we are heading. J. Antibiot. 2012, 65, 385-395. [CrossRef]

4. Locey, K.J.; Lennon, J.T. Scaling laws predict global microbial diversity. Proc. Natl. Acad. Sci. USA 2016, 113, 5970-5975. [CrossRef]

5. Barka, E.A.; Vatsa, P.; Sanchez, L.; Gaveau-Vaillant, N.; Jacquard, C.; Klenk, H.-P.; Clément, C.; Ouhdouch, Y.; van Wezel, G.P. Taxonomy, physiology, and natural products of Actinobacteria. Microbiol. Mol. Biol. Rev. 2016, 80, 1-43. [PubMed]

6. Dhakal, D.; Pokhrel, A.R.; Shrestha, B.; Sohng, J.K. Marine rare actinobacteria: Isolation, characterization, and strategies for harnessing bioactive compounds. Front. Microbiol. 2017, 8, 1106. [CrossRef]

7. Subramani, R.; Aalbersberg, W. Culturable rare actinomycetes: Diversity, isolation and marine natural product discovery. Appl. Microbiol. Biotechnol. 2013, 97, 9291-9321. [PubMed]

8. Azman, A.S.; Othman, I.; Velu, S.S.; Chan, K.G.; Lee, L.H. Mangrove rare actinobacteria: Taxonomy, natural compound and discovery of bioactivity. Front. Microbiol. 2015, 6, 856. [CrossRef]

9. Arul Jose, P.; Jha, B. Intertidal marine sediment harbours Actinobacteria with promising bioactive and biosynthetic potential. Sci. Rep. 2017, 7, 10041. [CrossRef] 
10. Chen, P.; Zhang, L.; Guo, X.; Dai, X.; Liu, L.; Xi, L.; Wang, J.; Song, L.; Wang, Y.; Zhu, Y.; et al. Diversity, biogeography, and biodegradation potential of actinobacteria in the deep-sea sediments along the southwest indian ridge. Front Microbiol. 2016, 7, 1340. [CrossRef] [PubMed]

11. Claverías, F.P.; Undabarrena, A.; González, M.; Seeger, M.; Cámara, B. Culturable diversity and antimicrobial activity of Actinobacteria from marine sediments in Valparaíso bay, Chile. Front. Microbiol. 2015, 6, 737. [CrossRef] [PubMed]

12. Hames-Kocabas, E.E.; Uzel, A. Isolation strategies of marine-derived actinomycetes from sponge and sediment samples. J. Microbiol. Methods 2012, 88, 342-347. [CrossRef]

13. Maldonado, L.A.; Fenical, W.; Jensen, P.R.; Kauffman, C.A.; Mincer, T.J.; Ward, A.C.; Bull, A.T.; Goodfellow, M. Salinispora arenicola gen. nov., sp. nov. and Salinispora tropica sp. nov., obligate marine actinomycetes belonging to the family Micromonosporaceae. Int. J. Syst. Evol. Microbiol. 2005, 55, 1759-1766. [CrossRef] [PubMed]

14. Zotchev, S.B. Marine actinomycetes as an emerging resource for the drug development pipelines. J. Biotechnol. 2012, 158, 68-175. [CrossRef]

15. Overmann, J.; Lepleux, C. Marine Bacteria and Archaea: Diversity, adaptations, and culturability. In The Marine Microbiome: An Untapped Source of Biodiversity and Biotechnological Potential; Stal, L.J., Cretoiu, M.S., Eds.; Springer: Cham, Switzerland, 2016; pp. 21-55.

16. Schwager, E.; Luo, C.; Huttenhower, C.; Morgan, X.C. Sequencing and other tools for studying microbial communities: Genomics and "meta'omic" tools are enabling us to explore the microbiome from three complementary perspectives-Taxonomic, functional and ecological. Microbe 2015, 10, 419-425. [CrossRef]

17. Kaeberlein, T.; Lewis, K.; Epstein, S.S. Isolating "uncultivable" microorganisms in pure culture in a simulated natural environment. Science 2002, 296, 1127-1129. [CrossRef]

18. Zengler, K.; Toledo, G.; Rappé, M.; Elkins, J.; Mathur, E.J.; Short, J.M.; Keller, M. Cultivating the uncultured. Proc. Natl. Acad. Sci. USA 2002, 99, 15681-15686. [CrossRef]

19. Vartoukian, S.R.; Palmer, R.M.; Wade, W.G. Strategies for culture of 'unculturable' bacteria. FEMS Microbiol. Lett. 2010, 309, 1-7. [CrossRef]

20. Stewart, E.J. Growing unculturable bacteria. J. Bacteriol. 2012, 194, 4151-4160. [CrossRef]

21. Kamagata, Y. Keys to cultivating uncultured microbes: Elaborate enrichment strategies and resuscitation of dormant cells. Microbes Environ. 2015, 30, 289-290. [CrossRef]

22. Jiang, Y.; Li, Q.; Chen, X.; Jiang, C. Isolation and cultivation methods of Actinobacteria. In Actinobacteria-Basics and Biotechnological Applications; Dhanasekaran, D., Jiang, Y., Eds.; InTech: London, UK, 2016; Chapter 2; pp. 39-57.

23. Azman, A.S.; Zainal, N.; Mutalib, N.A.; Yin, W.F.; Chan, K.G.; Lee, L.H. Monashia flava gen. nov., sp. nov., an actinobacterium of the family Intrasporangiaceae. Int. J. Syst. Evol. Microbiol. 2016, 66, 554-561. [CrossRef] [PubMed]

24. Lai, H.; Wei, X.; Jiang, Y.; Chen, X.; Li, Q.; Jiang, Y.; Jiang, C.; Gillerman, L. Halopolyspora alba gen. nov., sp. nov., isolated from sediment. Int. J. Syst. Evol. Microbiol. 2014, 64, 2775-2780. [CrossRef] [PubMed]

25. Zhang, G.; Wang, S.; Wang, L. Sediminivirga luteola gen. nov., sp. nov., a member of the family Brevibacteriaceae, isolated from marine sediment. Int. J. Syst. Evol. Microbiol. 2016, 66, 1494-1498. [CrossRef]

26. Lai, H.; Jiang, Y.; Chen, X.; Li, Q.; Jiang, C.; Jiang, Y.; Wei, X. Haloactinomyces albus gen. nov., sp. nov., isolated from the dead sea. Int. J. Syst. Evol. Microbiol. 2017, 67, 1163-1168. [PubMed]

27. Huang, H.Q.; Xing, S.S.; Yuan, W.D.; Wang, Y.; Liu, M.; Sun, Q.G.; Lin, X.Z.; Bao, S.X. Nocardiopsis mangrovei sp. nov., isolated from mangrove sediment. Antonie Van Leeuwenhoek 2015, 107, 1541-1556. [CrossRef] [PubMed]

28. Jensen, P.R.; Gontang, E.; Mafnas, C.; Mincer, T.J.; Fenical, W. Culturable marine actinomycete diversity from tropical pacific ocean sediments. Environ. Microbiol. 2005, 7, 1039-1048. [CrossRef]

29. Selvin, J.; Shanmughapriya, S.; Gandhimathi, R.; Kiran, G.S.; Ravji, T.R.; Natarajaseenivasan, K.; Hema, T.A. Optimization and production of novel antimicrobial agents from sponge associated marine actinomycetes Nocardiopsis dassonvillei MAD08. Appl. Microbiol. Biotechnol. 2009, 83, 435-445. [CrossRef]

30. Maldonado, L.A.; Stach, J.E.M.; Pathom-aree, W.; Ward, A.C.; Bull, A.T.; Goodfellow, M. Diversity of cultivable actinobacteria in geographically widespread marine Sediments. Antonie Van Leeuwenhoek 2005, 87, 11-18. [CrossRef]

31. Mincer, T.J.; Fenical, W.; Jensen, P.R. Cultured and culture-independent diversity within the obligate marine actinomycete genus Salinispora. Appl. Environ. Microbiol. 2005, 71, 7019-7028. [CrossRef] 
32. Gontang, E.A.; Fenical, W.; Jensen, P.R. Phylogenetic diversity of Gram-positive bacteria cultured from marine sediments. Appl. Environ. Microbiol. 2007, 73, 3272-3282. [CrossRef]

33. Kennedy, J.; Baker, P.; Piper, C.; Cotter, P.D.; Walsh, M.; Mooij, M.J.; Bourke, M.B.; Rea, M.C.; O'Connor, P.M.; Ross, R.P.; et al. Isolation and analysis of bacteria with antimicrobial activities from the marine sponge Haliclona simulans collected from Irish waters. Mar. Biotechnol. 2009, 11, 384-396. [CrossRef]

34. Maldonado, L.A.; Frangoso-Yanez, D.; Perez-Garcia, A.; Rosellon-Druker, J.; Quintana, E. Actinobacterial diversity from marine sediments collected in Mexico. Antonie Van Leeuwenhoek 2009, 95, 111-120. [CrossRef]

35. Wang, S.; Zhou, Y.; Zhang, G. Nocardioides flavus sp. nov., isolated from marine sediment. Int. J. Syst. Evol. Microbiol. 2016, 66, 5275-5280.

36. Jang, G.I.; Cho, Y.; Cho, B.C. Pontimonas salivibrio gen. nov., sp. nov., a new member of the family Microbacteriaceae isolated from a seawater reservoir of a solar saltern. Int. J. Syst. Evol. Microbiol. 2013, 63, 2124-2131. [CrossRef]

37. Lee, S.D. Tamlicoccus marinus gen. nov., sp. nov., isolated from seawater. Int. J. Syst. Evol. Microbiol. 2013, 63, 1951-1954. [CrossRef]

38. De Menezes, C.B.; Tonin, M.F.; Silva, L.J.; de Souza, W.R.; Parma, M.; de Melo, I.S.; Zucchi, T.D.; Destéfano, S.A.; Fantinatti-Garboggini, F. Marmoricola aquaticus sp. nov., an actinomycete isolated from a marine sponge. Int. J. Syst. Evol. Microbiol. 2015, 65, 2286-2291. [CrossRef]

39. Afonso de Menezes, C.B.; Afonso, R.S.; Souza, W.R.; Parma, M.; Melo, I.S.; Zucchi, T.D.; Fantinatti-Garboggini, F. Williamsia spongiae sp. nov., an actinomycete isolated from the marine sponge Amphimedon viridis. Int. J. Syst. Evol. Microbiol. 2017, 67, 1260-1265.

40. Souza, D.T.; Silva, F.S.P.D.; Silva, L.J.D.; Crevelin, E.J.; Moraes, L.A.B.; Zucchi, T.D.; Melo, I.S. Saccharopolyspora spongiae sp. nov., a novel actinomycete isolated from the marine sponge Scopalina ruetzleri (Wiedenmayer, 1977). Int. J. Syst. Evol. Microbiol. 2017, 67, 2019-2025. [CrossRef]

41. Ramaprasad, E.V.; Sasikala, C.; Ramana, C.V. Ornithinimicrobium algicola sp. nov., a marine actinobacterium isolated from the green alga of the genus Ulva. Int. J. Syst. Evol. Microbiol. 2015, 65, 4627-4631. [CrossRef]

42. Phongsopitanun, W.; Kudo, T.; Ohkuma, M.; Pittayakhajonwut, P.; Suwanborirux, K.; Tanasupawat, S. Micromonospora sediminis sp. nov., isolated from mangrove sediment. Int. J. Syst. Evol. Microbiol. 2016, 66, 3235-3240. [CrossRef]

43. Zhang, D.F.; Wang, H.F.; Xiong, Z.J.; Tian, X.P.; Liu, L.; Zhang, X.M.; Jiang, Z.; Zhang, S.; Li, W.J. Mariniluteicoccus flavus gen. nov., sp. nov., a new member of the family Propionibacteriaceae, isolated from a deep-sea sediment. Int. J. Syst. Evol. Microbiol. 2014, 64, 1051-1056. [CrossRef]

44. Pathom-aree, W.; Stach, J.E.M.; Ward, A.C.; Horikoshi, K.; Bull, A.T.; Goodfellow, M. Diversity of actinomycetes isolated from Challenger deep sediment $(10,898 \mathrm{~m})$ from the Mariana Trench. Extremophiles 2006, 10, 181-189. [CrossRef]

45. Takizawa, M.; Colwell, R.R.; Hill, R.T. Isolation and diversity of actinomycetes in the Chesapeake Bay. Appl. Environ. Microbiol. 1993, 59, 997-1002.

46. Fenical, W.; Jensen, P.R. Developing a new resource for drug discovery: Marine actinomycete bacteria. Nat. Chem. Biol. 2006, 2, 666-673. [CrossRef] [PubMed]

47. Jiang, Y.; Cao, Y.R.; Zhao, L.X.; Wang, Q.; Jin, R.X.; He, W.X.; Xue, Q.H. Treatment of ultrasonic to soil sample for increase of the kind of rare actinomycetes. Acta Microbiol. Sin. 2010, 50, 1094-1097.

48. Margulis, L.; Chapman, M.J. Kingdoms and domains. In An Illustrated Guide to the Phyla of Life on Earth, 1st ed.; Elsevier Science, Marine Biological Laboratory: Woods Hole, MA, USA, 2009; p. 732.

49. Jensen, P.R.; Dwight, R.; Fenical, W. Distribution of actinomycetes in near-shore tropical marine sediments. Appl. Environ. Microbiol. 1991, 57, 1102-1108. [PubMed]

50. Lee, L.H.; Azman, A.S.; Zainal, N.; Eng, S.K.; Ab Mutalib, N.S.; Yin, W.F.; Chan, K.G. Microbacterium mangrovi sp. nov., an amylolytic actinobacterium isolated from mangrove forest soil. Int. J. Syst. Evol. Microbiol. 2014, 64, 3513-3519. [CrossRef] [PubMed]

51. Lee, L.H.; Azman, A.S.; Zainal, N.; Yin, W.F.; Mutalib, N.S.; Chan, K.G. Sinomonas humi sp. nov., an amylolytic actinobacterium isolated from mangrove forest soil. Int. J. Syst. Evol. Microbiol. 2015, 65, 996-1002. [CrossRef] [PubMed]

52. Ren, J.; Li, L.; Wei, B.; Tang, Y.L.; Deng, Z.X.; Sun, M.; Hong, K. Micromonospora wenchangensis sp. nov., isolated from mangrove soil. Int. J. Syst. Evol. Microbiol. 2013, 63, 2389-2395. [CrossRef] [PubMed] 
53. Mincer, T.J.; Jensen, P.R.; Kauffman, C.A.; Fenical, W. Widespread and persistent populations of a major new marine actinomycete taxon in ocean sediments. Appl. Environ. Microbiol. 2002, 68, 5005-5011. [CrossRef]

54. Bredholdt, H.; Tjaervik, E.; Johnsen, G.; Zotchev, S.B. Actinomycetes from sediments in the Trondheim fjord, Norway: Diversity and biological activity. Mar. Drugs 2008, 6, 12-24. [CrossRef]

55. Kokare, C.R.; Mahadik, K.R.; Kadam, S.S. Isolation of bioactive marine Actinomycetes from sediments isolated from Goa and Maharashtra coastlines (west coast of India). Indian J. Mar. Sci. 2004, 33, 248-256.

56. Naikpatil, S.V.; Rathod, J.L. Selective isolation and antimicrobial activity of rare Actinomycetes from mangrove sediment of Karwar. J. Ecobiotechnol. 2011, 3, 48-53.

57. Mangamuri, U.K.; Muvva, V.; Poda, S.; Kamma, S. Isolation, identification and molecular characterization of rare Actinomycetes from mangrove ecosystem of Nizampatnam. Malays. J Microbiol. 2012, 8, 83-91. [CrossRef]

58. Terahara, T.; Kobayashi, T.; Imada, C. An effective method based on wet-heat treatment for the selective isolation of Micromonospora from estuarine sediments. World J. Microbiol. Biotechnol. 2013, 29, 1677-1684. [CrossRef] [PubMed]

59. Solano, G.; Rojas-Jiménez, K.; Jaspars, M.; Tamayo-Castillo, G. Study of the diversity of culturable Actinomycetes in the North Pacific and Caribbean coasts of Costa Rica. Antonie Van Leeuwenhoek 2009, 96, 71-78. [CrossRef]

60. Hong, K.; Gao, A.H.; Xie, Q.Y.; Gao, H.; Zhuang, L.; Lin, H.P.; Yu, H.P.; Li, J.; Yao, X.S.; Goodfellow, M.; et al. Actinomycetes for marine drug discovery isolated from mangrove soils and plants in China. Mar. Drugs 2009, 7, 24-44. [CrossRef] [PubMed]

61. Bredholdt, H.; Galatenko, O.A.; Engelhardt, K.; Tjaervik, E.; Terekhova, L.P.; Zotchev, S.B. Rare actinomycete bacteria from the shallow water sediments of the Trondheim fjord, Norway: Isolation, diversity and biological activity. Environ. Microbiol. 2007, 9, 2756-2764. [CrossRef] [PubMed]

62. Cumsille, A.; Undabarrena, A.; González, V.; Claverías, F.; Rojas, C.; Cámara, B. Biodiversity of actinobacteria from the South Pacific and the assessment of Streptomyces chemical diversity with metabolic profiling. Mar. Drugs 2017, 15, 286. [CrossRef]

63. Skropeta, D.; Wei, L. Recent advances in deep-sea natural products. Nat. Prod. Rep. 2014, 31, 999-1025. [CrossRef]

64. Tiwari, K.; Gupta, R.K. Diversity and isolation of rare actinomycetes: An overview. Crit. Rev. Microbiol. 2012, 39, 256-294. [CrossRef] [PubMed]

65. Martinez-Murcia, A.J.; Collins, M.D. A phylogenetic analysis of the genus Leuconostoc based on reverse transcriptase sequencing of 16S rRNA. FEMS Microbiol. Lett. 1990, 70, 73-83. [CrossRef]

66. Collins, M.D.; Rodrigues, U.; Ash, C.; Aguirre, M.; Farrow, J.A.E.; Martinez-Murcia, A.; Phillips, B.A.; Williams, A.M.; Wallbanks, S. Phylogenetic analysis of the genus Lactobacillus and related lactic acid bacteria as determined by reverse transcriptase sequencing of $16 \mathrm{~S}$ rRNA. FEMS Microbiol. Lett. 1991, 77, 5-12. [CrossRef]

67. Amann, R.I.; Lin, C.; Key, R.; Montgomery, L.; Stahl, D.A. Diversity among Fibrobacter isolates: Towards a phylogenetic classification. Syst. Appl. Microbiol. 1992, 15, 23-31. [CrossRef]

68. Fox, G.E.; Wisotzkey, J.D.; Jurtshuk, P., Jr. How close is close: $16 \mathrm{~S}$ rRNA sequence identity may not be sufficient to guarantee species identity. Int. J. Syst. Bacteriol. 1992, 42, 166-170. [CrossRef] [PubMed]

69. Martinez-Murcia, A.J.; Benlloch, S.; Collins, M.D. Phylogenetic interrelationships of members of the genera Aeromonas and Pleisiomonas as determined by $16 \mathrm{~S}$ ribosomal DNA sequencing: Lack of congruence with results of DNA-DNA hybridizations. Int. J. Syst. Bacteriol. 1992, 42, 412-421. [CrossRef] [PubMed]

70. Schlaberg, R.; Simmon, K.E.; Fisher, M.A. A systematic approach for discovering novel, clinically relevant bacteria. Emerg. Infect. Dis. 2012, 18, 422-430. [CrossRef] [PubMed]

71. Yilmaz, P.; Parfrey, L.W.; Yarza, P.; Gerken, J.; Pruesse, E.; Quast, C.; Schweer, T.; Peplies, J.; Ludwig, W.; Glöckner, F.O. The SILVA and "All-species Living Tree Project (LTP)" taxonomic frameworks. Nucleic Acids Res. 2014, 42, 643-648. [CrossRef]

72. Snelgrove, P.; Blackburn, T.; Hutchings, P.A.; Alongi, D.M.; Grassle, J.F.; Hummel, H.; King, G.; Koike, I.; Lambshead, P.J.D.; Ramsing, N.B.; et al. The importance of marine sediment biodiversity in ecosystem processes. Ambio 1997, 26, 578-583.

73. Harino, H.; Arai, T.; Ohji, M.; Miyazaki, N. Organotin contamination in deep sea environment. In Ecotoxicology of Antifouling Biocides; Arai, T., Harino, H., Ohji, M., Langston, W.J., Eds.; Springer: New York, NY, USA, 2009; pp. 95-97. 
74. Skropeta, D. Deep-sea natural products. Nat. Prod. Rep. 2008, 25, 1131-1166. [CrossRef]

75. Durden, J.M.; Bett, B.J.; Jones, D.O.B.; Huvenne, V.A.I.; Ruhl, H.A. Abyssal hills hidden source of increased habitat heterogeneity, benthic megafaunal biomass and diversity in the deep sea. Prog. Oceanogr. 2015, 137, 209-218. [CrossRef]

76. Haefner, B. Drugs from the deep: Marine natural products as drug candidates. Drug Discov. Today 2003, 8 , 536-544. [CrossRef]

77. Hobbie, J.E.; Daley, R.J.; Jasper, S. Use of nuclepore filters for counting bacteria by fluorescence microscopy. Appl. Environ. Microbiol. 1977, 33, 1225-1228. [PubMed]

78. Porter, K.G.; Feig, Y.S. The use of DAPI for identifying and counting aquatic microflora. Limnol. Oceanogr. 1980, 25, 943-948. [CrossRef]

79. Whitman, W.B.; Coleman, D.C.; Wiebe, W.J. Prokaryotes: The unseen majority. Proc. Natl. Acad. Sci. USA 1998, 95, 6578-6583. [CrossRef] [PubMed]

80. Das, S.; Mangwani, N. Ocean acidification and marine microorganisms: Responses and consequences. Oceanologia 2015, 57, 349-361. [CrossRef]

81. Vicente, J.; Stewart, A.; Song, B.; Hill, R.T.; Wright, J.L. Biodiversity of actinomycetes associated with caribbean sponges and their potential for natural product discovery. Mar. Biotechnol. 2013, 15, 413-424. [CrossRef]

82. Veyisoglu, A.; Sazak, A.; Cetin, D.; Guven, K.; Sahin, N. Saccharomonospora amisosensis sp. nov., isolated from deep marine sediment. Int. J. Syst. Evol. Microbiol. 2013, 63, 3782-3786. [CrossRef] [PubMed]

83. Zhang, D.F.; Chen, W.; He, J.; Zhang, X.M.; Xiong, Z.J.; Sahu, M.K.; Sivakumar, K.; Li, W.J. Saccharomonospora oceani sp. nov. isolated from marine sediments in Little Andaman, India. Antonie Van Leeuwenhoek 2013, 103, 1377-1384. [CrossRef]

84. Zhang, D.F.; Jiang, Z.; Zhang, X.M.; Yang, L.L.; Tian, X.P.; Long, L.J.; Zhang, S.; Li, W.J. Actinophytocola sediminis sp. nov., an actinomycete isolated from a marine sediment. Int. J. Syst. Evol. Microbiol. 2014, 64, 2834-2840. [CrossRef]

85. Zhang, D.F.; Jiang, Z.; Li, L.; Liu, B.B.; Zhang, X.M.; Tian, X.P.; Zhang, S.; Li, W.J. Pseudonocardia sediminis sp. nov., isolated from marine sediment. Int. J. Syst. Evol. Microbiol. 2014, 64, 745-750. [CrossRef]

86. Wei, X.; Jiang, Y.; Chen, X.; Jiang, Y.; Lai, H. Amycolatopsis flava sp. nov., a halophilic actinomycete isolated from dead sea. Antonie Van Leeuwenhoek 2015, 108, 879-885. [CrossRef]

87. Jiang, Y.; Wei, X.; Chen, X.; Jiang, Y.; Xue, Q.; Lai, H.; Jiang, C. Saccharopolyspora griseoalba sp. nov., a novel actinomycete isolated from the dead sea. Antonie Van Leeuwenhoek 2016, 109, 1635-1641. [CrossRef] [PubMed]

88. Zhang, G.; Wang, L.; Li, J.; Zhou, Y. Amycolatopsis albispora sp. nov., isolated from deep-sea sediment. Int. J. Syst. Evol. Microbiol. 2016, 66, 3860-3864. [CrossRef] [PubMed]

89. Zhang, G.; Wang, L.; Li, J.; Zhou, Y. Pseudonocardia profundimaris sp. nov., isolated from marine sediment. Int. J. Syst. Evol. Microbiol. 2017, 67, 1693-1697. [CrossRef] [PubMed]

90. Fan, X.; Qiao, Y.; Gao, X.; Zhang, X.H. Nocardioides pacificus sp. nov., isolated from deep sub-seafloor sediment. Int. J. Syst. Evol. Microbiol. 2014, 64, 2217-2222. [CrossRef] [PubMed]

91. Zhang, D.F.; Zhong, J.M.; Zhang, X.M.; Jiang, Z.; Zhou, E.M.; Tian, X.P.; Zhang, S.; Li, W.J. Nocardioides nanhaiensis sp. nov., an actinobacterium isolated from a marine sediment sample. Int. J. Syst. Evol. Microbiol. 2014, 64, 2718-2722. [CrossRef]

92. Deng, S.; Chang, X.; Zhang, Y.; Ren, L.; Jiang, F.; Qu, Z.; Peng, F. Nocardioides antarcticus sp. nov., isolated from marine sediment. Int. J. Syst. Evol. Microbiol. 2015, 65, 2615-2621. [CrossRef]

93. Lee, D.W.; Lee, A.H.; Lee, H.; Kim, J.J.; Khim, J.S.; Yim, U.H.; Kim, B.S. Nocardioides litoris sp. nov., isolated from the Taean seashore. Int. J. Syst. Evol. Microbiol. 2017, 67, 2332-2336. [CrossRef]

94. Zhang, D.F.; Pan, H.Q.; He, J.; Zhang, X.M.; Zhang, Y.G.; Klenk, H.P.; Hu, J.C.; Li, W.J. Description of Streptomonospora sediminis sp. nov. and Streptomonospora nanhaiensis sp. nov., and reclassification of Nocardiopsis arabia Hozzein \& Goodfellow 2008 as Streptomonospora arabica comb. nov. and emended description of the genus Streptomonospora. Int. J. Syst. Evol. Microbiol. 2013, 63, 4447-4455.

95. Pan, H.Q.; Zhang, D.F.; Li, L.; Jiang, Z.; Cheng, J.; Zhang, Y.G.; Wang, H.F.; Hu, J.C.; Li, W.J. Nocardiopsis oceani sp. nov. and Nocardiopsis nanhaiensis sp. nov., actinomycetes isolated from marine sediment of the South China Sea. Int. J. Syst. Evol. Microbiol. 2015, 65, 3384-3391. [CrossRef] [PubMed]

96. Zhang, Y.; Ren, H.; Zhang, G. Microbacterium hydrothermale sp. nov., an actinobacterium isolated from hydrothermal sediment. Int. J. Syst. Evol. Microbiol. 2014, 64, 3508-3512. [CrossRef] [PubMed] 
97. Hamada, M.; Shibata, C.; Tamura, T.; Suzuki, K. Agromyces marinus sp. nov., a novel actinobacterium isolated from sea sediment. J. Antibiot. 2014, 67, 703-706. [CrossRef]

98. Mawlankar, R.R.; Mual, P.; Sonalkar, V.V.; Thorat, M.N.; Verma, A.; Srinivasan, K.; Dastager, S.G. Microbacterium enclense sp. nov., isolated from sediment sample. Int. J. Syst. Evol. Microbiol. 2015, 65, 2064-2070. [CrossRef]

99. Yan, L.; Wang, J.; Chen, Z.; Guan, Y.; Li, J. Microbacterium nanhaiense sp. nov., an actinobacterium isolated from sea sediment. Int. J. Syst. Evol. Microbiol. 2015, 65, 3697-3702. [CrossRef] [PubMed]

100. Hamada, M.; Shibata, C.; Tamura, T.; Suzuki, K. Zhihengliuella flava sp. nov., an actinobacterium isolated from sea sediment, and emended description of the genus Zhihengliuella. Int. J. Syst. Evol. Microbiol. 2013, 63, 4760-4764. [CrossRef]

101. Dastager, S.G.; Tang, S.K.; Srinivasan, K.; Lee, J.C.; Li, W.J. Kocuria indica sp. nov., isolated from a sediment sample. Int. J. Syst. Evol. Microbiol. 2014, 64, 869-874. [CrossRef] [PubMed]

102. Zhang, G.; Zhang, Y.; Yin, X.; Wang, S. Nesterenkonia alkaliphila sp. nov., an alkaliphilic, halotolerant actinobacteria isolated from the western Pacific Ocean. Int. J. Syst. Evol. Microbiol. 2015, 65, 516-521. [CrossRef]

103. Jiang, Z.; Zhang, W.H.; Yuan, C.G.; Chen, J.Y.; Cao, L.X.; Park, D.J.; Xiao, M.; Kim, C.J.; Li, W.J. Kocuria subflava sp. nov., isolated from marine sediment from the Indian Ocean. Antonie Van Leeuwenhoek 2015, 108, 1349-1355. [CrossRef]

104. Fan, X.; Zhang, Z.; Li, Z.; Zhang, X.H. Luteococcus sediminum sp. nov., isolated from deep subseafloor sediment of the South Pacific Gyre. Int. J. Syst. Evol. Microbiol. 2014, 64, 2522-2527. [CrossRef]

105. Puente-Sánchez, F.; Sánchez-Román, M.; Amils, R.; Parro, V. Tessaracoccus lapidicaptus sp. nov., an actinobacterium isolated from the deep subsurface of the Iberian pyrite belt. Int. J. Syst. Evol. Microbiol. 2014, 64, 3546-3552. [CrossRef]

106. Thongphrom, C.; Kim, J.H.; Bora, N.; Kim, W. Tessaracoccus arenae sp. nov., isolated from sea sand. Int. J. Syst. Evol. Microbiol. 2017, 67, 2008-2013. [CrossRef]

107. Dastager, S.G.; Mawlankar, R.; Tang, S.K.; Krishnamurthi, S.; Ramana, V.V.; Joseph, N.; Shouche, Y.S. Rhodococcus enclensis sp. nov., a novel member of the genus Rhodococcus. Int. J. Syst. Evol. Microbiol. 2014, 64, 2693-2699. [CrossRef] [PubMed]

108. Bai, J.L.; Wang, Y.; Qin, S.; Ding, P.; Xing, K.; Yuan, B.; Cao, C.L.; Huang, Y.; Zhang, Y.Q.; Jiang, J.H. Nocardia jiangsuensis sp. nov., an actinomycete isolated from coastal soil. Int. J. Syst. Evol. Microbiol. 2016, 66, 4633-4638. [CrossRef]

109. Phongsopitanun, W.; Kudo, T.; Mori, M.; Shiomi, K.; Pittayakhajonwut, P.; Suwanborirux, K.; Tanasupawat, S. Micromonospora fluostatini sp. nov., isolated from marine sediment. Int. J. Syst. Evol. Microbiol. 2015, 65, 4417-4423. [CrossRef]

110. Veyisoglu, A.; Carro, L.; Guven, K.; Cetin, D.; Spröer, C.; Schumann, P.; Klenk, H.P.; Goodfellow, M.; Sahin, N. Micromonospora yasonensis sp. nov., isolated from a black sea sediment. Antonie Van Leeuwenhoek 2016, 109, 1019-1028. [CrossRef]

111. Veyisoglu, A.; Carro, L.; Cetin, D.; Guven, K.; Spröer, C.; Pötter, G.; Klenk, H.P.; Sahin, N.; Goodfellow, M. Micromonospora profundi sp. nov., isolated from deep marine sediment. Int. J. Syst. Evol. Microbiol. 2016, 66, 4735-4743. [CrossRef] [PubMed]

112. Park, S.; Jung, Y.T.; Won, S.M.; Lee, J.S.; Yoon, J.H. Demequina activiva sp. nov., isolated from a tidal flat. Int. J. Syst. Evol. Microbiol. 2015, 65, 2042-2047. [CrossRef] [PubMed]

113. Park, S.; Jung, Y.T.; Won, S.M.; Yoon, J.H. Demequina litorisediminis sp. nov., isolated from a tidal flat, and emended description of the genus Demequina. Int. J. Syst. Evol. Microbiol. 2016, 66, 4197-4203.

114. Hamada, M.; Shibata, C.; Tamura, T.; Yamamura, H.; Hayakawa, M.; Suzuki, K. Janibacter cremeus sp. nov., an actinobacterium isolated from sea sediment. Int. J. Syst. Evol. Microbiol. 2013, 63, 3687-3690. [CrossRef] [PubMed]

115. Zhang, G.; Ren, H.; Wang, S.; Chen, X.; Yang, Y.; Zhang, Y.; Jiang, Y. Janibacter indicus sp. nov., isolated from hydrothermal sediment of the Indian Ocean. Int. J. Syst. Evol. Microbiol. 2014, 64, 2353-2357. [CrossRef]

116. You, Z.Q.; Li, J.; Qin, S.; Tian, X.P.; Wang, F.Z.; Zhang, S. Georgenia sediminis sp. nov., a moderately thermophilic actinobacterium isolated from sediment. Int. J. Syst. Evol. Microbiol. 2013, 63, 4243-4247. [CrossRef]

117. Wang, S.; Xu, X.; Wang, L.; Jiao, K.; Zhang, G. Georgenia subflava sp. nov., isolated from a deep-sea sediment. Int. J. Syst. Evol. Microbiol. 2015, 65, 4146-4150. [CrossRef] 
118. Matsumoto, A.; Kasai, H.; Matsuo, Y.; Shizuri, Y.; Ichikawa, N.; Fujita, N.; Omura, S.; Takahashi, Y. Ilumatobacter nonamiense sp. nov. and Ilumatobacter coccineum sp. nov., isolated from seashore sand. Int. J. Syst. Evol. Microbiol. 2013, 63, 3404-3408. [CrossRef]

119. Chen, P.; Zhang, L.; Wang, J.; Ruan, J.; Han, X.; Huang, Y. Brevibacterium sediminis sp. nov., isolated from deep-sea sediments from the Carlsberg and southwest Indian ridges. Int. J. Syst. Evol. Microbiol. 2016, 66, 5268-5274. [PubMed]

120. Du, Z.J.; Miao, T.T.; Lin, X.Z.; Liu, Q.Q.; Chen, G.J. Flaviflexus huanghaiensis gen. nov., sp. nov., an actinobacterium of the family Actinomycetaceae. Int. J. Syst. Evol. Microbiol. 2013, 63, 1863-1867. [CrossRef] [PubMed]

121. Hamada, M.; Tamura, T.; Shibata, C.; Yamamura, H.; Hayakawa, M.; Schumann, P.; Suzuki, K. Paraoerskovia sediminicola sp. nov., an actinobacterium isolated from sea sediment, and emended description of the genus Paraoerskovia. Int. J. Syst. Evol. Microbiol. 2013, 63, 2637-2641. [CrossRef]

122. Cho, Y.; Jang, G.I.; Cho, B.C. Nocardioides marinquilinus sp. nov., isolated from coastal seawater. Int. J. Syst. Evol. Microbiol. 2013, 63, 2594-2599. [CrossRef] [PubMed]

123. Cho, Y.; Jang, G.I.; Hwang, C.Y.; Kim, E.H.; Cho, B.C. Nocardioides salsibiostraticola sp. nov., isolated from biofilm formed in coastal seawater. Int. J. Syst. Evol. Microbiol. 2013, 63, 3800-3806. [CrossRef] [PubMed]

124. Wang, L.; Li, J.; Zhang, G. Nocardioides rotundus sp. nov., isolated from deep seawater. Int. J. Syst. Evol. Microbiol. 2016, 66, 1932-1936. [CrossRef]

125. Zhang, L.; Xi, L.; Qiu, D.; Song, L.; Dai, X.; Ruan, J.; Huang, Y. Cellulomonas marina sp. nov., isolated from deep-sea water. Int. J. Syst. Evol. Microbiol. 2013, 63, 3014-3018. [CrossRef]

126. Zhang, L.; Xi, L.; Ruan, J.; Huang, Y. Kocuria oceani sp. nov., isolated from a deep-sea hydrothermal plume. Int. J. Syst. Evol. Microbiol. 2017, 67, 164-169. [CrossRef] [PubMed]

127. Kaur, G.; Kumar, N.; Mual, P.; Kumar, A.; Kumar, R.M.; Mayilraj, S. Brachybacterium aquaticum sp. nov., a novel actinobacterium isolated from seawater. Int. J. Syst. Evol. Microbiol. 2016, 66, 4705-4710. [CrossRef]

128. Yang, J.; Gao, J.; Cheung, A.; Liu, B.; Schwendenmann, L. Vegetation and sediment characteristics in expanding mangrove forest in New Zealand. Eastuar. Coast. Shelf. Sci. 2013, 134, 11-18. [CrossRef]

129. Hong, K. Actinomycetes from mangrove and their secondary metabolites. Wei Sheng Wu Xue Bao 2013, 53, 1131-1141.

130. Supong, K.; Suriyachadkun, C.; Suwanborirux, K.; Pittayakhajonwut, P.; Thawai, C. Verrucosispora andamanensis sp. nov., isolated from a marine sponge. Int. J. Syst. Evol. Microbiol. 2013, 63, 3970-3974. [CrossRef] [PubMed]

131. Supong, K.; Suriyachadkun, C.; Pittayakhajonwut, P.; Suwanborirux, K.; Thawai, C. Micromonospora spongicola sp. nov., an actinomycete isolated from a marine sponge in the Gulf of Thailand. J. Antibiot. 2013, 66, 505-509. [CrossRef]

132. Wu, J.F.; Li, J.; You, Z.Q.; Zhang, S. Prauserella coralliicola sp. nov., isolated from the coral Galaxea fascicularis. Int. J. Syst. Evol. Microbiol. 2014, 64, 3341-3345. [CrossRef] [PubMed]

133. Kaur, G.; Mual, P.; Kumar, N.; Verma, A.; Kumar, A.; Krishnamurthi, S.; Mayilraj, S. Microbacterium aureliae sp. nov., a novel actinobacterium isolated from Aurelia aurita, the moon jellyfish. Int. J. Syst. Evol. Microbiol. 2016, 66, 4665-4670. [CrossRef]

134. Fukano, H.; Wada, S.; Kurata, O.; Katayama, K.; Fujiwara, N.; Hoshino, Y. Mycobacterium stephanolepidis sp. nov., a rapidly growing species related to Mycobacterium chelonae, isolated from marine teleost fish, Stephanolepis cirrhifer. Int. J. Syst. Evol. Microbiol. 2017, 67, 2811-2817. [CrossRef] [PubMed]

135. Lee, J.Y.; Hyun, D.W.; Soo Kim, P.; Sik Kim, H.; Shin, N.R.; Yun, J.H.; Jung, M.J.; Kim, M.S.; Woong Whon, T.; Bae, J.W. Arthrobacter echini sp. nov., isolated from the gut of a purple sea urchin, Heliocidaris crassispina. Int. J. Syst. Evol. Microbiol. 2016, 66, 1887-1893. [CrossRef] [PubMed]

136. Thawai, C.; Rungjindamai, N.; Klanbut, K.; Tanasupawat, S. Nocardia xestospongiae sp. nov., isolated from a marine sponge in the Andaman sea. Int. J. Syst. Evol. Microbiol. 2017, 67, 1451-1456.

137. Kämpfer, P.; Glaeser, S.P.; Busse, H.J.; Abdelmohsen, U.R.; Hentschel, U. Rubrobacter aplysinae sp. nov., isolated from the marine sponge Aplysina aerophoba. Int. J. Syst. Evol. Microbiol. 2014, 64, 705-709. [CrossRef]

138. Kämpfer, P.; Glaeser, S.P.; Busse, H.J.; Abdelmohsen, U.R.; Ahmed, S.; Hentschel, U. Actinokineospora spheciospongiae sp. nov., isolated from the marine sponge Spheciospongia vagabunda. Int. J. Syst. Evol. Microbiol. 2015, 65, 879-884. [CrossRef] 
139. Sarmiento-Vizcaíno, A.; González, V.; Braña, A.F.; Molina, A.; Acuña, J.L.; García, L.A.; Blanco, G. Myceligenerans cantabricum sp. nov., a barotolerant actinobacterium isolated from a deep cold-water coral. Int. J. Syst. Evol. Microbiol. 2015, 65, 1328-1334. [CrossRef] [PubMed]

140. Hamada, M.; Shibata, C.; Saitou, S.; Tamura, T.; Komaki, H.; Ichikawa, N.; Oguchi, A.; Hosoyama, A.; Fujita, N.; Yamamura, H.; et al. Proposal of nine novel species of the genus Lysinimicrobium and emended description of the genus Lysinimicrobium. Int. J. Syst. Evol. Microbiol. 2015, 65, 4394-4402. [CrossRef]

141. Zhang, L.; Li, L.; Deng, Z.; Hong, K. Micromonospora zhanjiangensis sp. nov., isolated from mangrove forest soil. Int. J. Syst. Evol. Microbiol. 2015, 65, 4880-4885. [CrossRef] [PubMed]

142. Li, L.; Hong, K. Micromonospora ovatispora sp. nov. isolated from mangrove soil. Int. J. Syst. Evol. Microbiol. 2016, 66, 889-893. [CrossRef] [PubMed]

143. Xie, Q.Y.; Ren, J.; Li, L.; Li, Y.; Deng, Z.X.; Hong, K. Micromonospora mangrovi sp. nov., isolated from mangrove soil. Antonie Van Leeuwenhoek 2016, 109, 483-491. [CrossRef] [PubMed]

144. Muangham, S.; Suksaard, P.; Mingma, R.; Matsumoto, A.; Takahashi, Y.; Duangmal, K. Nocardiopsis sediminis sp. nov., isolated from mangrove sediment. Int. J. Syst. Evol. Microbiol. 2016, 66, 3835-3840.

145. Hamada, M.; Shibata, C.; Tamura, T.; Nurkanto, A.; Ratnakomala, S.; Lisdiyanti, P.; Suzuki, K.I. Kocuria pelophila sp. nov., an actinobacterium isolated from the rhizosphere of a mangrove. Int. J. Syst. Evol. Microbiol. 2016, 66, 3276-3280. [CrossRef]

146. Lee, L.H.; Zainal, N.; Azman, A.S.; Mutalib, N.S.; Hong, K.; Chan, K.G. Mumia flava gen. nov., sp. nov., an actinobacterium of the family Nocardioidaceae. Int. J. Syst. Evol. Microbiol. 2014, 64, 1461-1467. [CrossRef]

147. Liu, M.; Xing, S.S.; Yuan, W.D.; Wei, H.; Sun, Q.G.; Lin, X.Z.; Huang, H.Q.; Bao, S.X. Pseudonocardia nematodicida sp. nov., isolated from mangrove sediment in Hainan, China. Antonie Van Leeuwenhoek 2015, 108, 571-577. [CrossRef]

148. Tang, Y.L.; Lin, H.P.; Xie, Q.Y.; Li, L.; Peng, F.; Deng, Z.; Hong, K. Actinoallomurus acanthiterrae sp. nov., an actinomycete isolated from rhizosphere soil of the mangrove plant Acanthus ilicifolius. Int. J. Syst. Evol. Microbiol. 2013, 63, 1874-1879. [CrossRef]

149. Suksaard, P.; Duangmal, K.; Srivibool, R.; Xie, Q.; Hong, K.; Pathom-aree, W. Jiangella mangrovi sp. nov., isolated from mangrove soil. Int. J. Syst. Evol. Microbiol. 2015, 65, 2569-2573. [CrossRef]

150. Hamada, M.; Shibata, C.; Nurkanto, A.; Ratnakomala, S.; Lisdiyanti, P.; Tamura, T.; Suzuki, K. Serinibacter tropicus sp. nov., an actinobacterium isolated from the rhizosphere of a mangrove, and emended description of the genus Serinibacter. Int. J. Syst. Evol. Microbiol. 2015, 65, 1151-1154. [CrossRef]

151. Suksaard, P.; Mingma, R.; Srisuk, N.; Matsumoto, A.; Takahashi, Y.; Duangmal, K. Nonomuraea purpurea sp. nov., an actinomycete isolated from mangrove sediment. Int. J. Syst. Evol. Microbiol. 2016, 66, 4987-4992.

152. Duangmal, K.; Muangham, S.; Mingma, R.; Yimyai, T.; Srisuk, N.; Kitpreechavanich, V.; Matsumoto, A.; Takahashi, Y. Kineococcus mangrovi sp. nov., isolated from mangrove sediment. Int. J. Syst. Evol. Microbiol. 2016, 66, 1230-1235. [CrossRef] [PubMed]

153. Genilloud, O. Actinomycetes: Still a source of novel antibiotics. Nat. Prod. Rep. 2017, 34, $1203-1232$. [CrossRef] [PubMed]

154. Waksman, S.A.; Woodruff, H.B. Bacteriostatic and bactericidal substances produced by a soil actinomyces. Proc. Soc. Exp. Biol. Med. 1940, 45, 609. [CrossRef]

155. Waksman, S.A.; Woodruff, H.B. Selective antibiotic action of various substances of microbial origin. J. Bacteriol. 1942, 44, 373-384. [PubMed]

156. Schatz, A.; Waksman, S.A. Effect of streptomycin and other antibiotic substances upon Mycobacterium tuberculosis and related organisms. Proc. Soc. Exp. Biol. Med. 1944, 57, 244-248. [CrossRef]

157. Subramani, R.; Aalbersberg, W. Marine actinomycetes: An ongoing source of novel bioactive metabolites. Microbiol. Res. 2012, 167, 571-580. [CrossRef]

158. Butler, M.S.; Blaskovich, M.A.; Cooper, M.A. Antibiotics in the clinical pipeline at the end of 2015. J. Antibiot. 2017, 70, 3-24.

159. Feling, R.H.; Buchanan, G.O.; Mincer, T.J.; Kauffman, C.A.; Jensen, P.R.; Fenical, W. Salinosporamide A: A highly cytotoxic proteasome inhibitor from a novel microbial source, a marine bacterium of the new genus Salinospora. Angew. Chem. Int. Ed. Engl. 2003, 42, 355-357. [CrossRef]

160. Asolkar, R.N.; Freel, K.C.; Jensen, P.R.; Fenical, W.; Kondratyuk, T.P.; Park, E.J.; Pezzuto, J.M. Arenamides A-C, cytotoxic NFkB Inhibitors from the marine actinomycete Salinispora arenicola. J. Nat. Prod. 2009, 72, 396-402. [CrossRef] [PubMed] 
161. Jang, K.H.; Nam, S.J.; Locke, J.B.; Kauffman, C.A.; Beatty, D.S.; Paul, L.A.; Fenical, W. Anthracimycin, a potent anthrax antibiotic from a marine-derived actinomycete. Angew. Chem. Int. Ed. Engl. 2013, 52, 7822-7824. [CrossRef]

162. Leutou, A.S.; Yang, I.; Kang, H.; Seo, E.K.; Nam, S.J.; Fenical, W. Nocarimidazoles A and B from a marine-derived actinomycete of the genus Nocardiopsis. J. Nat. Prod. 2015, 78, 2846-2849. [CrossRef] [PubMed]

163. Raju, R.; Piggott, A.M.; Quezada, M.; Capon, R.J. Nocardiopsins C and D and nocardiopyrone A: New polyketides from an Australian marine-derived Nocardiopsis sp. Tetrahedron 2013, 69, 692-698. [CrossRef]

164. Kobayashi, K.; Fukuda, T.; Terahara, T.; Harunari, E.; Imada, C.; Tomoda, H. Diketopiperazines, inhibitors of sterol O-acyltransferase, produced by a marine-derived Nocardiopsis sp. KM2-16. J. Antibiot. 2015, 68, 638-641. [CrossRef]

165. Skellam, E.J.; Stewart, A.K.; Strangman, W.K.; Wright, J.L. Identification of micromonolactam, a new polyene macrocyclic lactam from two marine Micromonospora strains using chemical and molecular methods: clarification of the biosynthetic pathway from a glutamate starter unit. J. Antibiot. 2013, 66, 431-441. [CrossRef] [PubMed]

166. Sarmiento-Vizcaíno, A.; Braña, A.F.; Pérez-Victoria, I.; Martín, J.; de Pedro, N.; Cruz, M.; Díaz, C.; Vicente, F.; Acuña, J.L.; Reyes, F.; et al. Paulomycin G, a new natural product with cytotoxic activity against tumor cell lines produced by deep-sea sediment derived Micromonospora matsumotoense M-412 from the Avilés Canyon in the Cantabrian sea. Mar. Drugs 2017, 15, 271. [CrossRef]

167. Kyeremeh, K.; Acquah, K.S.; Sazak, A.; Houssen, W.; Tabudravu, J.; Deng, H.; Jaspars, M. Butremycin, the 3-hydroxyl derivative of ikarugamycin and a protonated aromatic tautomer of $5^{\prime}$-methylthioinosine from a Ghanaian Micromonospora sp. K310. Mar. Drugs 2014, 12, 999-1012. [CrossRef]

168. Zhang, Y.; Adnani, N.; Braun, D.R.; Ellis, G.A.; Barns, K.J.; Parker-Nance, S.; Guzei, I.A.; Bugni, T.S. Micromonohalimanes A and B: Antibacterial halimane-type diterpenoids from a marine Micromonospora species. J. Nat. Prod. 2016, 79, 2968-2972. [CrossRef] [PubMed]

169. Mullowney, M.W.; ÓhAinmhire, E.; Tanouye, U.; Burdette, J.E.; Pham, V.C.; Murphy, B.T. A pimarane diterpene and cytotoxic angucyclines from a marine-derived Micromonospora sp. in Vietnam's east sea. Mar. Drugs 2015, 13, 5815-5827. [CrossRef] [PubMed]

170. Fu, P.; MacMillan, J.B. Thiasporines A-C, thiazine and thiazole derivatives from a marine-derived Actinomycetospora chlora. J. Nat. Prod. 2015, 78, 548-551. [CrossRef]

171. Ye, X.; Anjum, K.; Song, T.; Wang, W.; Yu, S.; Huang, H.; Lian, X.Y.; Zhang, Z. A new curvularin glycoside and its cytotoxic and antibacterial analogues from marine actinomycete Pseudonocardia sp. HS7. Nat. Prod. Res. 2016, 30, 1156-1161. [CrossRef] [PubMed]

172. Kyeremeh, K.; Acquah, K.S.; Camas, M.; Tabudravu, J.; Houssen, W.; Deng, H.; Jaspars, M. Butrepyrazinone, a new pyrazinone with an unusual methylation pattern from a Ghanaian Verrucosispora sp. K51G. Mar. Drugs 2014, 12, 5197-5208. [CrossRef]

173. Niu, S.; Zhou, T.T.; Xie, C.L.; Zhang, G.Y.; Yang, X.W. Microindolinone A, a novel 4,5,6,7-tetrahydroindole, from the deep-sea-derived actinomycete Microbacterium sp. MCCC 1A11207. Mar. Drugs 2017, 15, 230. [CrossRef]

174. Li, J.L.; Huang, L.; Liu, J.; Song, Y.; Gao, J.; Jung, J.H.; Liu, Y.; Chen, G. Acetylcholinesterase inhibitory dimeric indole derivatives from the marine actinomycetes Rubrobacter radiotolerans. Fitoterapia 2015, 102, 203-207. [CrossRef]

175. Kwon, Y.; Kim, S.H.; Shin, Y.; Bae, M.; Kim, B.Y.; Lee, S.K.; Oh, K.B.; Shin, J.; Oh, D.C. A new benzofuran glycoside and indole alkaloids from a sponge-associated rare actinomycete, Amycolatopsis sp. Mar. Drugs 2014, 12, 2326-2340. [CrossRef]

176. Wyche, T.P.; Standiford, M.; Hou, Y.; Braun, D.; Johnson, D.A.; Johnson, J.A.; Bugni, T.S. Activation of the nuclear factor E2-related factor 2 pathway by novel natural products halomadurones A-D and a synthetic analogue. Mar. Drugs 2013, 11, 5089-5099. [CrossRef]

177. Fu, P.; Kong, F.; Li, X.; Wang, Y.; Zhu, W. Cyanogramide with a new spiro[indolinone-pyrroloimidazole] skeleton from Actinoalloteichus cyanogriseus. Org. Lett. 2014, 16, 3708-3711. [CrossRef]

178. Peng, F.; Wang, C.; Xie, Y.; Jiang, H.; Chen, L.; Uribe, P.; Bull, A.T.; Goodfellow, M.; Jiang, H.; Lian, Y. A new 20-membered macrolide produced by a marine-derived Micromonospora strain. Nat. Prod. Res. 2013, 27, 1366-1371. 
179. Kim, M.C.; Kwon, O.W.; Park, J.S.; Kim, S.Y.; Kwon, H.C. Nocapyrones H-J, 3,6-disubstituted $\alpha$-pyrones from the marine actinomycete Nocardiopsis sp. KMF-001. Chem. Pharm. Bull. 2013, 61, 511-515. [CrossRef] [PubMed]

180. Wu, Z.C.; Li, S.; Nam, S.J.; Liu, Z.; Zhang, C. Nocardiamides A and B, two cyclohexapeptides from the marine-derived actinomycete Nocardiopsis sp. CNX037. J. Nat. Prod. 2013, 76, 694-701. [CrossRef]

181. Lane, L.; Nam, S.-J.; Fukuda, T.; Yamanaka, K.; Kauffman, C.A.; Jensen, P.R.; Fenical, W.; Moore, B.S. Structures and comparative characterization of biosynthetic gene clusters for cyanosporasides, enediyne-derived natural products from marine actinomycetes. J. Am. Chem. Soc. 2013, 135, 4171-4174. [CrossRef]

182. Abdelmohsen, U.R.; Cheng, C.; Viegelmann, C.; Zhang, T.; Grkovic, T.; Ahmed, S.; Quinn, R.J.; Hentschel, U.; Edrada-Ebel, R. Dereplication strategies for targeted isolation of new antitrypanosomal actinosporins A and B from a marine sponge associated-Actinokineospora sp. EG49. Mar. Drugs 2014, 12, 1220-1244. [CrossRef]

183. Ellis, G.A.; Wyche, T.P.; Fry, C.G.; Braun, D.R.; Bugni, T.S. Solwaric acids A and B, antibacterial aromatic acids from a marine Solwaraspora sp. Mar. Drugs 2014, 12, 1013-1022. [CrossRef]

184. Trzoss, L.; Fukuda, T.; Costa-Lotufo, L.V.; Jimenez, P.; La Clair, J.J.; Fenical, W. Seriniquinone, a selective anticancer agent, induces cell death by autophagocytosis, targeting the cancer-protective protein dermcidin. Proc. Natl. Acad. Sci. USA 2014, 111, 14687-14692. [CrossRef]

185. Fu, P.; Zhu, Y.; Mei, X.; Wang, Y.; Jia, H.; Zhang, C.; Zhu, W. Acyclic congeners from Actinoalloteichus cyanogriseus provide insights into cyclic bipyridine glycoside formation. Org. Lett. 2014, 16, 4264-4267. [CrossRef]

186. Wyche, T.P.; Piotrowski, J.S.; Hu, Y.; Braun, D.; Deshpande, R.; Mcllwain, S.; Ong, I.M.; Myers, C.L.; Guzei, I.A.; Westler, W.M.; et al. Forazoline A: Marine-derived polyketide with antifungal in vivo efficacy. Angew. Chem. Int. Ed. Engl. 2014, 53, 11583-11586. [CrossRef]

187. Wagner, M.; Abdel-Mageed, W.M.; Ebel, R.; Bull, A.T.; Goodfellow, M.; Fiedler, H.P.; Jaspars, M. Dermacozines H-J isolated from a deep-sea strain of Dermacoccus abyssi from Mariana Trench sediments. J. Nat. Prod. 2014, 77, 416-420. [CrossRef] [PubMed]

188. Eltamany, E.E.; Abdelmohsen, U.R.; Ibrahim, A.K.; Hassanean, H.A.; Hentschel, U.; Ahmed, S.A. New antibacterial xanthone from the marine sponge-derived Micrococcus sp. EG45. Bioorg. Med. Chem. Lett. 2014, 24, 4939-4942. [CrossRef] [PubMed]

189. Kim, Y.; Ogura, H.; Akasaka, K.; Oikawa, T.; Matsuura, N.; Imada, C.; Yasuda, H.; Igarashi, Y. Nocapyrones: $\alpha$ - and $\gamma$-pyrones from a marine-derived Nocardiopsis sp. Mar. Drugs 2014, 12, 4110-4125. [CrossRef] [PubMed]

190. Kawahara, T.; Itoh, M.; Izumikawa, M.; Kozone, I.; Sakata, N.; Tsuchida, T.; Shin-ya, K. New hydroxamate metabolite, MBJ-0003, from Micromonospora sp. 29867. J. Antibiot. 2014, 67, 261-263. [CrossRef] [PubMed]

191. Liu, D.; Lin, H.; Proksch, P.; Tang, X.; Shao, Z.; Lin, W. Microbacterins A and B, new peptaibols from the deep sea actinomycete Microbacterium sediminis sp. nov. YLB-01(T). Org. Lett. 2015, 17, 1220-1223. [CrossRef]

192. Schulze, C.J.; Navarro, G.; Ebert, D.; DeRisi, J.; Linington, R.G. Salinipostins A-K, long-chain bicyclic phosphotriesters as a potent and selective antimalarial chemotype. J. Org. Chem. 2015, 80, 1312-1320. [CrossRef] [PubMed]

193. Gan, M.; Liu, B.; Tan, Y.; Wang, Q.; Zhou, H.; He, H.; Ping, Y.; Yang, Z.; Wang, Y.; Xiao, C. Saccharothrixones A-D, tetracenomycin-type polyketides from the marine-derived actinomycete Saccharothrix sp. 10-10. J. Nat. Prod. 2015, 78, 2260-2265. [CrossRef] [PubMed]

194. Thi, Q.V.; Tran, V.H.; Maia, H.D.; Le, C.V.; Hong MLe, T.; Murphy, B.T.; Chau, V.M.; Pham, V.C. Antimicrobial metabolites from a marine-derived actinomycete in Vietnam's east sea. Nat. Prod. Commun. 2016, 11, 49-51. [CrossRef] [PubMed]

195. Zhang, X.M.; Zhang, D.F.; Li, W.J.; Lu, C.H. Pseudonocardides A-G, new $\gamma$-butyrolactones from marine-derived Pseudonocardia sp. YIM M13669. Helv. Chim. Acta 2016, 99, 191-196. [CrossRef]

196. Zhang, H.; Saurav, K.; Yu, Z.; Mándi, A.; Kurtán, T.; Li, J.; Tian, X.; Zhang, Q.; Zhang, W.; Zhang, C. $\alpha$-Pyrones with diverse hydroxy substitutions from three marine-derived Nocardiopsis strains. J. Nat. Prod. 2016, 79, 1610-1618. [CrossRef]

197. Thi, Q.V.; Tran, V.H.; Mai, H.D.; Le, C.V.; Hong, M.L.T.; Murphy, B.T.; Chau, V.M.; Pham, V.C. Secondary metabolites from an actinomycete from Vietnam's east sea. Nat. Prod. Commun. 2016, 11, 401-404. [CrossRef] 
198. Xie, C.L.; Niu, S.W.; Zhou, T.T.; Zhang, G.Y.; Yang, Q.; Yang, X.W. Chemical constituents and chemotaxonomic study on the marine actinomycete Williamsia sp. MCCC 1A11233. Biochem. Syst. Ecol. 2016, 67, 129-133. [CrossRef]

199. Lee, J.; Han, C.; Gu Lee, T.; Chin, J.; Choi, H.; Lee, W.; Jeong Paik, M.; Hwan Won, D.; Jeong, G.; Ko, J.; et al. Marinopyrones A-D, $\alpha$-pyrones from marine-derived actinomycetes of the family Nocardiopsaceae. Tetrahedron Lett. 2016, 57, 1997-2000. [CrossRef]

200. Huang, P.; Xie, F.; Ren, B.; Wang, Q.; Wang, J.; Wang, Q.; Abdel-Mageed, W.M.; Liu, M.; Han, J.; Oyeleye, A.; et al. Anti-MRSA and anti-TB metabolites from marine-derived Verrucosispora sp. MS100047. Appl. Microbiol. Biotechnol. 2016, 100, 7437-7447. [CrossRef]

201. Fukuda, T.; Takahashi, M.; Nagai, K.; Harunari, E.; Imada, C.; Tomoda, H. Isomethoxyneihumicin, a new cytotoxic agent produced by marine Nocardiopsis alba KM6-1. J. Antibiot. 2017, 70, 590-594. [CrossRef] [PubMed]

202. Xie, C.L.; Liu, Q.; Xia, J.M.; Gao, Y.; Yang, Q.; Shao, Z.Z.; Liu, G.; Yang, X.W. Anti-allergic compounds from the deep-sea-derived actinomycete Nesterenkonia flava MCCC 1K00610. Mar. Drugs 2017, 15, 71. [CrossRef]

203. Zhang, X.M.; Sun, M.W.; Shi, H.; Lu, C.H. $\alpha$-pyrone derivatives from a marine actinomycete Nocardiopsis sp. YIM M13066. Nat. Prod. Res. 2017, 31, 2245-2249. [CrossRef]

204. Yim, C.Y.; Le, T.C.; Lee, T.G.; Yang, I.; Choi, H.; Lee, J.; Kang, K.Y.; Lee, J.S.; Lim, K.M.; Yee, S.T.; et al. Saccharomonopyrones A-C, New $\alpha$-pyrones from a marine sediment-derived bacterium Saccharomonospora sp. CNQ-490. Mar. Drugs 2017, 15, 239. [CrossRef] [PubMed]

205. Gong, T.; Zhen, X.; Li, X.L.; Chen, J.J.; Chen, T.J.; Yang, J.L.; Zhu, P. Tetrocarcin Q, a new spirotetronate with a unique glycosyl group from a marine-derived actinomycete Micromonospora carbonacea LS276. Mar. Drugs 2017, 16, 74. [CrossRef] [PubMed]

206. Gui, C.; Zhang, S.; Zhu, X.; Ding, W.; Huang, H.; Gu, Y.C.; Duan, Y.; Ju, J. Antimicrobial spirotetronate metabolites from marine-derived Micromonospora harpali SCSIO GJ089. J. Nat. Prod. 2017, 80, 1594-1603. [CrossRef]

207. Sun, M.; Chen, X.; Li, W.; Lu, C.; Shen, Y. New diketopiperazine derivatives with cytotoxicity from Nocardiopsis sp. YIM M13066. J. Antibiot. 2017, 70, 795-797. [CrossRef]

208. Igarashi, M.; Sawa, R.; Yamasaki, M.; Hayashi, C.; Umekita, M.; Hatano, M.; Fujiwara, T.; Mizumoto, K.; Nomoto, A. Kribellosides, novel RNA $5^{\prime}$-triphosphatase inhibitors from the rare actinomycete Kribbella sp. MI481-42F6. J. Antibiot. 2017, 70, 582-589. [CrossRef] [PubMed]

209. Braña, A.F.; Sarmiento-Vizcaíno, A.; Pérez-Victoria, I.; Otero, L.; Fernández, J.; Palacios, J.J.; Martín, J.; de la Cruz, M.; Díaz, C.; Vicente, F.; et al. Branimycins B and C, antibiotics produced by the abyssal actinobacterium Pseudonocardia carboxydivorans M-227. J. Nat. Prod. 2017, 80, 569-573. [CrossRef] [PubMed]

210. Sun, M.; Ou, J.; Li, W.; Lu, C. Quinoline and naphthalene derivatives from Saccharopolyspora sp. YIM M13568. J. Antibiot. 2017, 70, 320-322. [CrossRef] [PubMed]

211. Ziemert, N.; Alanjaryab, M.; Weber, T. The evolution of genome mining in microbes-a review. Nat. Prod. Rep. 2016, 33, 988-1005. [PubMed]

212. Hug, J.J.; Bader, C.D.; Remškar, M.; Cirnski, K.; Müller, R. Concepts and methods to aaccess novel antibiotics from actinomycetes. Antibiotics 2018, 7, 44. [CrossRef]

213. Wei, Y.; Zhang, L.; Zhou, Z.; Yan, X. Diversity of gene clusters for polyketide and nonribosomal peptide biosynthesis revealed by metagenomic analysis of the yellow sea sediment. Front. Microbiol. 2018, 9, 295. [CrossRef]

214. Katz, L.; Baltz, R.H. Natural product discovery: Past, present, and future. J. Ind. Microbiol. Biotechnol. 2016, 43, 155-176. [CrossRef]

215. Schorn, M.A.; Alanjary, M.M.; Aguinaldo, K.; Korobeynikov, A.; Podell, S.; Patin, N.; Lincecum, T.; Jensen, P.R.; Ziemert, N.; Moore, B.S. Sequencing rare marine actinomycete genomes reveals high density of unique natural product biosynthetic gene clusters. Microbiology 2016, 162, 2075-2086. [CrossRef]

216. Loureiro, C.; Medema, M.H.; van der Oost, J.; Sipkema, D. Exploration and exploitation of the environment for novel specialized metabolites. Curr. Opin. Biotechnol. 2018, 50, 206-213. [CrossRef] [PubMed]

217. Yamanaka, K.; Reynolds, K.A.; Kersten, R.D.; Ryan, K.S.; Gonzalez, D.J.; Nizet, V.; Dorrestein, P.C.; Moore, B.S. Direct cloning and refactoring of a silent lipopeptide biosynthetic gene cluster yields the antibiotic taromycin A. Proc. Natl. Acad. Sci. USA 2014, 111, 1957-1962. [CrossRef] 
218. Duncan, K.R.; Crüsemann, M.; Lechner, A.; Sarkar, A.; Li, J.; Ziemert, N.; Wang, M.; Bandeira, N.; Moore, B.S.; Dorrestein, P.C.; et al. Molecular networking and pattern-based genome mining improves discovery of biosynthetic gene clusters and their products from Salinispora species. Chem. Biol. 2015, 22, 460-471. [CrossRef] [PubMed]

219. Richter, T.K.; Hughes, C.C.; Moore, B.S. Sioxanthin, a novel glycosylated carotenoid, reveals an unusual subclustered biosynthetic pathway. Environ. Microbiol. 2015, 17, 2158-2171. [CrossRef] [PubMed]

220. Schulze, C.J.; Donia, M.S.; Siqueira-Neto, J.L.; Ray, D.; Raskatov, J.A.; Green, R.E.; McKerrow, J.H.; Fischbach, M.A.; Linington, R.G. Genome-directed lead discovery: Biosynthesis, structure elucidation, and biological evaluation of two families of polyene macrolactams against Trypanosoma brucei. ACS Chem. Biol. 2015, 10, 2373-2381. [CrossRef] [PubMed]

221. Tian, J.; Chen, H.; Guo, Z.; Liu, N.; Li, J.; Huang, Y.; Xiang, W.; Chen, Y. Discovery of pentangular polyphenols hexaricins A-C from marine Streptosporangium sp. CGMCC 4.7309 by genome mining. Appl. Microbiol. Biotechnol. 2016, 100, 4189-4199. [CrossRef]

222. Tan, Y.; Hu, Y.; Wang, Q.; Zhou, H.; Wang, Y.; Gan, M. Tetrocarcins N and O, glycosidic spirotetronates from a marine-derived Micromonospora sp. identified by PCR-based screening. RSC Adv. 2016, 6, 91773-91778. [CrossRef]

223. Feng, Y.; Liu, J.; Carrasco, Y.P.; MacMillan, J.B.; De Brabander, J.K. Rifamycin biosynthetic congeners: Isolation and total synthesis of rifsaliniketal and total synthesis of salinisporamycin and saliniketals A and B. J. Am. Chem. Soc. 2016, 138, 7130-7142. [CrossRef]

224. Jiang, X.; Zhang, Q.; Zhu, Y.; Nie, F.; Wu, Z.; Yang, C.; Zhang, L.; Tian, X.; Zhang, C. Isolation, structure elucidation and biosynthesis of benzo[b]fluorine nenestatin A from deep-sea derived Micromonospora echinospora SCSIO 04089. Tetrahedron 2017, 73, 3585-3590. [CrossRef]

225. Thomas, T.; Moitinho-Silva, L.; Lurgi, M.; Björk, J.R.; Easson, C.; Astudillo-García, C.; Olson, J.B.; Erwin, P.M.; López-Legentil, S.; Luter, H.; et al. Diversity, structure and convergent evolution of the global sponge microbiome. Nat. Commun. 2016, 7, 11870. [CrossRef] [PubMed]

226. Sunagawa, S.; Coelho, L.P.; Chaffron, S.; Kultima, J.R.; Labadie, K.; Salazar, G.; Djahanschiri, B.; Zeller, G.; Mende, D.R.; Alberti, A.; et al. Ocean plankton. Structure and function of the global ocean microbiome. Science 2015, 348, 1261359. [CrossRef] [PubMed]

(C) 2019 by the authors. Licensee MDPI, Basel, Switzerland. This article is an open access article distributed under the terms and conditions of the Creative Commons Attribution (CC BY) license (http://creativecommons.org/licenses/by/4.0/). 